\author{
Universidade de São Paulo \\ Instituto de Física
}

SBI-IFUSP

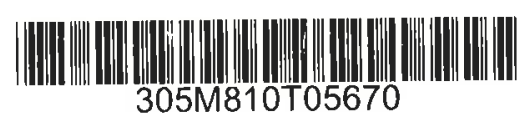

\title{
Modelagem de fotodetectores baseados em pontos quânticos que operam na faixa do infravermelho
}

\author{
André Luiz dos Santos \\ Orientadora: Profa. Dra. Euzi Conceição F. da Silva
}

Dissertação de Mestrado apresentada ao Instituto de

Física para a obtenção do título de Mestre em

Ciências

Banca Examinadora:

Profa. Dra. Euzi Conceição F. da Silva

Prof. Dr. Alexandre Levine

Prof. Dr. Américo Sheitiro Tabata
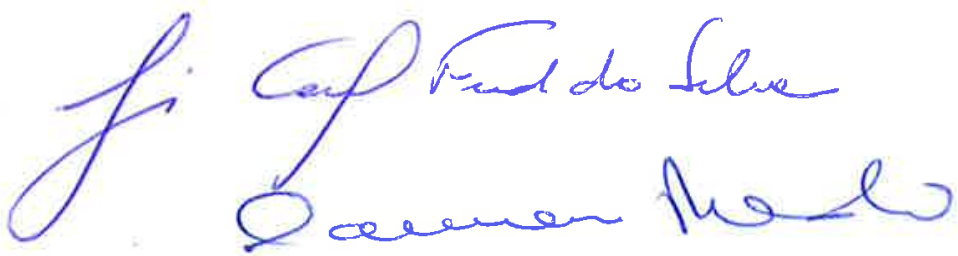

São Paulo

2012 


\section{FICHA CATALOGRÁFICA}

Preparada pelo Serviço de Biblioteca e Informação do Instituto de Física da Universidade de São Paulo

Santos, André Luiz dos

Modelagem de fotodetectores baseados em pontos quânticos que operam no infravermelho - . São Paulo, 2012

(Dissertação de Mestrado) - Universidade de São Paulo. Instituto de Física - Depto. Física dos Materiais e Mecânica

Orientador: Profa. Dra. Euzi Conceição F. da Silva Área de Concentração: Física do Estado Sólido

Unitermos: 1. Fotodetectores 2. Fisica ótica 3. Ótica quântica

USP/IF/SBI-020/2012 
Dedico este trabalho à minha família, em especial à minha esposa Andressa e ao meu filho Adrian. 


\section{Agradecimentos}

Agradeço à Profa. Euzi Conceição Fernandes, pela orientação, pela confiança, pelas discussões e pela dedicação depositada neste trabalho.

Agradeço aos meus familiares pelo opoio nos momentos difíceis.

Agradeço também aos meus amigos e professores do IFUSP, cujos nomes não serão mencionados pois são muitos.

Agradeço também ao membros do grupo LNMS pelas discussões e pelos esclarecimentos nas reuniões.

E, finalmente, à CAPES pelo apoio financeiro. 


\section{Resumo}

Nesse trabalho utilizamos um modelo analítico para avaliar o desempenho de estruturas semicondutoras contendo pontos quânticos que servem de base para a fabricação de fotodetectores que operam na faixa do infravermelho. O desempenho desses dispositivos foram avaliados através da corrente no escuro e da detectividade. Os trabalhos existentes na literatura, baseados neste modelo, não consideram a dependência da estrutura eletrônica do ponto quântico com suas dimensões. Desta forma, neste trabalho, analisamos o comportamento da corrente no escuro e da detectividade em função de vários parâmetros que definem a estrutura da amostra, levando em consideração as dimensões dos QDs. Nossos resultados mostraram quais parâmetros devemos ajustar para fazer fotodetectores: (1) que contenham a maior densidade de QDs com dimensões compatíveis com a energia de ionização desejada; (2) que maximizam o desempenho do dispositivo e (3) minimizam o ruído do mesmo. 


\section{Abstract}

In this work we used an analytical model to calculate the dark current and the detectivity of infrared photodetectors based on InAs quantum dots semiconductor heterostructures. The existing works reported in the literature based on this analytical model do not take into account the electronic structure of the QD in the calculations. In this way, in the present work, we took into account the QD dimensions when we analized the dependence of the dark current and the detectivity on the parameters which define the sample structure. Our findings show which parameters must be adjusted in order to obtain photodetectors with: (1) the larger density of QDs with dimensions compatible with the wanted ionization energy; (2) that maximize the performance; (3) and that minimize the noise of the devices. 


\section{Sumário}

1 Introdução 1

2 Pontos quânticos auto-organizados de InGaAs $\quad \mathbf{8}$

2.1 O crescimento de camadas semicondutoras tensas . . . . . . . . . 8

2.2 O processo de formação de pontos quânticos de InGaAs . . . . . . . . 9

3 Modelamento teórico da corrente no escuro e da detectividade 13

3.1 Modelamento teórico da corrente no escuro . . . . . . . . . . . . . . . 13

3.1 .1 Geração térmica . . . . . . . . . . . . . . . . . 16

3.1 .2 Probabilidade de captura . . . . . . . . . . . . . . 21

3.1.3 Corrente no escuro . . . . . . . . . . . . . . . . . . . . . 23

3.2 Modelamento teórico da detectividade . . . . . . . . . . . 23

4 Estrutura eletrônica de pontos quânticos $\mathbf{2 5}$

4.1 Modelo analítico para o cálculo dos níveis de energia de um ponto quântico . . . . . . . . . . . . . . . . . . . 25

4.2 Potencial de confinamento para pontos quânticos de $\operatorname{In}_{x} \mathrm{Ga}_{1-x}$ As com barreira de GaAs, incluindo o efeito da tensão . . . . . . . . . . . . . 29

4.3 Estrutura eletrônica dos pontos quânticos de InAs . . . . . . . . . . . 33

5 Resultados da corrente no escuro e da detectividade dos fotodetetores

5.1 Corrente no escuro e detectividade em função dos fatores externos . . 42

5.2 Corrente no escuro e detectividade em função dos parâmetros estruturais . . . . . . . . . . . . . . . . . . . . . 46 46

5.3 Corrente no escuro e detectividade em função da estrutura eletrônica 49

6 Conclusões 
7 Anexo 1 - Autoenergias do poço de potencial finito escrito em termos das autoenergias do poço de potencial infinito

7.1 Autoenergias do poço finito . . . . . . . . . . . . . 58

7.2 Solução para o poço finito escrita em termos da série do potencial infinito . . . . . . . . . . . . . . . . 6 60

7.3 Inversão de série . . . . . . . . . . . . . . . 65

Bibliografia 


\section{Lista de Figuras}

1.1 Transmitância de radiação na região do infravermelho em uma camada de ar de 1830 metros de espessura ao nível do mar com $17 \mathrm{~mm}$ de água precipitável. As siglas NIR, MIR e FIR referem-se à radiação com comprimentos de onda nas regiões do infravermelho próximo, médio e distante, respectivamente. . . . . . . . . . . . . . . 4

1.2 Energia do gap em função do parâmetro de rede de alguns materiais semicondutores. . . . . . . . . . . . . . . . . . .

2.1 (a) Representação de materias cristalinos com diferentes parâmetros de rede (distância entre círculos vizinhos): o substrato (círculos pretos) e o filme epitaxial (círculos vermelhos). (b) Crescimento coerente de um filme epitaxial sob tensão onde o parâmetro de rede da epicamada ajusta-se naturalmente ao parâmetro de rede do substrato. (c) Rearranjo dos átomos da epicamada por causa do excesso de energia potencial elástica que resulta na formação de pequenas ilhas de material tensionado (os pontos quânticos) com o mesmo parâmetro de rede que o do substrato. Abaixo dos pontos quânticos resta um filme ultra fino (de aproximadamente uma monocamada) conhecido por wetting layer. (d) Depois de formados os QDs, retoma-se o crescimento cobrindo-se os pontos quânticos com uma nova camada de material semicondutor, camada esta que recebe o nome de cobertura.

3.1 Representação esquemática da sequência de camadas semicondutoras de um fotodetector de pontos quânticos. . . . . . . . . . . . . . . 14

3.2 Representação esquemática dos processos que determinam o transporte de elétrons em um QDIP. 
3.3 Representação esquemática do transporte de elétrons na ausência do fluxo de fótons incidentes, que resulta da competição entre dois processos: (1) o processo de armadilhamento de elétrons pelos pontos quânticos; (2) e o processo de excitação térmica. . . . . . . . . . . 16

3.4 Esquema dos níveis de energia de um ponto quântico de InAs/GaAs no qual o segundo nível coincide com o fundo da banda de condução da barreira. . . . . . . . . . . . . . . . . . . 19

4.1 No alto da figura mostramos uma imagem de um QD obtida por microscopia de transmissão eletrônica [42]. No resto da figura mostramos a justificativa para a forma parabólica descrita na Eq. 4.11, onde $r_{1}$, $r_{2}$ e $r_{3}$ indicam posições radiais em relação ao centro do QD e $t_{1}, t_{2}$ e $t_{3}$ as espessuras do QD em cada uma dessas posições. . . . . . . . . 27

4.2 Diagrama mostrando o perfil da banda de condução $E_{c}(z)$ que tem como referência o fundo da banda de condução do poço não tenso, ou seja, as energias são medidas a partir desta referência (linha pontilhada). A energia do gap do $\mathrm{GaAs}$ não tenso em $\mathrm{T}=300 \mathrm{~K}$ é $E_{g, \mathrm{GaAs}}^{n t}=1,5192 \mathrm{eV}$ e do InAs é $E_{g, \mathrm{InAs}}^{n t}=0,41 \mathrm{eV}$. Com estes valores obtemos $\Delta E_{g}=1109 \mathrm{meV}$ (Eq. 4.21) e $\Delta E_{c}=776 \mathrm{meV}$ (Eq. 4.20). . 30

4.3 Energia do gap da liga não tensa de $\operatorname{In}_{\mathrm{x}} \mathrm{Ga}_{1-\mathrm{x}} \mathrm{As}$ em função da concentração de In calculada para as temperaturas $\mathrm{T}=2 \mathrm{~K}, 77 \mathrm{~K}$ e $300 \mathrm{~K}$ de acordo com as expressões apresentadas na Tabela 4.2 . . . 32

4.4 Descontinuidade do gap na banda de condução $\Delta E_{c}(x)$ (calculada de acordo com a expressão 4.20) e potencial devido a tensão (termo $a_{c} \operatorname{Tr}(\epsilon)$ ) (curva pontilhada) em função da concentração de índio. A região cinza (sombreada) é a altura da barreira de potencial e é calculada como $V_{0}(x)=\Delta E_{c}(x)-a_{c} \operatorname{Tr}[\epsilon(\mathrm{x})] \ldots \ldots . \ldots 33$

4.5 Potencial de confinamento $V_{0}(x)$ em função da concentração de índio. Esta curva foi obtida com a expressão: $V_{0}(x)=\left[\Delta E_{c}-a_{c} \operatorname{Tr}(\epsilon)\right]$ (veja Eq. 4.17). Para $x=1, \Delta E_{c}=0,776 \mathrm{eV}$ e $a_{c} \operatorname{Tr}(\epsilon)=0,310 \mathrm{eV}$. Logo, o potencial de confinamento para o InAs não tenso $(x=1)$ passou de 0,776 eV para 0,466 eV para o InAs tenso (compare com a Fig. 4.2). 
4.6 Representação esquemática da estrutura eletrônica ideal dos QDs que podem ser utilizados para a construção de fotodetectores de radiação infravermelha de banda estreita. A energia de ionização deve ser aproximadamente igual à diferença entre as energias do estado fundamental e do primeiro estado excitado do QD. . . . . . . . . 34

4.7 Raio da base $a_{Q D}(\AA)$ em função da altura do QD $\ell_{Q D}(\AA)$ para diferentes concentrações de In. Estas curvas representam os QDs cujas dimensões possuem dois níveis, sendo que a energia do primeiro estado excitado coincide com a altura da barreira. . . . . . . . . . 35

4.8 Energia de ionização (eixo do lado esquerdo) com seu correspondente comprimento de onda (eixo do lado direito) em função da altura do QD para diferentes concetrações de In. A faixa em cinza seleciona os QDs que possuem energia de ionização dentro da janela de mínima absorção atmosférica $(8-12 \mu \mathrm{m}) . \ldots \ldots$. . . . . . . . . 37

4.9 Energia de ionização (eixo do lado esquerdo) com seu respectivo comprimento de onda (eixo do lado direito) em função da altura do QD para diferentes concetrações de In. A faixa em cinza corresponde a janela de mínima absorção atmosférica $3-5 \mu \mathrm{m} . \quad \ldots . . \ldots .38$

4.10 Energia de ionização (eixo esquerdo) com seu respectivo comprimento de onda (eixo direito) em função da altura do QD (eixo horizontal inferior) com o seu respectivo raio (eixo horizontal superior) para QDs de InAs. A faixa em cinza destaca a região de mínima absorção atmosférica $(8-12 \mu \mathrm{m})$ e a faixa em amarelo seleciona as dimensões dos QDs de InAs que são possíveis obter-se no sistema MBE. . . . . . 39

4.11 Energia de ionização (eixo esquerdo) com seu respectivo comprimento de onda (eixo direito) em função da altura do QD (eixo horizontal inferior) com o seu respectivo raio (eixo horizontal superior) dos QDs de $\mathrm{In}_{0.8} \mathrm{Ga}_{0.2}$ As. A faixa em cinza destaca a região de mínima absorção atmosférica $(8-12 \mu \mathrm{m})$.

5.1 Corrente no escuro e número médio de elétrons nos QDs (inset) em função da tensão aplicada, na temperatura de operação de $\mathrm{T}=77 \mathrm{~K}$, para diferentes razões entre as concentrações de doadores $\left(\Sigma_{D}\right)$ e de QDs $\left(\Sigma_{Q D}\right)$. Os outros parâmetros estruturais utilizados para o cálculo foram: $K=10$ (número de camadas), $L=40 \mathrm{~nm}$ (espaçamento entre as camadas) e $\sigma=10 \times 10^{-11} \mathrm{~cm}^{-2}$ (seção de fotoescape). . . . 43 
5.2 Detectividade em função da tensão aplicada, na temperatura de operação de $\mathrm{T}=77 \mathrm{~K}$, para diferentes razões entre as concentrações de doadores $\left(\Sigma_{D}\right)$ e de QDs $\left(\Sigma_{Q D}\right)$. Os outros parâmetros estruturais utilizados para o cálculo foram: $K=10$ (número de camadas), $L=40 \mathrm{~nm}$ (espaçamento entre as camadas) e $\sigma=10 \times 10^{-11} \mathrm{~cm}^{-2}$ (seção de fotoescape). . . . . . . . . . . . . . . . . . 44 4

5.3 Corrente no escuro em função da temperatura para diferentes tensões de porta e para as dimensões de QDs apresentadas na Tabela 5.2. Os outros parâmetros estruturais utilizados para o cálculo foram: $K=10$ (número de camadas), $L=40 \mathrm{~nm}$ (espaçamento entre as camadas), $\Sigma_{D}=0,6 \times \Sigma_{Q D}$ (concentração de doadores) e $\Sigma_{Q D}=2 \times 10^{10} \mathrm{~cm}^{-2}$ (concentração de QDs). . . . . . . . . . . . . . . . . . 45

5.4 Detectividade em função da temperatura para diferentes tensões de porta, para as dimensões de QDs apresentadas na Tabela 5.2. Os parâmetros estruturais utilizados para estes cálculos foram $K=10$ (número de camadas), $L=40 \mathrm{~nm}$ (espaçamento entre as camadas), $\Sigma_{D}=0,6 \times \Sigma_{Q D}$ (concentração de doadores), $\Sigma_{Q D}=2 \times 10^{10} \mathrm{~cm}^{-2}$ (concentração de QDs) e $\sigma=10 \times 10^{-11} \mathrm{~cm}^{-2}$ (seção de fotoescape).

5.5 Corrente no escuro e número médio de elétrons (inset) em função do número de camadas $(K)$ para diferentes espessuras da região ativa. As dimensões dos QDs utilizadas nos cálculos estão apresentadas na Tabela 5.2. Os outros parâmetros estruturais utilizados no cálculo foram: $\Sigma_{D}=0,6 \times \Sigma_{Q D}$ (concentração de doadores) e $\Sigma_{Q D}=2 \times$ $10^{10} \mathrm{~cm}^{-2}$ (concentração de QDs). Os fatores externos utilizados foram $\mathrm{V}=1 \mathrm{~V}$ e $\mathrm{T}=77 \mathrm{~K}$

5.6 Detectividade e número médio de elétrons (inset) em função do número de camadas $(K)$ para diferentes espessuras da região ativa. As dimensões dos QDs utilizadas nos cálculos estão apresentadas na Tabela 5.2. Os outros parâmetros estruturais utilizados para estes cálculos foram: $\Sigma_{D}=0,6 \times \Sigma_{Q D}$ (concentração de doadores), $\Sigma_{Q D}=2 \times$ $10^{10} \mathrm{~cm}^{-2}$ (concentração de QDs) e $\sigma=10 \times 10^{-10} \mathrm{~cm}^{-2}$ (seção de captura). Os fatores externos utilizados no cáculo foram $\mathrm{V}=1 \mathrm{~V}$ e $\mathrm{T}=77 \mathrm{~K} \ldots \ldots \ldots \ldots \ldots \ldots \ldots$ 
5.7 Corrente no escuro e número médio de elétrons (inset) em função da concentração de $\mathrm{QDs}\left(\Sigma_{Q D}\right)$ para diferentes tensões de porta. As dimensões dos QDs utilizadas nos cálculos estão apresentadas na. Tabela 5.2. Os outros parâmetros utilizados para os cálculos foram $\Sigma_{D}=0,6 \times \Sigma_{Q D}$ (concentração de doadores) e $\mathrm{T}=77 \mathrm{~K}$. A região amarela destaca as concentrações de QDs usualmente obtidas pelo crescimento por MBE. . . . . . . . . . . . . . . . . . . . 48

5.8 Detectividade em função da concetração de $\operatorname{QDs}\left(\Sigma_{Q D}\right)$ para diferentes tensões de porta. As dimensões dos QDs utilizadas estão apresentadas na Tabela 5.2. Os outros parâmetros utilizados para os cálculos foram $\Sigma_{D}=0,6 \times \Sigma_{Q D}$ (concentração de doadores), e $\sigma=10 \times 10^{-10} \mathrm{~cm}^{-2}$ (seção de captura) e $\mathrm{T}=77 \mathrm{~K}$. A faixa amarela destaca as concentrações de QDs usualmente obtidas pelo crescimento por MBE. . . . . 49

5.9 Corrente no escuro (a) e detectividade (b) em função da altura dos QDs para duas concetrações de In $(x=1$ e $x=0,8)$. Os outros parâmetros utilizados para os cálculos foram $\Sigma_{D}=0,6 \times \Sigma_{Q D}$ (concentração de doadores), $\Sigma_{Q D}=2 \times 10^{10} \mathrm{~cm}^{-2}$ (concentração de QDs), $\mathrm{V}=1 \mathrm{~V}$ e T $=77 \mathrm{~K} \ldots \ldots \ldots \ldots \ldots \ldots$

5.10 Corrente no escuro mínima em função da concentração de índio na

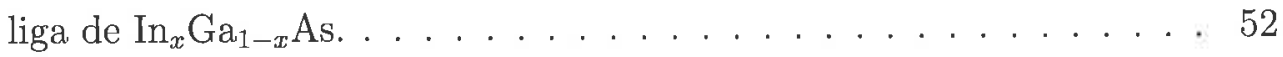




\section{Lista de Tabelas}

1.1 Espectro eletromagnético. . . . . . . . . . . . . 3

4.1 Parâmetros para os materiais GaAs e InAs: parâmetro de rede $a_{0}$, potencial de deformação da banda de condução $a_{c}$, constantes elásticas $C_{11}$ e $C_{12}$ e massa efetiva do elétron $m_{e}^{*}$. $m_{0}$ é a massa do elétron livre. 31

4.2 Expressões que descrevem a energia do gap não tenso $E_{g}^{n t}(x)$, as constantes elásticas $C_{11}$ e $C_{12}$, o potencial de deformação $a_{c}$, o parâmetro de rede $a_{0}$, e a massa efetiva do elétron $m_{e}^{*}$ para a liga de $\operatorname{In}_{\mathrm{x}} \mathrm{Ga}_{1-\mathrm{x}}$ As. 31

4.3 Expressões que descrevem o raio da base, $a_{Q D}(\AA)$, em função da altura do QD, $\ell_{Q D}(\AA)$, para diferentes concentrações de In. Estas curvas representam os QDs cujas dimensões resultam em QDs com apenas dois níveis de energia confinados, sendo que a energia do primeiro estado excitado coincide com a altura da barreira. . . . . . . 36

5.1 Parâmetros dos QDIPs de InAs. . . . . . . . . . . . . . . . . 42

5.2 Características da estrutura eletrônica de um QD com altura $\ell_{Q D}=$

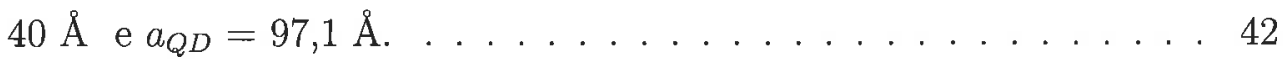




\section{Capítulo 1}

\section{Introdução}

Estamos assistindo, atualmente, em várias partes do mundo, a um enorme progresso tecnológico e científico devido ao aparecimento de novos instrumentos que desempenham papel fundamental para o desenvolvimento social. Em parte, esse avanço é o resultado do surgimento de dispositivos eletrônicos, ópticos e optoeletrônicos baseados em sofisticadas heteroestruturas semicondutoras envolvendo materiais semicondutores cada vez mais eficientes.

Por heteroestruturas semicondutoras entendemos um material artificialmente produzido, o qual se forma pela superposição de camadas alternadas de semicondutores distintos. Desde a idealização e fabricação das primeiras heteroestruturas semicondutoras [1-3], na década de setenta, a produção destes sistemas evoluiu rapidamente com o surgimento e o aprimoramento das técnicas de crescimento de materiais semicondutores. As modernas técnicas de crescimento de materiais semicondutores, tais como MBE [4] (molecular beam epitaxy), CBE [5] (chemical beam epitaxy) e MOCVD [6] (metalorganic chemical vapour deposition), permitem atualmente a produção de amostras monocristalinas com um número preciso de camadas atômicas, interfaces abruptas, perfis de dopagem sofisticados, alta pureza e baixo número de defeitos estruturais. Heteroestruturas semicondutoras crescidas em diversas arquiteturas formam a base de uma série de dispositivos eletrônicos, ópticos e optoeletrônicos e representam sistemas extremamente interessantes do ponto de vista da Física Básica [7-11].

Em nosso cotidiano somos rodeados de aparelhos que utilizam a tecnologia dos materiais semicondutores. Computadores, aparelhos de televisão, carros, telefones celulares e muitos outros equipamentos são constituídos por dispositivos eletrônicos e/ou optoeletrônicos semicondutores para desempenharem suas funções. No que 
se refere às mais recentes novidades relacionadas com as aplicações tecnológicas de heteroestruturas semicondutoras baseadas em novos materiais semicondutores podemos destacar, por exemplo, a fabricação de laseres de poços quânticos de GaN que emitem luz azul e têm grande interesse comercial. A obtenção de laseres de GaN emitindo no azul desencadeou, em passado recente, uma corrida no sentido de se aprimorar o conhecimento sobre este material, tanto no que se refere à otimização dos parâmetros de crescimento quanto no que se refere ao estudo de suas propriedades estruturais e eletrônicas, visando um melhor aproveitamento de suas potencialidades em aplicações tecnológicas [12-14].

No que se refere às inovações tecnológicas, atualmente, há um grande esforço no sentido de se desenvolver dispositivos semicondutores para a deteç̧ão de radiação no infravermelho. Como podemos observar na Tabela 1.1 a radiação no infravermelho é apenas uma pequena parcela do espectro eletromagnético. O interesse na faixa de radiação do infravermelho se deve ao fato de que é nessa faixa do espectro eletromagnético $(3-17 \mu \mathrm{m})$ que os modos vibracionais de muitas moléculas emitem radiação. Isso possibilita aplicações em várias áreas da esfera civil e militar. Podemos começar citando as aplicações na agropecuária onde a sua utilização é na quantificação de nutrientes do solo [15] e em frutas [16], para quantificar a resposta de plantações à aplicação de diferentes tipos de herbicidas e inseticidas [17], para detectar a umidade e compactação do solo [18], e na fabricação de sensores que ajudem no controle da qualidade dos alimentos. Além disso, lembrando que todos os corpos em uma temperatura diferente de zero emitem um espectro de radiação na faixa do infravermelho, temos também a possibilidade de produção de fotografias térmicas do corpo humano para diagnósticos médicos [19]. Podemos citar também a aplicação desses dispositivos na aviação civil, já que as imagens com o infravermelho podem auxiliar os pilotos na aterrissagem das aeronaves. Na área militar temos a detecção de explosivos ocultos e sensores para mísseis balísticos [20].

Para aplicações terrestres devemos observar que dependendo do comprimento de onda que o objeto emite a radiação e da distância percorrida por esse fluxo de radiação, ela poderá ser fortemente atenuada pelo espalhamento ou absorção de moléculas suspensas na atmosfera. As regiões em que as moléculas não absorvem ou não espalham radiação do espectro eletromagnético são denominadas janelas atmosféricas. As janelas atmosféricas na região de infravermelho, que são o objeto de interesse deste estudo, situam-se nas faixas de $3-5 \mu \mathrm{m}$ e $8-12 \mu \mathrm{m}$ (veja a Fig. 1.1). 
Tabela 1.1: Espectro eletromagnético.

\begin{tabular}{|c|c|c|}
\hline Região & Tipo & Faixa de Freqüência \\
\hline $\begin{array}{c}\text { Rádio } \\
\text { Frequência }\end{array}$ & $\begin{array}{c}\text { Freq. Muito Baixas } \\
\text { Freq. Baixas } \\
\text { Freq. Altas - Ondas Curtas } \\
\text { Freq. Muito Altas (VHF, UHF, SHF) - TV } \\
\text { Microondas }(30 \mathrm{~cm}-1 \mathrm{~mm}) \\
\end{array}$ & $\begin{array}{c}3-300 \mathrm{~Hz} \\
300 \mathrm{~Hz}-300 \mathrm{MHz} \\
300 \mathrm{KHz}-30 \mathrm{MHz} \\
30 \mathrm{MHz}-300 \mathrm{GHz} \\
300 \mathrm{GHz} \\
\end{array}$ \\
\hline Infravermelho & $\begin{array}{c}\text { Freq.: } 100 \mathrm{GHz}-100 \mathrm{THz} \\
\text { Muito Distante (XIR) } \\
\text { Distante (FIR) } \\
\text { Médio (MIR) } \\
\text { Próximo (NIR) }\end{array}$ & $\begin{array}{l}\text { Comprimento } \\
\text { de onda } \\
1000-15 \mu \mathrm{m} \\
15-6 \mu \mathrm{m} \\
6-3 \mu \mathrm{m} \\
3-0,75 \mu \mathrm{m} \\
\end{array}$ \\
\hline Visível & $\begin{array}{c}\text { Freq.: }>200 \mathrm{THz} \\
\text { Vermelho } \\
\text { Laranja } \\
\text { Amarelo } \\
\text { Verde } \\
\text { Azul } \\
\text { Violeta }\end{array}$ & $\begin{array}{c}\text { Comprimento } \\
\text { de onda } \\
770-622 \mathrm{~nm} \\
622-597 \mathrm{~nm} \\
597-577 \mathrm{~nm} \\
577-492 \mathrm{~nm} \\
492-455 \mathrm{~nm} \\
455-390 \mathrm{~nm}\end{array}$ \\
\hline Ultravioleta & $\begin{array}{c}\text { Freq.: } 10^{15}-10^{16} \mathrm{~Hz} \\
\text { UV-A (Pouco Nocivo) } \\
\text { UV-B (Nocivo, Absorvido por Ozônio) } \\
\text { UV-C (Muito Nocivo, Absorvido pelo Ar) }\end{array}$ & $\begin{array}{l}\text { Comprimento } \\
\text { de onda } \\
400-315 \mathrm{~nm} \\
315-280 \mathrm{~nm} \\
280-100 \mathrm{~nm} \\
\end{array}$ \\
\hline Raio - X & $10^{17}-10^{19} \mathrm{~Hz}$ & $10^{-9}-10^{-11} \mathrm{~m}$ \\
\hline Raios Gama & $10^{19}-10^{21} \mathrm{~Hz}$ & $10^{-11}-10^{-13} \mathrm{~m}$ \\
\hline
\end{tabular}

A tecnologia para a deteç̧ão dessas faixas do espectro eletromagnético já existe e é baseada em materiais do tipo bulk $[21,22]$ ou em heteroestruturas semicondutoras $[21,23]$ que podem funcionar através de transições interbanda ou intrabanda. Em um fotodetector do tipo interbanda a radiação incidente deve ter energia maior que o gap do material para que o elétron da banda de valência possa ser excitado para a banda de condução e dessa forma participar do processo de condução da corrente elétrica. Atualmente, os fotodetectores de infravermelho do tipo interbanda são baseados na liga ternária de $\mathrm{Hg}_{\mathrm{x}} \mathrm{Cd}_{1-\mathrm{x}} \mathrm{Te}$ (liga de $\mathrm{MCT}$, mercúrio-cádmio-telúrio) [21, 22] e os diferentes comprimentos de onda de operação desses dispositivos são obtidos variando-se a concentração de mercúrio conforme podemos observar na Fig. 1.2. Para a aplicação desta liga em dispositivos que produzem imagens com os FPAs (focal plane arrays), há a necessidade da produção de matrizes de $\mathrm{Hg}_{\mathrm{x}} \mathrm{Cd}_{1-\mathrm{x}} \mathrm{Te}$ da 


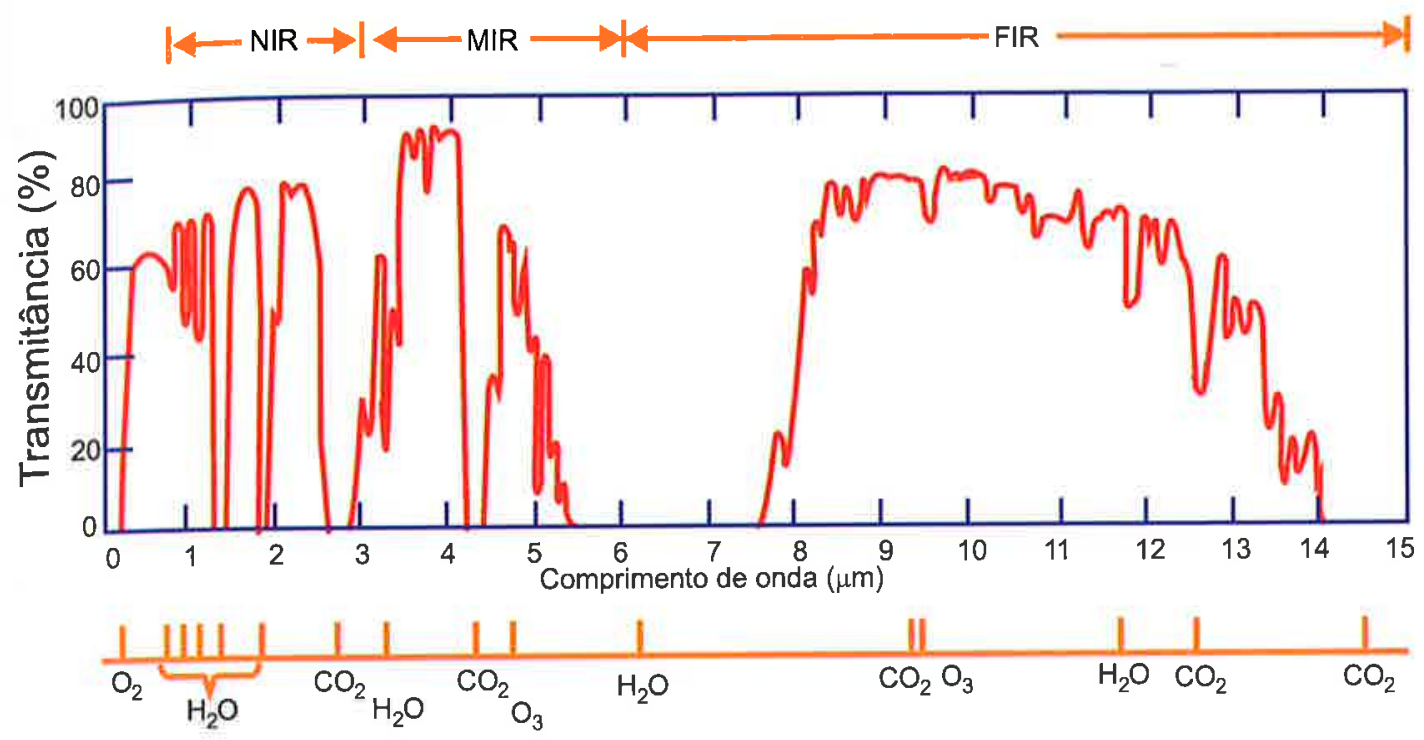

Absorção Molecular

Figura 1.1: Transmitância de radiação na região do infravermelho em uma camada de ar de 1830 metros de espessura ao nível do mar com $17 \mathrm{~mm}$ de água precipitável. As siglas NIR, MIR e FIR referem-se à radiação com comprimentos de onda nas regiões do infravermelho próximo, médio e distante, respectivamente.

ordem de $\mathrm{cm}^{2}$. Entretanto, existe uma grande dificuldade em se obter matrizes homogêneas dessas ligas devido à alta pressão do $\mathrm{Hg}$ durante o crescimento, o que torna complicado o controle da estequiometria e da composição desses materias. Isso faz com que essas matrizes se tornem quebradiças e o desempenho dos dispositivos baseados nessa liga diminua rapidamente para comprimento de onda maiores que $12 \mu \mathrm{m}$. Portanto, existe a necessidade de novas estruturas e novos materiais que possam operar em comprimentos de onda superiores a $12 \mu \mathrm{m}$.

A alternativa é a produção de detectores baseados nas transições do tipo intrabanda, que podem ter como meio ativo os poços quânticos (QWs, quantum wells) ou os pontos quânticos (QDs, quantum dots). Os fotodetectores que possuem como meio ativo os poços quânticos (QWIPs, quantum well infrared photodetectors) formados pelos compostos III-IV utilizam-se de transições intrabanda que podem ocorrer entre estados ligados ou entre um estado ligado e o contínuo. Os QWIPs possuem uma vantagem sobre aqueles da liga MCT, pois as técnicas para a obtenção das matrizes dos QWIPs já estão bem estabelecidas e os materias são crescidos com alta uniformidade e controle. Outras vantagens dos QWIPs são a operação em altos comprimentos de onda, alto rendimento, grandes matrizes bidimensionais, detecção de múltiplas cores e baixa taxa de recombinação Auger. As suas desvantagens são a alta 


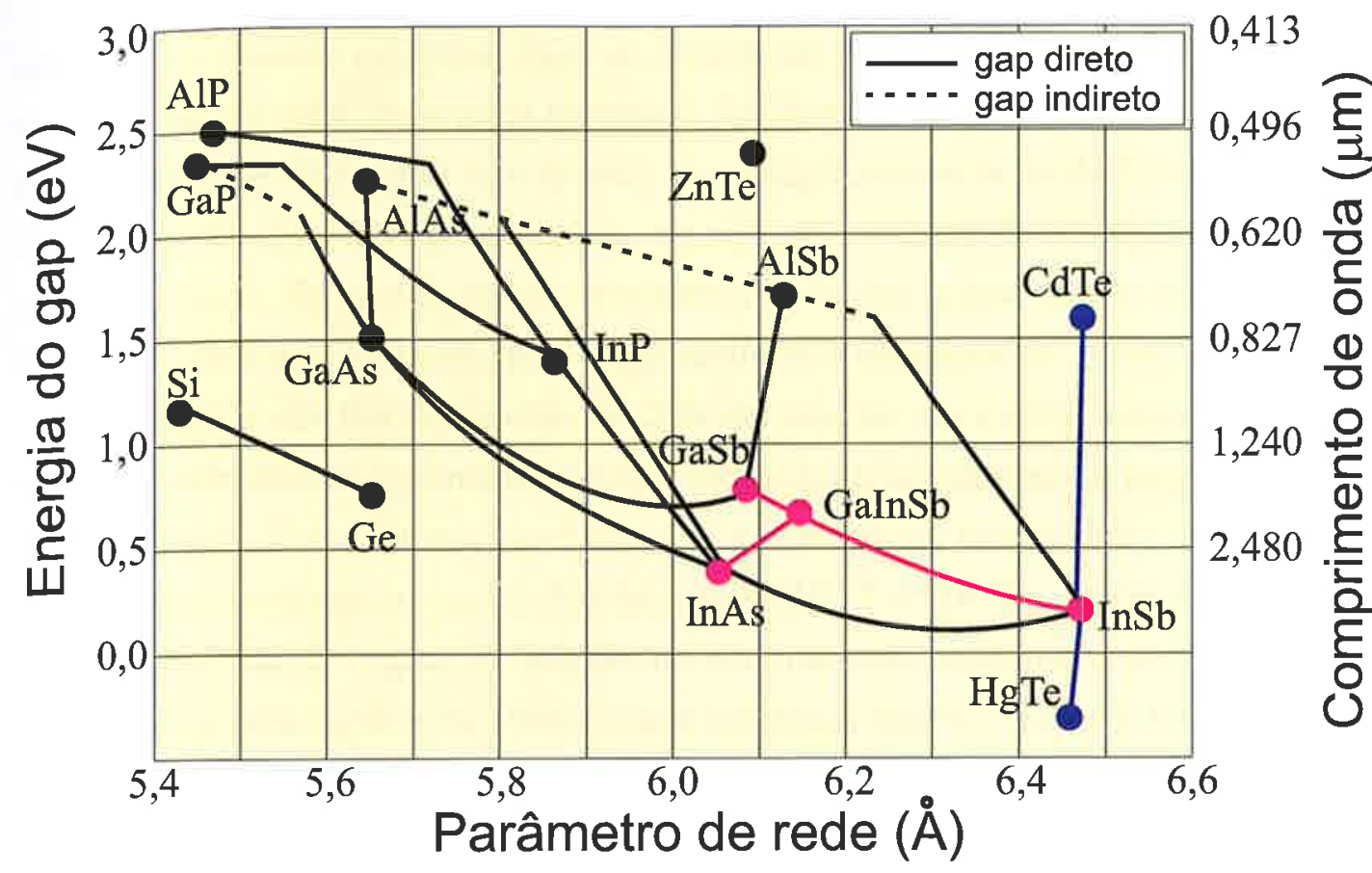

Figura 1.2: Energia do gap em função do parâmetro de rede de alguns materiais semicondutores.

taxa de geração térmica, a baixa eficiência quântica e, devido às regras de seleção do QWs, a ocorrência apenas de transições polarizadas na direção de crescimento.

Devido às desvantagens dos fotodetectores formados com a liga MCT e dos QWIPs, novas alternativas estão sendo atualmente investigadas e novos tipos de detectores estão sendo desenvolvidos. Dentre eles estão os detectores baseados nas transições intrabanda que tem como meio ativo os pontos quânticos auto-organizados embebidos nos materiais compostos III-V. Estes detectores denominados QDIPs (quantum dot infrared photodetectors) constituem o tema central desta dissertação.

A região ativa de um fotodetector de pontos quânticos é formada por um conjunto de camadas de pontos quânticos (por exemplo, pontos quânticos de InAs) separadas por camadas de material de gap maior (por exemplo, camadas de GaAs). Os pontos quânticos devem conter elétrons que serão excitados pela radiação infravermelha. Para isso, em geral, a região contendo os QDs é inserida entre duas camadas fortemente dopadas que fornecerão elétrons para os QDs. Atualmente, estão sendo produzidas estruturas onde as camadas do material semicondutor contendo os QDs são dopadas, ou seja, os próprios QDs dopados funcionam como um reservatório de elétrons, que serão fotoexcitados com radiação infravermelha para o contínuo ou estados muito próximos do contínuo, onde irão participar da corrente 
elétrica. No caso de excitação para os estados do contínuo obtém-se fotodetectores que operam em uma larga faixa espectral. No caso de excitação para estados localizados obtém-se detectores que operam em comprimentos de onda bem específicos. Os QDIPs são dispositivos unipolares, ou seja, só precisam de um tipo de portador para funcionar. Em geral, utiliza-se o elétron que têm massa efetiva menor que os burados e uma maior mobilidade, o que melhora o desempenho desses dispositivos.

A vantagem dos fotodetectores de QDs em relação aos outros dispositivos é devido ao confinamento tridimensional que reduz significativamente a geração térmica de portadores. Dessa forma, espera-se que a corrente no escuro desse detector seja menor que a corrente no escuro dos detectores MCT e QWIPs. Além disso, devido a não existência de regras de seleção no confinamento tridimensional, a absorção pode ocorrer com incidência normal (para materiais tipo-n). Tanto o tempo de vida do elétron como a redução da corrente no escuro indicam que os QDIPs podem operar em altas temperaturas [24]. A principal desvantagem do QDIP é a grande inomogeneidade na distribuição de tamanhos dos QDs, que acarreta um baixo coeficiente de absorção. É esta grande inomogeneidade que deteriora o desempenho e, consequentemente, reduz a eficiência quântica, como previsto teoricamente.

O objetivo desta dissertação é o modelamento teórico da corrente no escuro e da detectividade em estruturas que servem de base para a produção de fotodetectores de radiação infravermelha contendo pontos quânticos. Com o modelamento feito nesse trabalho vemos a possibilidade de obter resultados que auxiliem a fabricação desse tipo de dispositivo no Laboratório de Novos Materiais Semicondutores (LNMS) do IFUSP. Levando-se em consideração o que foi relatado nesta introdução é possível que tenhamos em um futuro próximo dispositivos eficientes, portáteis, seletivos e de baixo custo operando em temperaturas próximas da temperatura ambiente formado por heteroestruturas semicondutoras que possuam como meio ativo pontos quânticos. A apresentação dos resultados de nossa pesquisa foram organizados na seguinte forma: No Capítulo 2 fazemos uma breve descrição do processo de formação dos pontos quânticos auto-organizados de InGaAs. No Capítulo 3 descrevemos o modelo teórico utilizado para calcular a corrente de escuro e a detectividade dos fotodetectores de radiação infravermelha, que têm como meio ativo os pontos quânticos de InGaAs. Como no modelo utilizado precisa-se também conhecer a estrutura eletrônica dos pontos quânticos, no Capítulo 4 mostramos o modelo analítico utilizado para se calcular os níveis de confinamento dos elétrons nos QDs e também apresentamos os resultados obtidos com este modelo. No Capítulo $\mathbf{5}$ 
mostramos os resultados sobre a corrente de escuro e sobre a detectividade dos fotodetectores de InGaAs. No Capítulo 6 apresentamos as conclusões da nossa dissertação e, para finalizar, no Anexo 1 mostramos em detalhes o desenvolvimento do modelo analítico utilizado no cálculo da estrutura eletrônica dos pontos quânticos. 


\section{Capítulo 2}

\section{Pontos quânticos auto-organizados de InGaAs}

\subsection{O crescimento de camadas semicondutoras ten-}

sas

Durante um longo período, o princípio utilizado para a fabricação de heteroestruturas semicondutoras foi o crescimento de materiais de mesmo parâmetro de rede (ou bastante próximo) que o substrato utilizado. Uma enorme variedade de heteroestruturas semicondutoras foi produzida mudando-se a natureza, a composição, a espessura e a própria seqüência das camadas epitaxiais durante o crescimento. Na década de 80 , foi demonstrado que o crescimento de estruturas tensas, cujo parâmetro de rede era significativamente diferente daquele do substrato, podia fornecer sistemas físicos de grande interesse [25], principalmente para a Física Aplicada, como, por exemplo, na fabricação de laseres [26,27].

Para que o crescimento de uma estrutura com parâmetro de rede diferente do substrato seja coerente é necessário que algum tipo de deformação obrigue o material depositado a adotar o mesmo parâmetro de rede que o do substrato. Por exemplo, se o parâmetro de rede da camada epitaxial é maior do que o do substrato, a camada em crescimento (epicamada) deve deformar-se no sentido de reduzir o seu parâmetro de rede para que se estabeleça uma interface coerente com o substrato. Nestas condições cria-se uma interface cristalograficamente perfeita e a camada crescida sobre esta interface permanece isenta de defeitos estruturais. Em razão da deformação elástica necessária para o ajuste do parâmetro de rede da epicamada ao substrato, o sistema tende a acumular energia devido à tensão elástica sob o qual é mantido. Esta 
energia aumenta à medida que o número de camadas depositadas aumenta, até que uma espessura crítica seja atingida [28]. Neste exato momento, a energia elástica armazenada na camada tensa é tal que fica mais vantajoso, energeticamente, criar deslocações na interface (para relaxar a tensão) e adotar o parâmetro de rede natural do material que está sendo crescido.

Uma vez ultrapassada a espessura crítica, a superfície apresenta numerosos defeitos estruturais e o crescimento prossegue no modo tridimensional (a rugosidade aumenta rapidamente, e o crescimento não é mais considerado bidimensional, i.e., camada por camada). Esta transição do crescimento bidimensional (2D) para o crescimento tridimensional (3D) é de suma importância, pois é neste exato momento que se formam os pontos quânticos na superfície do filme. De fato, antes de criar deslocações, o sistema encontra um caminho alternativo para diminuir a energia elástica armazenada na camada, criando pequenas ilhas tridimensionais de material tenso, na beira das quais o parâmetro de rede é levemente relaxado, diminuindo assim a tensão na estrutura. Estas ilhas são chamadas pontos quânticos, e podem ser formadas na superfície do filme com uma inomogeneidade de tamanho inferior a $10 \%$, o que é excelente por se tratar de um processo espontâneo. Se o momento crítico for ultrapassado, os pontos quânticos coalescerão e formarão estruturas tridimensionais com numerosos defeitos estruturais, características de uma camada epitaxial com parâmetro de rede diferente do substrato. Os QDs auto-organizados são produtos naturais do crescimento de camadas semicondutoras sob tensão, como explicaremos a seguir.

\subsection{O processo de formação de pontos quânticos de InGaAs}

O desenvolvimento e o aprimoramento das técnicas de crescimento epitaxial, durante a década de 80 , estimulou fortemente o estudo de estruturas semicondutoras onde o confinamento dos portadores poderia ocorrer em uma ou mais direções do espaço. Provavelmente, o caso mais interessante e difícil de se obter de maneira controlada refere-se às estruturas que apresentam confinamento nas três direções do espaço, denominadas pontos quânticos ou átomos artificiais [29]. As primeiras tentativas de se produzir estruturas com potenciais de confinamento tridimensional utilizaram as técnicas de fotolitografia e eletrolitografia de alta resolução, bem como técnicas de crescimento sobre substratos pré-gravados. Contudo, estas técnicas 
depararam-se com a dificuldade de se produzir pontos quânticos com dimensões controladas ou pequenos o suficiente para garantir os efeitos de confinamento multidimensional. Além disso, os filmes produzidos com estas técnicas apresentavam má qualidade cristalina, com altas densidades de impurezas e defeitos estruturais provenientes dos tratamentos químicos. Um grande avanço foi obtido no início da década de 90 com a descoberta do processo de auto-organização (self-assembling) dos QDs, durante o crescimento epitaxial por MBE de camadas sob tensão [30-32].

Quando um filme epitaxial e o substrato sobre o qual ele é crescido possuem a mesma estrutura cristalina e um parâmetro de rede muito parecido (caso do AlGaAs sobre GaAs) ou idêntico (GaAs sobre GaAs), o material depositado adota naturalmente o mesmo parâmetro de rede que o do substrato (crescimento coerente), e o filme cresce camada por camada. Este modo de crescimento é conhecido como Frank-van der Merwe [33] e é o principal modo de crescimento de camadas semicondutoras isentas de tensão. No entanto, quando o material sublimado nas células de efusão (células de Knudsen) do equipamento de MBE tem um parâmetro de rede consideravelmente diferente daquele do substrato (por exemplo InAs sobre GaAs veja a Fig. 2.1a), a camada em crescimento é forçada a assumir o mesmo parâmetro de rede que o substrato. Isso significa que a energia potencial contida nas ligações químicas da epicamada não é mínima porque o parâmetro de rede do filme não é o seu natural. Neste caso, surge uma tensão mecânica que aumenta conforme aumenta a quantidade de material depositado (ou o número de camadas). Ainda assim, o crescimento é coerente e a epicamada é cristalograficamente perfeita e com parâmetro de rede idêntico ao do substrato (Fig. 2.1b). Este aumento de tensão não prossegue indefinidamente pois existe uma espessura crítica a partir da qual a tensão não pode mais ser contida pelas camadas epitaxiais. Quando isso acontece, os átomos recém-depositados se deslocam e se aglutinam formando pequenas ilhas tridimensionais tensionadas coerentes (Fig. 2.1c). Essas ilhas são chamadas de pontos quânticos e são literalmente pequenos aglomerados de átomos arranjados numa estrutura cristalina cujo parâmetro de rede ainda é o mesmo que o do substrato (por isso dita coerente), mas com um pequeno relaxamento em suas bordas. Este regime de crescimento é conhecido como Stranski-Krastanov [33].

Os QDs auto-organizados são distribuídos aleatoriamente (o que aparenta ser uma desvantagem em comparação com aqueles obtidos por litografia), porém seus diâmetros (variando de $70 \AA$ a $200 \AA$ ) podem ser controlados, assim como sua altura

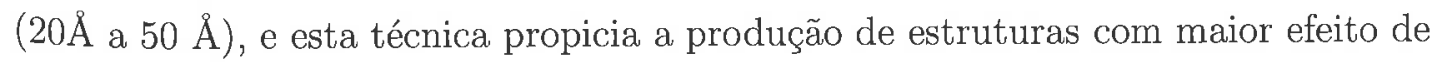


(a)

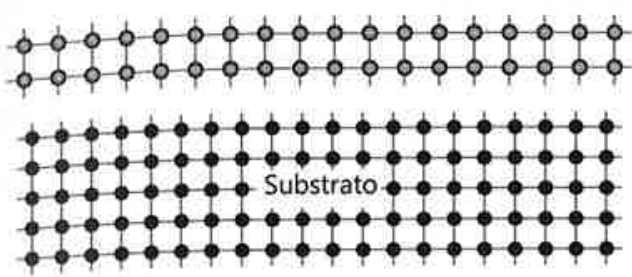

(c)

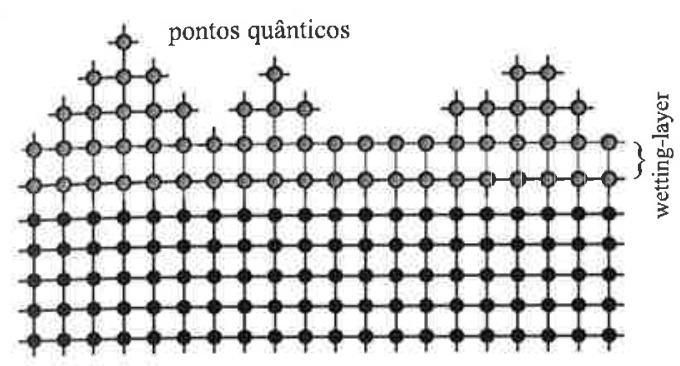

(b)

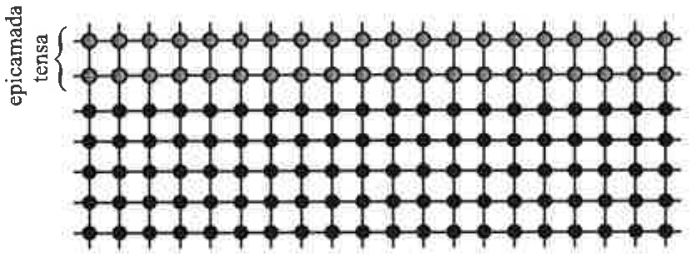

(d)

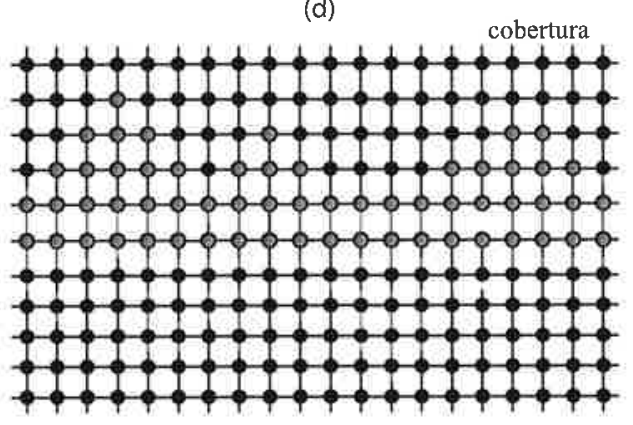

Figura 2.1: (a) Representação de materias cristalinos com diferentes parâmetros de rede (distância entre círculos vizinhos): o substrato (círculos pretos) e o filme epitaxial (círculos vermelhos). (b) Crescimento coerente de um filme epitaxial sob tensão onde o parâmetro de rede da epicamada ajusta-se naturalmente ao parâmetro de rede do substrato. (c) Rearranjo dos átomos da epicamada por causa do excesso de energia potencial elástica que resulta na formação de pequenas ilhas de material tensionado (os pontos quânticos) com o mesmo parâmetro de rede que o do substrato. Abaixo dos pontos quânticos resta um filme ultra fino (de aproximadamente uma monocamada) conhecido por wetting layer. (d) Depois de formados os QDs, retomase o crescimento cobrindo-se os pontos quânticos com uma nova camada de material semicondutor, camada esta que recebe o nome de cobertura.

confinamento que no caso da litografia [34].

Estudos sobre o processo de formação dos pontos quânticos de InAs sobre substratos de $\mathrm{GaAs}(100)$ mostram que estas estruturas são formadas quando a quantidade de InAs depositada é aproximadamente 1,6 monocamadas (MC) [34]. Nesta etapa, o processo de formação dos pontos quânticos envolve o rearranjo da camada de InAs depositada: parte dela (cerca de 1,2 MC) formará a wetting layer, sendo que o material restante irá constituir os pontos quânticos, propriamente ditos. Quando o crescimento prossegue, o InAs depositado fornecerá material para a geração de novos pontos ou, ainda, será responsável pelo aumento de suas dimensões. Terminada a deposição do InAs, prossegue-se o crescimento depositando-se uma camada de material semicondutor sobre os pontos quânticos, camada esta que recebe o nome de cobertura. 
Em meados de 1996, o grupo encarregado do crescimento de heteroestruturas semicondutoras do LNMS, liderado pelo Prof. Dr. Alain André Quivy, obteve com sucesso pontos quânticos auto-organizados de $\operatorname{In}_{\mathrm{x}} \mathrm{Ga}_{1-\mathrm{x}} \mathrm{As}(0,25 \leq x \leq 1)$, cuja presença foi revelada por medidas de STM [35] (Scanning Tunneling Microscopy) e AFM [36] (Atomic-Force Microscopy). Mais recentemente, este grupo realizou um estudo detalhado sobre a formação de uma única camada de QDs [33]. Neste trabalho foi investigado todo o processo de formação e evolução dos QDs em função da temperatura de crescimento, da pressão de arsênio e da espessura da camada de $\operatorname{In}_{\mathrm{x}} \mathrm{Ga}_{1-\mathrm{x}}$ As. Atualmente, este grupo está interessado no crescimento de QDs de $\operatorname{In}_{\mathrm{x}} \mathrm{Ga}_{1-\mathrm{x}}$ As para serem usados como meio ativo em fotodetectores de radiação infravermelha, e é neste contexto que se insere o tema desta dissertação. Vamos determinar a corrente no escuro e a detectividade de estruturas semicondutoras utilizadas na fabricação de fotodetectores de radiação infravermelha que tem como meio ativo camadas de pontos quânticos de $\operatorname{In}_{\mathrm{x}} \mathrm{Ga}_{1-\mathrm{x}} \mathrm{As}$. Estas grandezas serão calculadas em função da geometria (altura e raio da base) dos pontos quânticos e constituirão informações importantes para o planejamento e produção experimental dos fotodetectores em desenvolvimento no LNMS. 


\section{Capítulo 3}

\section{Modelamento teórico da corrente no escuro e da detectividade}

Em muitas circunstâncias é interessante comparar e avaliar os diferentes materiais envolvidos na detecção de radiação. Para isso são utilizadas as figuras de mérito. Dizemos que as figuras de mérito de um fotodetector são parâmetros medidos nas mesmas condições para diferentes tipos de materiais, que indicam a qualidade do desempenho dos dispositivos. Nesse trabalho vamos analisar as seguintes figuras de mérito:

- corrente no escuro;

- detectividade.

A corrente no escuro é a corrente de portadores gerados por excitação térmica. Ela limita o desempenho dos fotodetectores por ser um ruído do dispositivo. A detectividade é definida basicamente como a razão entre o sinal e o ruído do detector. Nas próximas seções descreveremos os modelos utilizados para descrever a corrente no escuro e a detectividade em função de parâmetros estruturais do dispositivo.

\subsection{Modelamento teórico da corrente no escuro}

Nesta seção descreveremos o modelo téorico proposto por Ryzhii e colaboradores [37] e utilizado nesta dissertação para o cálculo da corrente no escuro em fotodetectores de pontos quânticos que operam na região do infravermelho. De acordo com este modelo, considera-se que a estrutura dos QDIPs é formada por camadas de QDs separadas entre si por um material semicondutor de espessura $L$ e com gap de 


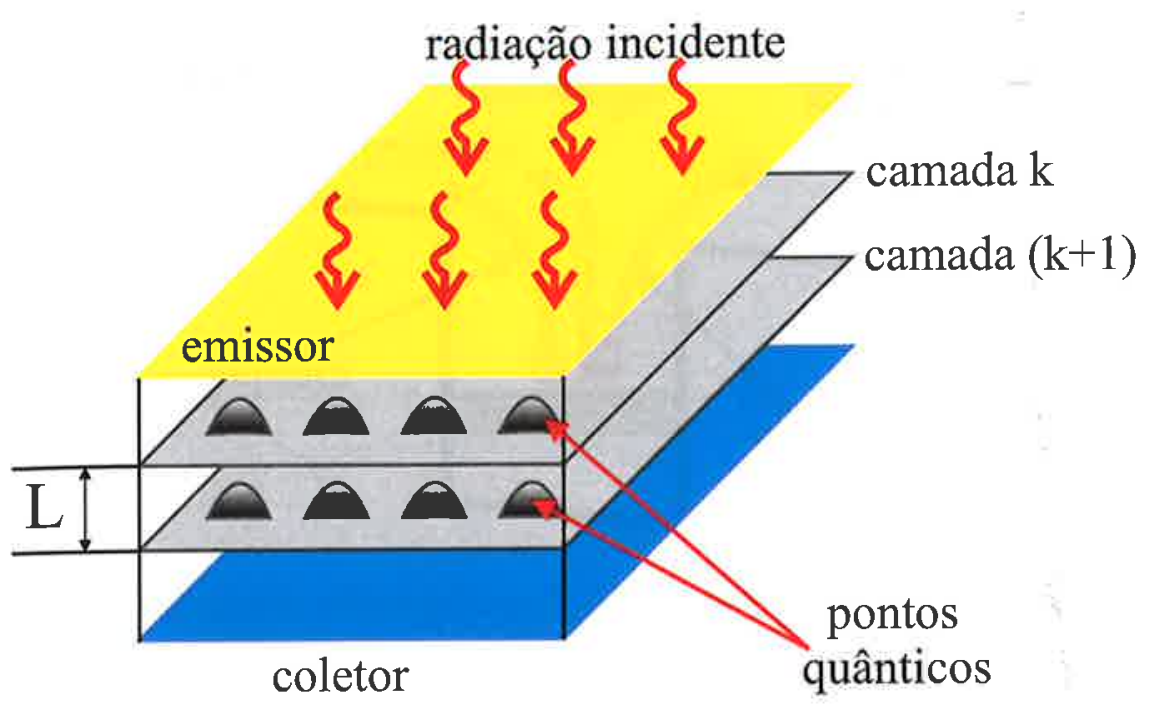

Figura 3.1: Representação esquemática da sequência de camadas semicondutoras de um fotodetector de pontos quânticos.

energia maior do que aquele que compõe os QDs. No formalismo do modelo, cada camada de QDs é identificada pelo índice $k(k=1,2, \ldots K$, onde $K$ é o número total de camadas de QDs empilhadas na região ativa). Assume-se que todas as camadas são idênticas e que estão dopadas com átomos doadores. Assume-se também que os QDs em uma dada camada $k$ são todos idênticos (mesma geometria e tamanho) e que estão distribuídos de forma regular e periódica em toda a superfície da camada. A região ativa dos fotodetectores, que é formada basicamente pelas camadas de QDs, é inserida entre duas regiões fortemente dopadas, demoninadas emissor e coletor, que servem de contatos ohmicos. Na Fig. 3.1 mostramos um desenho esquemático da estrutura do fotodetector que acabamos de descrever.

Cada camada de QDs é descrita pelos seguintes parâmetros:

- $\sum_{Q D}$ é a densidade superficial de pontos quânticos na camada $k$;

- $\sum_{D}$ é a densidade superficial de átomos dopantes na camada $k$.

O modelo também considera que a dimensão lateral do ponto quântico, descrita pelo raio de sua base $a_{Q D}$, é suficientemente grande em comparação com a sua dimensão transversal, descrita pela altura do $Q D, \ell_{Q D}$. Esta condição é imposta para que o QD tenha um único nível de energia associado com a quantização transversal e que o primeiro estado excitado do QD coincida com o fundo da banda de condução da barreira, ou seja, o modelo é válido apenas quando o QD tem dois 


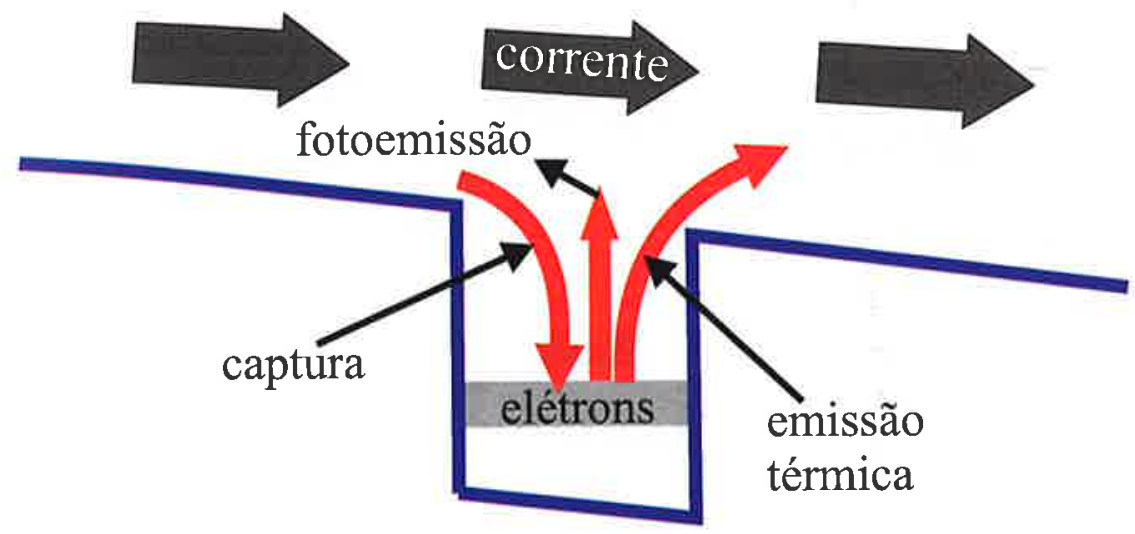

Figura 3.2: Representação esquemática dos processos que determinam o transporte de elétrons em um QDIP.

níveis de confinamento. Ele não contempla o fato que se as dimensões dos QDs forem suficientemente grandes, o número de estados ligados irá aumentar e, consequentemente, que também aumentará a capacidade dos QDs de aceitar um maior número de elétrons.

Ainda de acordo com este modelo, a conservação de carga no QD é dada pelo balanço entre os processos de captura, de fotoexcitação e de excitação térmica dos elétrons, que estão representados esquematicamente na Fig. 3.2. A equação de balanceamento (Eq. 3.1) pode ser escrita com uma forma parecida com aquela utilizada para descrever os QWIPs [38]:

$$
\frac{\langle J\rangle}{q \sum_{Q D}} p_{k}=G_{k}+G_{p h},
$$

onde $q$ é a carga do elétron, $(\langle J\rangle)$ é a densidade de corrente média na direção lateral, ${ }^{1} G_{k}$ é a taxa de geração térmica de elétrons na $k$-ésima camada de QDs para os estados do contínuo, $p_{k}$ é a seção de choque de captura pela $k$-ésima camada de pontos quânticos dos elétrons termicamente excitados, $G_{p h}$ é a taxa de geração de elétrons pelos fótons incidentes. Esta taxa é dada por:

$$
G_{p h}=\sigma \phi\left\langle N_{k}\right\rangle
$$

onde $\sigma$ é a seção de fotoescape, $\phi$ é o fluxo de fótons por unidade de tempo (radiação infravermerlha incidente) e $\left\langle N_{k}\right\rangle$ é o número médio de elétrons armadilhados

\footnotetext{
${ }^{1}$ Aqui, a média sobre a densidade de corrente $\langle J\rangle$ foi feita na direção lateral, pois a equação de balanceamento do número de elétrons que estamos considerando é a conservação de carga na $k$-ésima camada.
} 


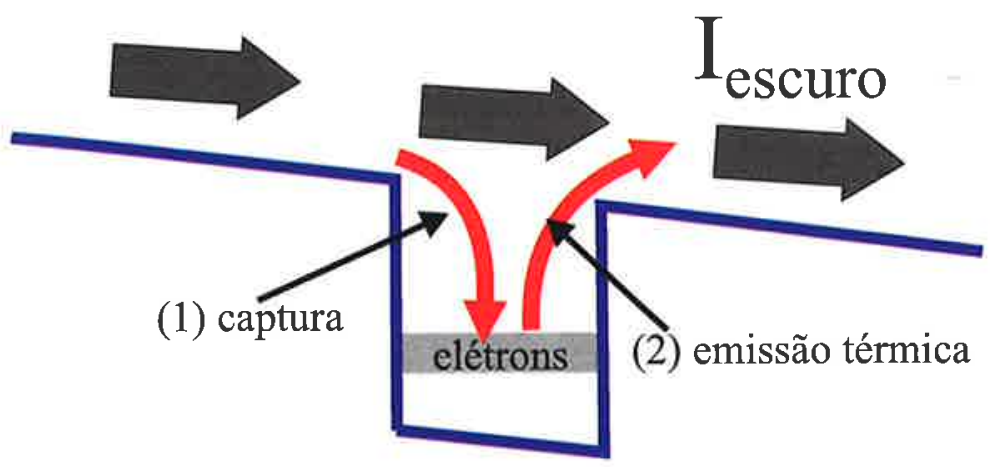

Figura 3.3: Representação esquemática do transporte de elétrons na ausência do fluxo de fótons incidentes, que resulta da competição entre dois processos: (1) o processo de armadilhamento de elétrons pelos pontos quânticos; (2) e o processo de excitação térmica.

em um ponto quântico. Este número médio pode ser estimado conhecendo-se a concentração dos átomos dopantes. Na ausência do fluxo de fótons $\phi$, a densidade de corrente torna-se a corrente no escuro. Na Figura 3.3 mostramos os dois processos que determinam a corrente no escuro do dispositivo de acordo com o modelo Ryzhii e colaboradores [37]: (1) o processo de armadilhamento de elétrons pelos pontos quânticos; (2) e o processo de excitação térmica dos elétrons que estão armadilhados nos QDs para os estados de condução. Como estamos interessados apenas na corrente no escuro, vamos assumir que o segundo termo do lado direito da Eq. 3.1 é nulo (= fluxo de fótons nulo). Assim, na ausência do fluxo de fótons, obtemos da Eq. 3.1 a expressão que descreve a corrente no escuro dos QDIPs:

$$
\left\langle J_{\text {escuro }}\right\rangle=q \sum_{Q D} \frac{G_{k}}{p_{k}}
$$

Como vemos na Eq. 3.3, a corrente no escuro é dada pela razão entre a taxa de geração térmica pela seção de choque de captura, processos que descreveremos a seguir.

\subsubsection{Geração térmica}

Definimos a geração térmica de elétrons na $k$-ésima camada $\left(G_{k}\right)$ como sendo a taxa de emissão térmica de elétrons na $k$-ésima camada $\left(e_{k}\right)$. Para fazer o cálculo de $e_{k}$ precisamos conhecer a estatística de emissão térmica dos QDs de InGaAs/GaAs, e para isso, utilizamos o modelo proposto por Engström e Landsberg [39]. A geometria considerada nessa descrição é tal que existem apenas dois níveis de confinamento de 
elétrons nos QDs, sendo que o primeiro estado excitado coincide com a altura da barreira.

Para se obter a taxa de emissão térmica da $k$-ésima camada vamos considerar um ensemble de QDs na $k$-ésima camada e avaliar qual é a probabilidade de um QD com $l$ níveis de energia possuir $r$ elétrons. $O$ ensemble grande canônico de QDs é formado pelo conjunto $\{(l, r), P(l, r)\}$, de microestados $(l, r)$ com a sua respectiva probabilidade $P(l, r)$. [40] Para se obter esta probabilidade vamos considerar um reservatório $R$ de QDs em contato com um sistema $S$ com $l$ estados e com a capacidade de capturar $M$ elétrons contados pelo índice $i=1,2,3, \ldots$. Dessa forma, a probabilidade de se encontrar um QD com $l$ níveis de energia com $r$ elétrons é dada pela expressão:

$$
P(l, r)=c \times \Omega_{R}\left(E_{0}-E(l, r), N_{0}-N(l, r)\right)
$$

onde $E_{0}$ é a energia total no ensemble de QDs, $N_{0}$ é o número total de élétrons, $E(l, r)$ é a energia associada à configuração $l$ com $r$ elétrons e $N(l, r)$ é o número de elétrons na configuração $l$. Tomando o logarítimo da Eq. 3.4 obtemos:

$$
\ln P(l, r)=\text { constante }+\ln \Omega_{R}\left(E_{0}-E(l, r), N_{0}-N(l, r)\right)
$$

Fazendo a expansão de Taylor na expressão acima teremos:

$\ln P(l, r)=$ constante $-E(l, r) \times\left(\frac{\partial \ln \Omega_{R}}{\partial E}\right)_{E_{0}, N_{0}}-N(l, r) \times\left(\frac{\partial \ln \Omega_{R}}{\partial N}\right)_{E_{0}, N_{0}}$

Usando a definição de entropia proporcionada pelo segundo postulado da Mecânica Estatística temos

$$
\left(\frac{\partial \ln \Omega_{R}}{\partial E}\right)=\frac{1}{k_{B} T}
$$

e

$$
\left(\frac{\partial \ln \Omega_{R}}{\partial N}\right)=-\frac{\mu}{k_{B} T}
$$

e podemos reescrever a Eq. 3.6 como

$$
\ln P(l, r)=\text { constante }-\frac{1}{k_{B} T} E(l, r)+\frac{\mu}{k_{B} T} N(l, r)
$$

Portanto, a probabilidade de se encontrar um QD com $l$ níveis de energia com $r$ 
elétrons é expressa da seguinte forma:

$$
P(l, r)=C \exp \left(-\frac{1}{k_{B} T} E(l, r)\right) \exp \left(\frac{\mu}{k_{B} T} N(l, r)\right)
$$

onde $C$ é uma constante de normalização. A probabilidade de o QD possuir $r$ elétrons é dada fazendo-se a soma sobre todos os $l$ estados na Eq. 3.10. Assim, obtemos:

$$
P(r)=\sum_{l} P(l, r)=C \lambda^{r} Z_{r}
$$

onde

$$
\lambda=\exp \left(\frac{\mu}{k_{B} T}\right)
$$

$\mathrm{Na}$ Eq 3.11, a função de partição no ensemble canônico para um QD com $r$ elétrons $\left(Z_{r}\right)$ é expressa por

$$
Z_{r}=\sum_{l} \exp \left(-\frac{1}{k_{B} T} E(l, r)\right)
$$

Se o estado do elétron é degenerado, para cada $r$, a soma sobre as configurações $l$ pode ser limitada sobre o nível degenerado de $E(r)$. Entretanto, assumindo que a degenerecência dos níveis de energia seja separada por unidades de $k_{B} T$, a soma em $l$ na equação 3.13 pode ser aproximada pelo número de permutações acessíveis ao estado

$$
Z_{r}=g_{r} \exp \left(-\frac{1}{k_{B} T} E(r)\right) .
$$

Normalizando a Eq. 3.11,

$$
\sum_{i=0}^{M} P(r)=1
$$

obtemos

$$
P(r)=\frac{\lambda^{r} Z_{r}}{\sum_{i=0}^{M} \lambda^{i} Z_{i}}
$$

Agora, dada a probabilidade de o QD possuir $r$ elétrons (Eq. 3.16) podemos cálcular a taxa de emissão térmica dos elétrons $e_{T}$. Para isso, vamos considerar QDs com apenas dois níveis, conforme é apresentado na Figura 3.4. Nesse esquema consideramos que o segundo nível coincide com o fundo da banda de condução da barreira. Dessa forma o QD com $r$ elétrons pode emitir elétrons em uma taxa $e_{r} \mathrm{e}$ pode capturar o seu $r$-ésimo elétron a uma taxa $c_{r}$.

No equilíbrio térmico, o número de elétrons ejetados dos QDs é igual ao número 


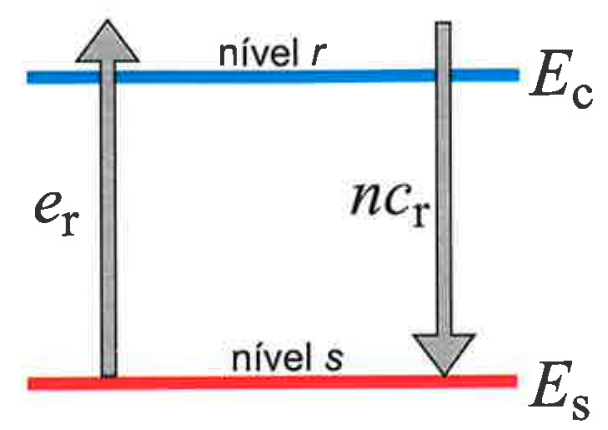

Figura 3.4: Esquema dos níveis de energia de um ponto quântico de InAs/GaAs no qual o segundo nível coincide com o fundo da banda de condução da barreira.

de elétrons capturados pelos QDs, ou seja, podemos escrever

$$
e_{r} P(r)=c_{r} n P(r-1)
$$

onde a densidade eletrônica é dada $n=N_{c} \exp \left(-\frac{E_{c}-\mu}{k_{B} T}\right)$ sendo $N_{c}$ a densidade de estados efetiva na banda de condução. A emissão térmica fica determinada pela seguinte expressão

$$
e_{r}=c_{r} n \frac{P(r-1)}{P(r)}
$$

A equação 3.18 mostra que a emissão térmica depende da razão entre as probabilidades $P(r-1)$ e $P(r)$. Esta razão é obtida usando-se a função de partição obtida na Eq. 3.14 na Eq. 3.16. Dessa forma, obtemos a seguinte relação para a razão entre as probabilidades:

$$
\frac{P(r-1)}{P(r)}=\frac{1}{\lambda} \frac{g_{r-1}}{g_{r}} \exp \left[\frac{E(r)-E(r-1)}{k_{B} T}\right] .
$$

Substituindo a Eq. 3.19 na Eq. 3.18, obtemos

$$
e_{r}=\frac{g_{r-1}}{g_{r}} c_{r} N_{c} \exp \left\{-\frac{E_{c}-[E(r)-E(r-1)]}{k_{B} T}\right\},
$$

sendo que a diferença de energia $[E(r)-E(r-1)]$ na Eq. 3.20 é a energia adicionada ao ensemble quando um elétron é capturado, para o qual assumiu-se que todos os primeiros $i$ elétrons são capturados para algum nível degenerado, e todas as energias diferentes da energia $[E(r)-E(r-1)]$ acima de $r=i$ tem o mesmo valor.

Para pontos quânticos de InGaAs/GaAs com a estrutura eletrônica descrita na 
Figura 3.4, o nível $s$ é degenerado. Assim,

$$
E(r)-E(r-1)=E_{s}, \quad \text { para } r=1,2 .
$$

A razão da emissão térmica dos elétrons no nível $s$ (estado fundamental), com $r$ elétrons, para o primeiro estado excitado dos QDs, ${ }^{2}$ é expressa por

$$
e_{r}=\frac{g_{r-1}}{g_{r}} c_{r} N_{c} \exp \left\{-\frac{\Delta E_{s}}{k_{B} T}\right\}, r=1,2
$$

onde $\Delta E_{s}=E_{c}-E_{s}$ e $E_{c}$ é o fundo da banda de condução da barreira.

Vamos assumir que a influência da temperatura na energia $\Delta E_{s}$ pode ser expressa por:

$$
\Delta E_{s}=\Delta E_{s}^{0}-\alpha_{s} T
$$

Na Eq. 3.23, $\alpha_{s}$ é uma constante e $\Delta E_{s}^{0}$ é a energia na temperatura nula. Podemos entender $\alpha_{s}$ como a contribuição da entropia da rede, na qual podemos associar uma entropia total com a captura de um elétron da seguinte forma

$$
\Delta S_{s, r}=\alpha_{s}+k_{B} \ln \frac{g_{s, r-1}}{g_{s, r}}
$$

Substituindo a expressão dada na Eq. 3.24 na Eq. 3.22 obtemos uma relação para a emissão térmica, dependente do fator de Boltzmann e da entropia total da rede:

$$
e_{s, r}=c_{s, r} N_{c} \exp \left(\frac{\Delta S_{s, r}}{k_{B}}\right) \exp \left\{-\frac{\Delta E_{s}}{k_{B} T}\right\}, r=1,2
$$

A variação de entropia na emissão de um elétron é negativa, pois a entropia diminuí com a diminuição do número de partículas. E, lembrando das equações de estado na representação da entropia, temos $\frac{\mu}{T}=\Delta S_{s, r}$. Então a Eq. 3.25 é reescrita como:

$$
e_{s, r}=c_{s, r} N_{c} \exp \left(\frac{\mu}{k_{B} T}\right) \exp \left\{-\frac{\Delta E_{s}}{k_{B} T}\right\}, r=1,2 .
$$

A expressão anterior depende do potencial químico, que está relacionado com a energia de Fermi $E_{F}$ do sistema. Neste formalismo, considera-se que a $k$-ésima camada de QDs contém um gás bidimensional de elétrons (2DEG) [8]. A energia de

\footnotetext{
${ }^{2}$ Neste modelo, estamos considerando que o primeiro estado excitado coincide com o fundo da banda de condução da barreira.
} 
Fermi de um gás bidimensional é dada por:

$$
\epsilon_{F}=\pi \frac{\hbar^{2}}{m} n
$$

onde $n$ é a densidade superficial de elétrons na camada $k$ no equilíbrio. Assim, podemos aproximar essa densidade de elétrons na camada $k$ pelo número médio de elétrons na camada $k$ dividida pela área do $\mathrm{QD}\left(n=\frac{\left\langle N_{k}\right\rangle}{a_{Q D}^{2}}\right)$. Dessa forma, podemos reescrever o potencial químico como:

$$
\mu=\pi \frac{\hbar^{2}}{m_{e}^{*}} \frac{\left\langle N_{k}\right\rangle}{a_{Q D}^{2}} .
$$

Logo, a taxa de geração térmica de elétrons será dada pela seguinte expressão:

$$
G_{k}=G_{0} \exp \left(-\frac{E_{i o n}}{k_{B} T}\right) \exp \left(\frac{\pi \hbar^{2}\left\langle N_{k}\right\rangle}{m_{e}^{*} k_{B} T a_{Q D}^{2}}\right) .
$$

O significado dos parâmetros que aparecem na expressão anterior é descrito a seguir:

- $G_{0}$ é um fator que depende da estrutura do fotodetector;

- $E_{i o n}=E_{2}-E_{1}$ é a energia de ionização de um elétron que está no estado fundamental $E_{1}\left(E_{1}=E_{s}\right)$ para o primeiro estado excitado $E_{2}\left(E_{2}=E_{c}\right)$, que coincide com o fundo da banda de condução da barreira;

- $\left\langle N_{k}\right\rangle$ é o número médio de elétrons armadilhados em um ponto quântico. Este número médio pode ser estimado conhecendo-se a concentração dos átomos dopantes.

- $m_{e}^{*}$ é a massa efetiva do elétron;

- $\hbar$ é a constante de Planck;

- $k_{B}$ é a constante de Boltzmann;

- $a_{Q D}$ é o raio da base do QD.

\subsubsection{Probabilidade de captura}

Devido ao potencial causado pelas cargas armazenadas nos QDs, o perfil de potencial da camada $k$ se mostrará com morros em cima dos QDs e vales fora dos 
mesmos. Devido a esse efeito, a probabilidade de captura dependerá do número de elétrons que ocupam esses QDs. O potencial gerado por um QD da camada $k$ será identificado com os índices $i$ e $j$, que indicam a posição do QD na $k$-ésima camada. Assim, o potencial pode ser expresso como:

$$
\varphi_{k}^{i, j}=-\frac{N_{k}^{i, j}}{C_{Q D}} \cong-q \frac{\left\langle N_{k}\right\rangle}{C_{Q D}} .
$$

A grandeza $C_{Q D}$ é a capacitância do QD e é dada por:

$$
C_{Q D}=\frac{2 \epsilon a_{Q D}}{\pi \sqrt{\pi}}
$$

onde $\epsilon$ é a constante dielétrica do material que compõe o QD. Vamos agora considerar que a probabilidade de captura em função do potencial produzido por estes elétrons possa ser escrito da seguinte forma:

$$
p_{k} \propto \exp \left(\frac{-q \varphi}{k_{B} T}\right)
$$

As Eqs. 3.30 e 3.32 mostram que o aumento do número de elétrons nos QDs faz com que o potencial gerado pelos mesmos aumente. Consequentemente, ocorrerá uma diminuição da probabilidade de captura de elétrons pelos QDs. Se o QD estiver totalmente ocupado, ou seja, quando $N_{Q D}=\left\langle N_{k}\right\rangle$, os elétrons não mais poderão ser capturados por esse QD. Portanto, podemos escrever a Eq. 3.32 como:

$$
p_{k}=p_{0 k} \frac{N_{Q D}-\left\langle N_{k}\right\rangle}{N_{Q D}} \exp \left(-\frac{q^{2}\left\langle N_{k}\right\rangle}{C_{Q D} k_{B} T}\right) .
$$

Na expressão 3.33 os parâmetros são:

- $p_{0 k}$ é a probabilidade de captura em um QD não carregado, que tem um valor próximo da unidade;

- $N_{Q D}$ é o número máximo de elétrons que pode ocupar cada QD. No modelo que estamos adotando, cada QD pode ter, no máximo, dois níveis eletrônicos. Desta forma, o máximo valor que $N_{Q D}$ pode ter é igual a seis $\left(N_{Q D}=6\right.$ sendo que 2 elétrons ocupam o estado fundamental e 4 elétrons ocupam o primeiro estado excitado). Se as dimensões do QD forem tais que existe apenas um estado ligado, então $N_{Q D}$ pode assumir os valores 1 ou 2 . 


\subsubsection{Corrente no escuro}

Agora, depois de obtidas as expressões para a taxa de geração térmica (Eq. 3.29) e a probabilidade de captura (Eq. 3.33) na $k$-ésima camada, podemos reescrever a Eq. 3.3:

$$
\left\langle J_{\text {escuro }}\right\rangle=q \sum_{Q D} \frac{G_{0} \exp \left(-\frac{E_{i o n}}{k_{B} T}\right) \exp \left(\frac{\pi \hbar^{2}\left\langle N_{k}\right\rangle}{m_{e}^{*} k_{B} T a_{Q D}^{2}}\right)}{p_{0 k} \frac{N_{Q D}-\left\langle N_{k}\right\rangle}{N_{Q D}} \exp \left(-\frac{q^{2}\left\langle N_{k}\right\rangle}{C_{Q D} k_{B} T}\right)} .
$$

Na Eq. 3.34, o número médio de elétrons $\left\langle N_{k}\right\rangle$ depende da tensão aplicada segundo a expressão

$$
\left\langle N_{k}\right\rangle=\frac{V+V_{D}}{V_{Q D}},
$$

sendo que a faixa de tensões aplicadas $(V)$ para que os QDs não estejam totalmente preenchidos deve satisfazer a condição $k_{B} T<<q V<q\left(V_{Q D}-V_{D}\right)$. Na expressão anterior,

$$
V_{Q D}=\frac{q}{2 \epsilon} K(K+1) \Sigma_{Q D} L\left(1-\frac{0,72 \sqrt{2}}{\pi K L \sqrt{\Sigma_{Q D}}}\right) N_{Q D}
$$

e

$$
V_{D}=\frac{q}{2 \epsilon} K(K+1) \Sigma_{Q} L
$$

são tensões características do dispositivo.

\subsection{Modelamento teórico da detectividade}

De acordo com a referência [41], a detectividade $D^{*}$ (chamada de D estrela) é definida como

$$
D^{*}=\frac{\Re \sqrt{A}}{\sqrt{4 q\left\langle J_{\text {escuro }}\right\rangle A g}},
$$

onde $A$ é a área sensível do detector, $g$ é o ganho do dispositivo e $\Re$ é a responsividade do dispositivo. O ganho é dado pela seguinte expressão

$$
g=\frac{1}{K} \frac{\tau_{v i d a}}{\tau_{\text {trans }}}
$$

Na Eq. 3.39, $\tau_{v i d a}$ é o tempo de captura do portador e $\tau_{\text {trans }}$ é o tempo de trânsito do portador no dispositivo. A responsividade é uma figura de mérito que avalia a eficiência de conversão dos fótons incidentes no dispositivo que irão efetivamente formar o sinal no dispositivo. Esta figura de mérito é definida pela razão entre 
a corrente gerada no dispositivo pela potência de fótons incidentes, e é dada pela expressão

$$
\Re=\frac{I_{p h}}{\hbar \nu \phi} .
$$

onde $I_{p h}$ é a corrente gerada pelos fótons incidentes, $\nu$ é a frequência dos fótons incidentes e $\phi$ é o fluxo de fótons. A corrente gerada pelos fótons incidentes é obtida tomando-se o primeiro termo do segundo membro da Eq. 3.1 igual a zero. Assim a corrente será dada por:

$$
I_{p h}=q g K \sum_{Q D} G_{p h} A
$$

A detectividade é definida pela substituição das Eqs. 3.39, 3.40 e 3.41 na equação 3.38. Obtém-se assim a detectividade em termos das taxas de geração térmica e da geração de portadores pelos fótons

$$
D^{*}=\frac{\Sigma_{Q D} K G_{p h}}{2 \hbar \nu \sqrt{\Sigma_{Q D} K G_{k}}} .
$$

Substituindo as equações 3.2 e 3.29 em 3.42 obtemos

$$
D^{*}=\frac{\sigma}{2 \hbar \nu} \sqrt{\frac{\Sigma_{Q D} K}{G_{0}}}\left\langle N_{k}\right\rangle \exp \left[\frac{E_{i o n}-\frac{\pi \hbar^{2}\left\langle N_{k}\right\rangle}{m_{e}^{*} a_{Q D}^{2}}}{2 k_{B} T}\right] .
$$

Como podemos observar nas expressões 3.34 e 3.43 , a corrente no escuro e a detectividade dependem de vários parâmetros dentre os quais aqueles que estão relacionados com a forma e geometria dos QDs de forma direta ou indireta. De forma direta temos, por exemplo, o parâmetro $a_{Q D}$ que aparece explicitamente na expressão 3.33 e é o raio da base do QD. De forma indireta podemos citar a energia de ionização $E_{\text {ion }}$ que também depende da geometria do QD. Como o tamanho de um QD pode ser manipulado, dentro de certos limites, pelas condições de crescimento, neste trabalho investigamos o comportamento da corrente no escuro e da detectividade em função das dimensões dos QDs. 


\section{Capítulo 4}

\section{Estrutura eletrônica de pontos quânticos}

\subsection{Modelo analítico para o cálculo dos níveis de energia de um ponto quântico}

Como vimos na seção anterior, a corrente no escuro dos fotodetectores depende da energia de confinamento dos elétrons nos QDs. A seguir, vamos apresentar as principais equações que nos permitem determinar os níveis de energia dos elétrons e dos buracos confinados em pontos quânticos de acordo com um modelo simplificado [42]. A razão para a escolha deste modelo é que ele nos fornece uma expressão analítica para o cálculo das energias de confinamento. Com isso podemos obter as energias para várias configurações dos QDs com rapidez. Um cálculo mais ebaborado envolve a diagonalização de matrizes com grandes dimensões e demanda muito tempo de computação $[43,44]$.

A Hamiltoniana do sistema é dada por:

$$
H=\frac{p_{e}^{2}}{2 m_{e}^{*}}+\frac{p_{h}^{2}}{2 m_{h}^{*}}+V_{e}\left(\vec{r}_{e}\right)+V_{h}\left(\vec{r}_{h}\right)-\frac{e^{2}}{\epsilon\left|\vec{r}_{e}-\vec{r}_{h}\right|}
$$

onde os subscritos e e $h$ identificam o elétron e o buraco respectivamente, $m_{e}^{*}$ é a massa efetiva do elétron, $m_{h}^{*}$ é a massa efetiva do buraco, e $\epsilon$ é a constante dielétrica do material que compõe o QD. Nesta Hamiltoniana os dois primeiros termos do lado direito referem-se à energia cinética do elétron e à energia cinética do buraco, respectivamente. Os potenciais $V_{e}\left(\vec{r}_{e}\right)$ e $V_{h}\left(\vec{r}_{h}\right)$ são os potenciais de confinamento do elétron e do buraco, respectivamente. O último termo da Hamiltoniana descreve 
a interação coulombiana de um par eletron-buraco no QD. Os potenciais $V_{e}\left(\vec{r}_{e}\right)$ e $V_{h}\left(\vec{r}_{h}\right)$ são determinados pela descontinuidade do gap de energia do material que forma o QD (nesta dissertação, a liga ternária de InGaAs) e do material que está ao redor do QD (neste trabalho, o GaAs), que tem um gap de energia maior do que aquele da liga de InGaAs. Estes potenciais são da ordem de centenas de meV e, portanto, muito maiores que a interação coulombina entre o elétron e o buraco (da ordem de poucas dezenas de meV). Desta forma, a primeira aproximação do modelo consiste em desprezar a interação coulombiana do elétron com o buraco, ou seja, desprezar o último termo da expressão 4.1. Com isto, podemos considerar o elétron e o buraco como partículas independentes e a Eq. 4.1 pode ser transformada na equação de Schröedinger de uma única partícula:

$$
\left[-\frac{\hbar^{2}}{2 m_{e, h}^{*}} \nabla^{2}+V_{e, h}\left(\vec{r}_{e, h}\right)\right] \Psi_{e, h}=E \Psi_{e, h} .
$$

Esta equação deve ser resolvida para o elétron e o buraco separadamente, confinados em seus respectivos poços de potencial. Como estamos interessados apenas nos níveis de confinamento dos elétrons, nas equações seguintes abandonaremos o índice $h$ relacionado com os buracos.

No sistema de coordenadas cilíndricas, ${ }^{1}$ o Laplaciano é dado por:

$$
\nabla^{2}=\frac{1}{r} \frac{\partial}{\partial r}\left(r \frac{\partial}{\partial r}\right)+\frac{1}{r^{2}} \frac{\partial^{2}}{\partial \theta^{2}}+\frac{\partial^{2}}{\partial z^{2}}
$$

Substituindo o Laplaciano na Eq. 4.2 ficamos com:

$$
\left\{-\frac{\hbar^{2}}{2 m_{e}^{*}}\left[\frac{1}{r} \frac{\partial}{\partial r}\left(r \frac{\partial}{\partial r}\right)+\frac{1}{r^{2}} \frac{\partial^{2}}{\partial \theta^{2}}+\frac{\partial^{2}}{\partial z^{2}}\right]+V(r, z)\right\} \Psi(r, \theta, z)=E \Psi(r, \theta, z) .
$$

Se fizermos $\Psi(r, \theta, z)=g_{r}(z) f(r, \theta)$, a equação anterior pode ser separada em duas equações independentes. Uma delas (a Eq. 4.5) depende apenas da variável $z$,

$$
\left[-\frac{\hbar^{2}}{2 m_{e}^{*}} \frac{\partial^{2}}{\partial z^{2}}+V_{e}(r, z)\right] g_{r}(z)=E_{0}(r) g_{r}(z)
$$

e nos possibilita calcular as energias do elétron devido ao confinamento desta partícula na direção do crescimento da amostra (direção $z$ ). A outra equação depende apenas

\footnotetext{
${ }^{1}$ Foi escolhido o sistema cilíndrico de coordenadas, pois como podemos visualizar na Figura 4.1, - QD possui o formato de um parabolóide de revolução.
} 


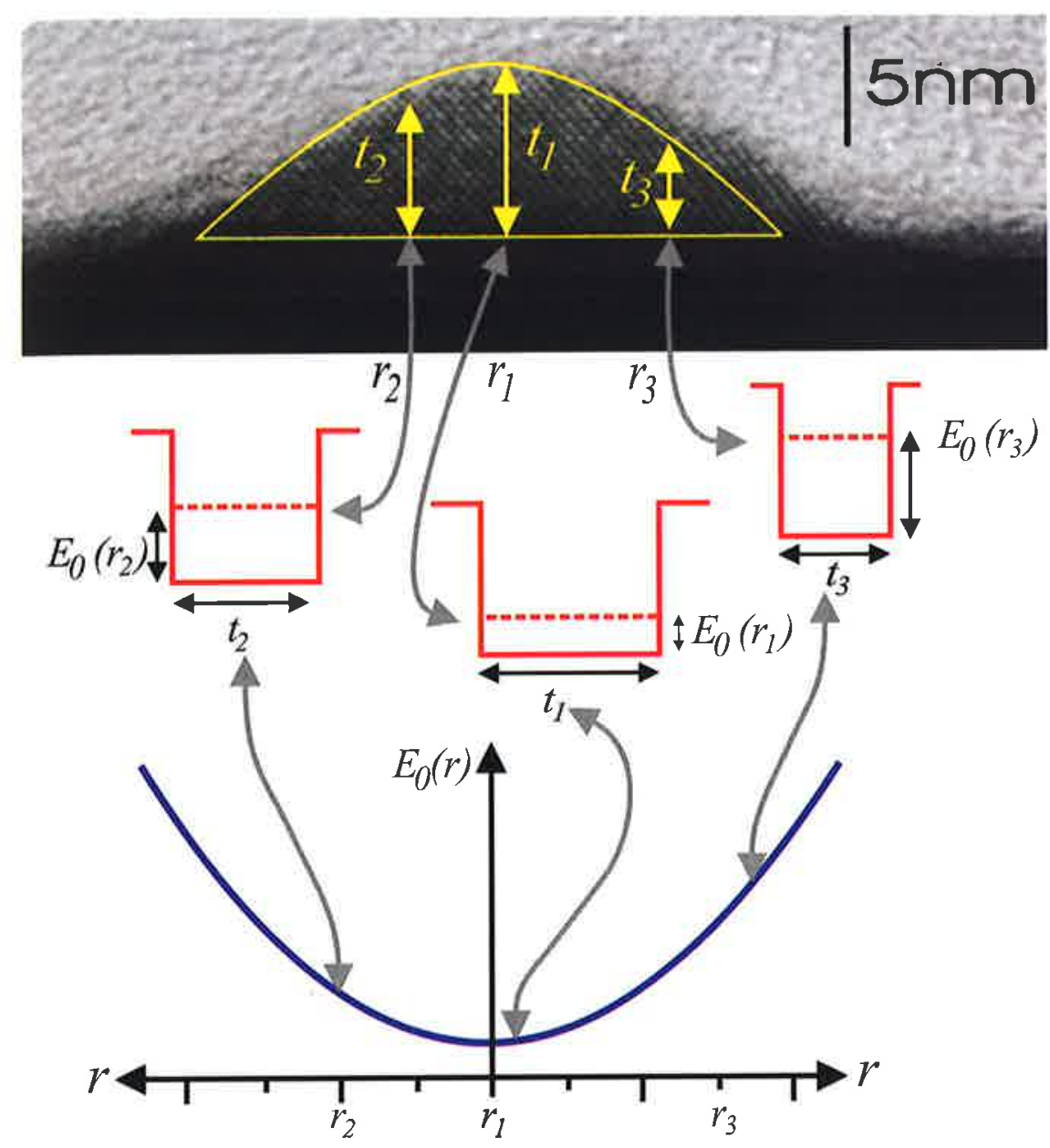

Figura 4.1: No alto da figura mostramos uma imagem de um QD obtida por microscopia de transmissão eletrônica [42]. No resto da figura mostramos a justificativa para a forma parabólica descrita na Eq. 4.11, onde $r_{1}, r_{2}$ e $r_{3}$ indicam posições radiais em relação ao centro do QD e $t_{1}, t_{2}$ e $t_{3}$ as espessuras do QD em cada uma dessas posições.

das variáveis $r$ e $\theta$. Ainda supondo que a função $g_{r}(z)$ varia muito pouco com o parâmetro $r$, podemos negligenciar o termo $r^{-2}[r(\partial / \partial r) r(\partial / \partial r)] g_{r}(z)$ e obtemos:

$$
\left\{-\frac{\hbar^{2}}{2 m_{e}^{*}}\left[\frac{1}{r} \frac{\partial}{\partial r}\left(r \frac{\partial}{\partial r}\right)+\frac{1}{r^{2}} \frac{\partial^{2}}{\partial \theta^{2}}+\right]+E_{0}(r)\right\} f(r, \theta)=E f(r, \theta) .
$$

onde o autovalor $E_{0}(r)$, obtido com a solução da Eq. 4.5, atua como um potencial efetivo para o movimento do elétron no plano $x y$. Os autovalores $E_{0}(r)$ podem ser determinados com a solução da Eq. 4.5 para todo valor $r$ medido a partir do centro do QD, onde $r$ não é uma variável, mas sim apenas um parâmetro. Com isso, cada valor de $r$ determina a largura $t(r)$ de um poço de potencial na direção $z$ como 
ilustrado na Fig. 4.1.

O potencial $V(r, z)$ é dado por:

$$
V_{e}(r, z)=\left\{\begin{array}{cl}
0 & \text { dentro do QD, isto é, para } 0 \leq z \leq t(r) \\
V_{0} & \text { fora do QD. }
\end{array}\right.
$$

onde $V_{0}$ é um dado de entrada no cálculo. Na seção 4.2 mostraremos como determinamos $V_{0}$.

O modelo analítico da referência [42] resolve a Eq. 4.5 usando como solução tentativa a série de Aronstein e Stroud [45] que utiliza como funções de base as soluções de uma partícula confinada em um poço de potencial infinito. Desta forma, as soluções obtidas para o potencial finito são dadas por:

$$
E_{0}(r)=\frac{P^{2}}{(1+P)^{2}} E_{\text {infinito }}(r)
$$

onde

$$
E_{\text {infinito }}(r)=\frac{\pi^{2} \hbar^{2}}{2 m_{e}^{*} t^{2}(r)}
$$

$\mathrm{e}$

$$
P=\frac{\sqrt{2 m_{e}^{*} V_{0}}}{\hbar} \frac{\ell_{Q D}}{2}
$$

sendo $\ell_{Q D}$ a altura do QD e $V_{0}$ a altura da barreira de potencial. Considerando que o QD tem a forma de um parabolóide (veja a Fig. 4.1) temos:

$$
z=\frac{\ell_{Q D}}{a_{Q D}^{2}} r^{2}
$$

$\mathrm{e}$

$$
t(r)=\ell_{Q D}-\frac{\ell_{Q D}}{a_{Q D}^{2}} r^{2} .
$$

Substituindo as Eqs. 4.9 e 4.12 na Eq. 4.8 obtemos

$$
E_{0}(r)=\frac{P^{2}}{(1+P)^{2}} \frac{\pi^{2} \hbar^{2}}{2 m_{e}^{*} \ell_{Q D}^{2}}\left[1+2\left(\frac{r}{a_{Q D}}\right)^{2}\right] .
$$

A análise da Eq. 4.13 mostra-nos que uma partícula no centro do QD sente um potencial harmônico efetivo que é igual à energia do estado fundamental de um poço 
de largura $\ell_{Q D}$. Substituindo a Eq. 4.13 em 4.6 teremos:

$$
\begin{aligned}
& \left\{-\frac{\hbar^{2}}{2 m_{e}^{*}}\left[\frac{1}{r} \frac{\partial}{\partial r}\left(r \frac{\partial}{\partial r}\right)+\frac{1}{r^{2}} \frac{\partial^{2}}{\partial \theta^{2}}\right]+\right. \\
& \left.+\frac{P^{2}}{(1+P)^{2}} \frac{\pi^{2} \hbar^{2}}{2 m_{e}^{*} t^{2}(r)}\left[1+2\left(\frac{r}{a_{Q D}^{2}}\right)\right]\right\} f(r, \theta)=E f(r, \theta)
\end{aligned}
$$

que tem como autovalores as energias

$$
E_{n}=E_{0}(r=0)+(n+1) \hbar \omega
$$

onde $E_{0}(r=0)$ é dada pela Eq. $4.13 \operatorname{com} r=0, n=0,1,2, \ldots$ e

$$
\omega=\frac{P}{(1+P)} \frac{\sqrt{2} \pi \hbar}{m_{e}^{*} \ell_{Q D} a_{Q D}} .
$$

\subsection{Potencial de confinamento para pontos quânticos de $\operatorname{In}_{x} \mathrm{Ga}_{1-x}$ As com barreira de GaAs, incluindo o efeito da tensão}

Em nosso trabalho analisaremos fotodetectores de QDs de InAs e outros contendo QDs de InGaAs. Para isso, devemos determinar a altura da barreira $V_{0}$ para o elétron confinado em QDs de $\operatorname{In}_{\mathrm{x}} \mathrm{Ga}_{1-\mathrm{x}}$ As. Como vimos no Cap. ??, o material semicondutor que compõe os QDs está tensionado pois tem seu parâmeto de rede adaptado ao parâmetro de rede do GaAs. Desta forma, para determinar a altura da barreira de potencial devemos incluir o efeito da tensão na determinação da barreira de potencial. Em um QD tensionado, o potencial de confinamento dos elétrons é escrito como [46]:

$$
V_{0}(z)=\left\{\begin{array}{cl}
0 & \text { na região do } \mathrm{QD} \\
\Delta E_{c}-a_{c} \operatorname{Tr}(\epsilon) & \text { fora do QD }
\end{array}\right.
$$

onde $\operatorname{Tr}(\epsilon)=\left(\epsilon_{\mathrm{xx}}+\epsilon_{\mathrm{yy}}+\epsilon_{\mathrm{zz}}\right)$ e $a_{c}$ é o potencial de deformação da banda de condução. Nesta definição de $V_{0}(z)$ as energias foram tomadas em relação ao fundo da banda de condução do poço de potencial não tenso. Para entender o potencial definido na 


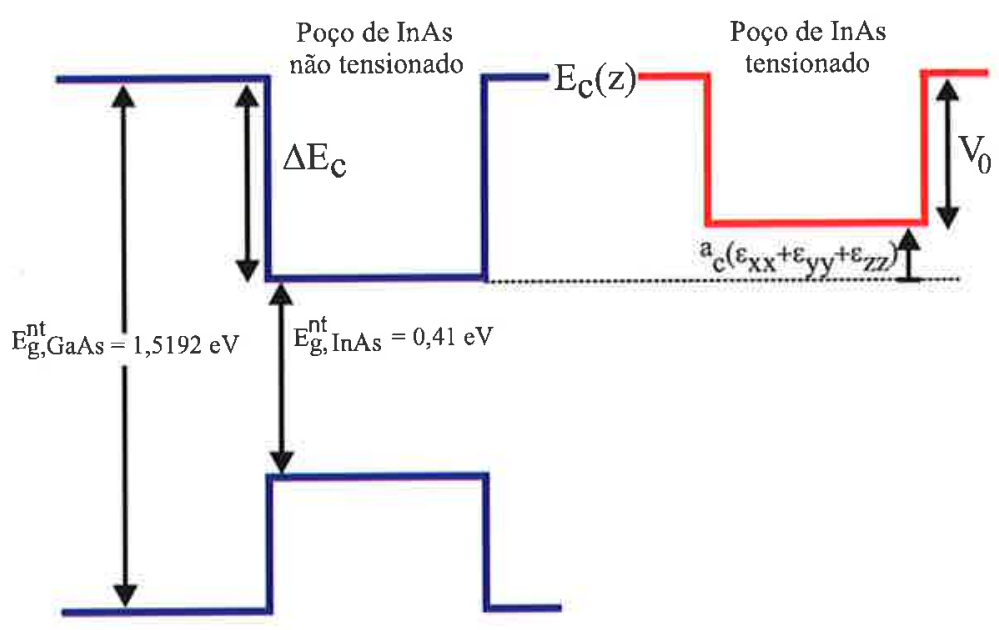

Figura 4.2: Diagrama mostrando o perfil da banda de condução $E_{c}(z)$ que tem como referência o fundo da banda de condução do poço não tenso, ou seja, as energias são medidas a partir desta referência (linha pontilhada). A energia do gap do GaAs não tenso em $\mathrm{T}=300 \mathrm{~K}$ é $E_{g, \text { GaAs }}^{n t}=1,5192 \mathrm{eV}$ e do InAs é $E_{g, \operatorname{InAs}}^{n t}=0,41 \mathrm{eV}$. Com estes valores obtemos $\Delta E_{g} \stackrel{g}{=} 1109 \mathrm{meV}$ (Eq. 4.21) e $\Delta E_{c}=776 \mathrm{meV}$ (Eq. 4.20).

expressão 4.17, veja a Figura 4.2.

As componentes do tensor de tensão (strain) são definidos como [47]:

$$
\begin{gathered}
\epsilon_{x x}(x)=\epsilon_{y y}(x)=\frac{a_{\text {substrato }}-a_{\text {filme }}(x)}{a_{\text {filme }}(x)} \\
\epsilon_{z z}(x)=-\frac{2 C_{12}(x)}{C_{11}(x)} \epsilon_{x x}(x)
\end{gathered}
$$

onde $a_{\text {filme }}(x)$ é o parâmetro de rede do material não tenso que constitui o QD, $C_{11} \mathrm{e}$ $C_{12}$ são constantes elásticas (parâmetros que dependem da composição $x$ se o filme for a liga de InGaAs), e $a_{\text {substrato }}$ é o parâmetro de rede do substrato.

A descontinuidade do gap para a banda de condução, $\Delta E_{c}$, é calculada por:

$$
\Delta E_{c}(x)=0,70 \times \Delta E_{g}(x)
$$

onde

$$
\Delta E_{g}(x)=E_{g, \mathrm{GaAs}}^{n t}-E_{g, \mathrm{In}_{\mathrm{x}} \mathrm{Ga}_{1-\mathrm{x}} \mathrm{As}}^{n t}
$$

sendo $E_{g, \mathrm{GaAs}}^{n t}$ a energia do gap do GaAs e $E_{g, \mathrm{In}_{\mathrm{x}} \mathrm{Ga}_{1-\mathrm{x}} \mathrm{As}}$ a energia do gap do $\operatorname{In}_{\mathrm{x}} \mathrm{Ga}_{1-\mathrm{x}} \mathrm{As}$, ambos não tensos. Na expressão 4.20 assuminos um offset de $70 \%$ para a banda de condução e $30 \%$ para a banda de valência [48]. Estes valores de offset são contro- 
Tabela 4.1: Parâmetros para os materiais GaAs e InAs: parâmetro de rede $a_{0}$, potencial de deformação da banda de condução $a_{c}$, constantes elásticas $C_{11}$ e $C_{12}$ e massa efetiva do elétron $m_{e}^{*}$. $m_{0}$ é a massa do elétron livre.

\begin{tabular}{|l|c|c|c|}
\hline \hline Parâmetros & GaAs & InAs & \\
\hline$a_{0}(\AA)$ & 5,6533 & 6,0584 & ref. [50] \\
$a_{c}(\mathrm{eV})$ & $-7,17$ & $-5,08$ & ref. [51] \\
$C_{11}\left(10^{11} \mathrm{dyn} / \mathrm{cm}^{2}\right)$ & 12,23 & 8,33 & ref. [51] \\
$C_{12}\left(10^{11} \mathrm{dyn} / \mathrm{cm}^{2}\right)$ & 5,71 & 4,53 & ref. [51] \\
$m_{e}^{*} / m_{0}$ & 0,067 & 0,023 & ref. [51] \\
\hline \hline
\end{tabular}

Tabela 4.2: Expressões que descrevem a energia do gap não tenso $E_{g}^{n t}(x)$, as constantes elásticas $C_{11}$ e $C_{12}$, o potencial de deformação $a_{c}$, o parâmetro de rede $a_{0}$, e a massa efetiva do elétron $m_{e}^{*}$ para a liga de $\operatorname{In}_{\mathrm{x}} \mathrm{Ga}_{1-\mathrm{x}}$ As.

\begin{tabular}{|l|c|c|}
\hline \hline Parâmetros & Expressões & \\
\hline$a_{0}(\AA)$ & $6,0584 x+(1-x) 5,6533$ & \\
$a_{c}(\mathrm{eV})$ & $-5,08 x-(1-x) 7,17$ & \\
$C_{11}\left(10^{11} \mathrm{dyn} / \mathrm{cm}^{2}\right)$ & $8,33 x+(1-x) 12,23$ & \\
$C_{12}\left(10^{11} \mathrm{dyn} / \mathrm{cm}^{2}\right)$ & $4,53 x+(1-x) 5,71$ & \\
$m_{e}^{*} / m_{0}$ & $0,023 x+(1-x) 0,067$ & \\
$E_{g}^{n t}(x)[\mathrm{eV}]$ para $\mathrm{T}=2 \mathrm{~K}$ & $1,5192-1,5837 x+0,475 x^{2}$ & ref. [52] \\
$E_{g}^{n t}(x)[\mathrm{eV}]$ para $\mathrm{T}=77 \mathrm{~K}$ & $1,508-1,47 x+0,375 x^{2}$ & ref. [53] \\
$E_{g}^{n t}(x)[\mathrm{eV}]$ para $\mathrm{T}=300 \mathrm{~K}$ & $1,43-1,53 x+0,45 x^{2}$ & ref. [54] \\
\hline
\end{tabular}

(a) Para a liga ternária $\operatorname{In}_{\mathrm{x}} \mathrm{Ga}_{1-\mathrm{x}}$ As um dado parâmetro $p$ pode ser obtido por interpolação linear entre os parâmetros dos compostos binários InAs e GaAs como: $p(x)=x \times p_{\text {InAs }}+(1-x) \times p_{\text {GaAs }}$. Veja a página 1879 da ref. [50].

versos e pode-se também adotar outros valores como, por exemplo, 60\%/40\% [49].

Na Tabela 4.1 mostramos os parâmetros que serão usados para descrever os compostos binários de InAs e GaAs. Fazendo interpolações lineares obtemos as expressões que nos permitem calcular os parâmetros para a liga de $\operatorname{In}_{\mathrm{x}} \mathrm{Ga}_{1-\mathrm{x}}$ As e que estão apresentadas na Tabela 4.2 .

Na Fig. 4.3 mostramos a energia do gap da liga não tensa de $\operatorname{In}_{\mathrm{x}} \mathrm{Ga}_{1-\mathrm{x}} \mathrm{As}$ em função da concentração de índio para três diferentes temperaturas ( $\mathrm{T}=2$, 77 e $300 \mathrm{~K}$ ) de acordo com as expressões empíricas apresentadas na Tabela 4.2.

Na Fig. 4.4 mostramos a descontinuidade da banda de condução $\left(\Delta E_{c}(x)\right)$ entre o $\operatorname{In}_{\mathrm{x}} \mathrm{Ga}_{1-\mathrm{x}} \mathrm{As}$ e o GaAs em função da concentração de índio para a temperatura 


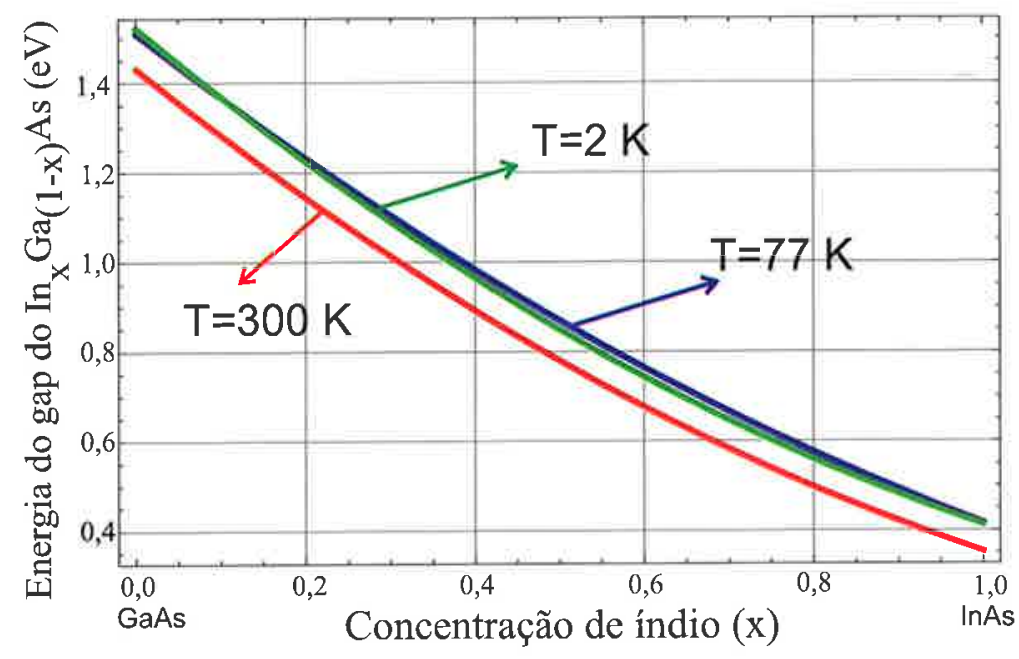

Figura 4.3: Energia do gap da liga não tensa de $\operatorname{In}_{\mathrm{x}} \mathrm{Ga}_{1-\mathrm{x}} \mathrm{As}$ em função da concentração de In calculada para as temperaturas $\mathrm{T}=2 \mathrm{~K}, 77 \mathrm{~K}$ e $300 \mathrm{~K}$ de acordo com as expressões apresentadas na Tabela 4.2.

$\mathrm{T}=2 \mathrm{~K}$ e também a altura da barreira $V_{0}$ (região sombreada) calculada incluindose o efeito da tensão. Nossos cálculos mostram (aqui não apresentados) que as curvas de $\Delta E_{c}(x)$ para $\mathrm{T}=77 \mathrm{~K}$ e $\mathrm{T}=300 \mathrm{~K}$ são praticamente coincidentes. Mesmo comparando-se as curvas de $\Delta E_{c}(x)$ para as três temperaturas, a variação entre elas é bem pequena. Logo, o cálculo dos níveis de confinamento em função da temperatura deve dar resultados muito próximos para as três diferentes temperaturas. Apenas na hora de se calcular uma transição da banda de condução para a banda de valência para se comparar o resultado com aquele de uma experiência de fotoluminescência, por exemplo, os valores do gap dos materiais para as diferentes temperaturas vão influenciar no resultado final. A região cinza (sombreada) representa a altura da barreira de potencial $V_{0}(x)$ [definida como $V_{0}(x)=\Delta E_{c}(x)-a_{c} \operatorname{Tr}(\epsilon(\mathrm{x}))$ ] em função da concentração de índio, tomando-se o fundo do poço não tensionado como referência.

De acordo com a teoria apresentada nesta seção, definimos uma expressão que nos permite calcular a altura da barreira de potencial em função da concentração de índio. Esta expressão, que está representada na Fig. 4.5, é dada por:

$$
V_{0}(x)[e V]=+0,556 x-0,0885 x^{2}
$$




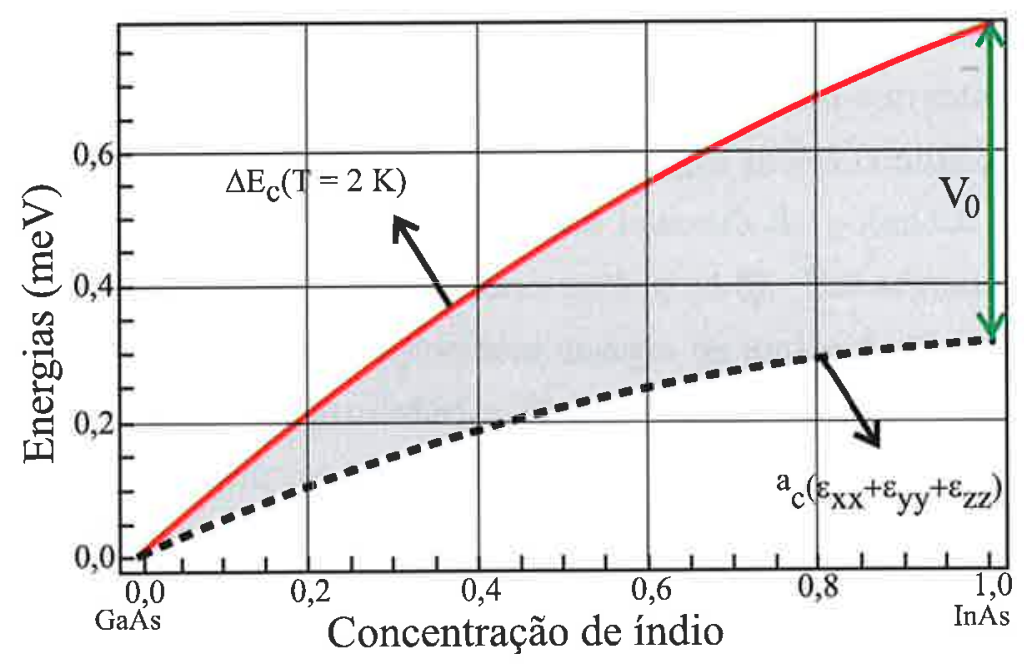

Figura 4.4: Descontinuidade do gap na banda de condução $\Delta E_{c}(x)$ (calculada de acordo com a expressão 4.20) e potencial devido a tensão (termo $a_{c} \operatorname{Tr}(\epsilon)$ ) (curva pontilhada) em função da concentração de índio. A região cinza (sombreada) é a altura da barreira de potencial e é calculada como $V_{0}(x)=\Delta E_{c}(x)-a_{c} \operatorname{Tr}[\epsilon(\mathrm{x})]$.

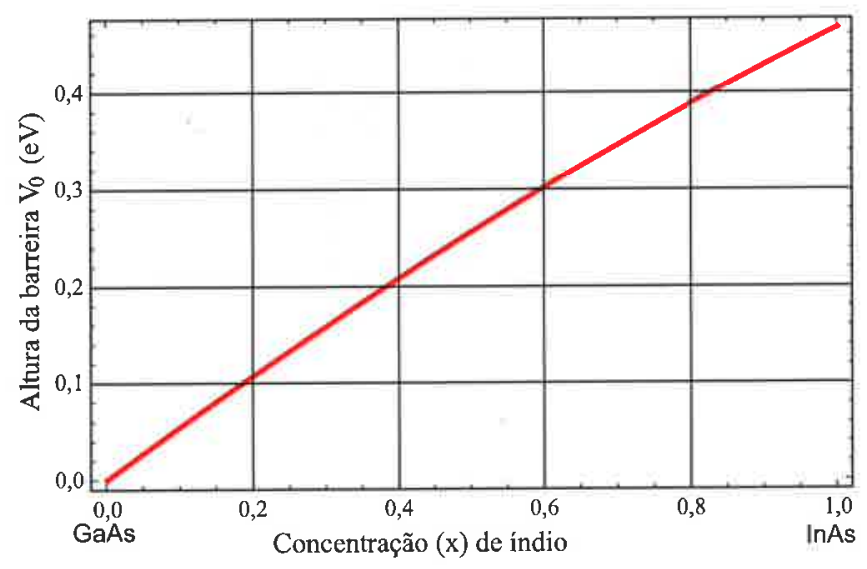

Figura 4.5: Potencial de confinamento $V_{0}(x)$ em função da concentração de índio. Esta curva foi obtida com a expressão: $V_{0}(x)=\left[\Delta E_{c}-a_{c} \operatorname{Tr}(\epsilon)\right]$ (veja Eq. 4.17). Para $x=1, \Delta E_{c}=0,776 \mathrm{eV}$ e $a_{c} \operatorname{Tr}(\epsilon)=0,310 \mathrm{eV}$. Logo, o potencial de confinamento para o InAs não tenso $(x=1)$ passou de $0,776 \mathrm{eV}$ para $0,466 \mathrm{eV}$ para o InAs tenso (compare com a Fig. 4.2).

\subsection{Estrutura eletrônica dos pontos quânticos de}

\section{InAs}

Nessa seção apresentaremos as energias de confinamento e as energias de ionização dos elétrons confinados em QDs de InAs, com diferentes dimensões, calculadas com 
o modelo analítico descrito nas seções anteriores deste capítulo. Como descrevemos no Capítulo 3, o modelo que adotamos para descrever a corrente no escuro e a detectividade é válido para QDs que têm apenas dois níveis confinados, sendo que o estado excitado deve estar bem próximo da barreira de potencial (ou seja, com energia quase no contínuo, como mostrado na Fig. 4.6). Em seguida, identificaremos, entre estes QDs, aqueles que possuem energia de ionização dentro de uma das janelas de mínima absorção atmosférica (3 a $5 \mu \mathrm{m}$ ou de 8 a $12 \mu \mathrm{m}$ ). Em uma etapa final, vamos procurar as dimensões de QDs de InAs/GaAs que possuem energia de ionização dentro de uma das janelas de mínima absorção atmosférica e que podem ser produzidos no $\mathrm{MBE}$, sabendo que o MBE produz QDs de InAs/GaAs com alturas da ordem de 40 a $70 \AA$ e raios da base entre 100 e $150 \AA$.

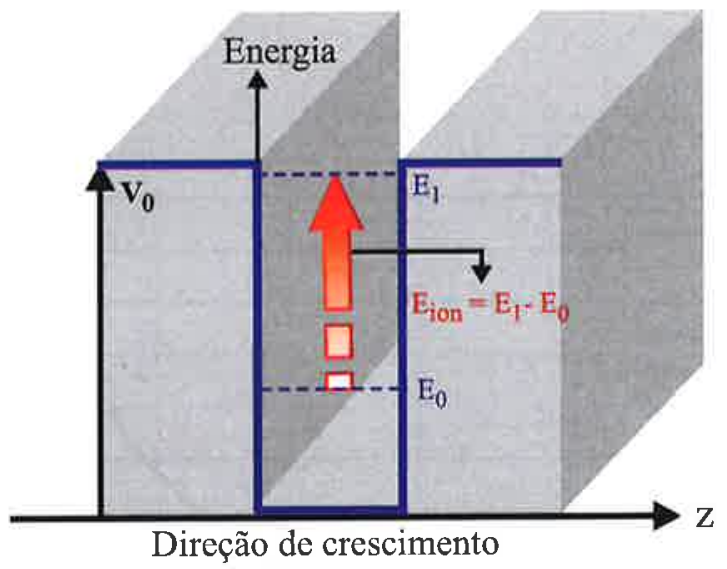

Figura 4.6: Representação esquemática da estrutura eletrônica ideal dos QDs que podem ser utilizados para a construção de fotodetectores de radiação infravermelha de banda estreita. A energia de ionização deve ser aproximadamente igual à diferença entre as energias do estado fundamental e do primeiro estado excitado do QD.

De acordo com as Eqs. 4.15 e 4.22, a energia de confinamento dos elétrons nos QDs é função do raio da base, da altura do QD e da concentração de In, ou seja, $E_{n}=E_{n}\left(a_{Q D}, \ell_{Q D}, x\right)$; e a altura da barreira é função da concentração de In $V_{0}=V_{0}(x)$. Para encontramos a relação entre o raio da base $\left(a_{Q D}\right)$ e altura $\left(\ell_{Q D}\right)$ dos QDs que resultam em QDs com dois níveis de energia, vamos impor a condição que a energia do primeiro estado excitado deve ser igual a altura da barreira, ou seja, que deve satisfazer a seguinte condição:

$$
E_{1}\left(a_{Q D}, \ell_{Q D}, x\right)=V_{0}(x)
$$

Obtemos assim, as relações entre $a_{Q D}$ e $\ell_{Q D}$ para as diferentes concentrações de 
In que serão utilizadas na obtenção das energias de ionização. As expressões obtidas estão apresentadas na Tabela 4.3 e o comportamento destas curvas estão descritos na Fig. 4.7. Nesta figura, observamos que os QDs com concentrações de In entre $1 \leq x<0,7$ possuem menor dependência com a variação da concentração de In. Dessa maneira, as alturas e os raios da base dos QDs que possuem o primeiro estado excitado coincidente com a barreira e tem concentrações de In no intervalo $1 \leq x<0,7$ terão valores bem próximos. Também podemos observar uma maior dependência das curvas com a diminuíção da concentração de In, ou seja, observamos um aumento acentuado dos raios da base em uma mesma faixa de alturas de QDs quando $x>70 \%$.

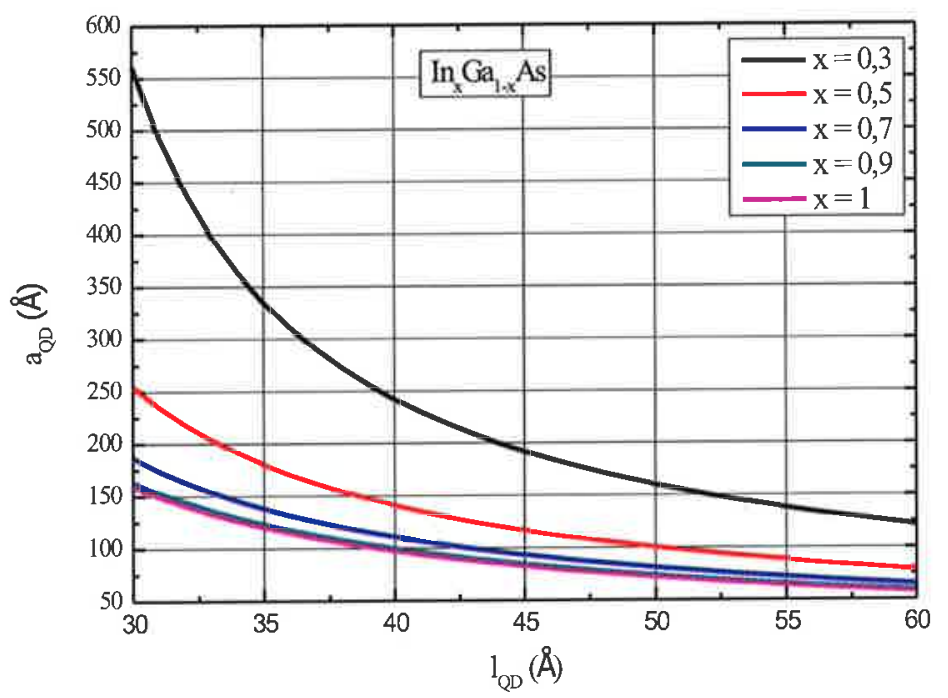

Figura 4.7: Raio da base $a_{Q D}(\AA)$ em função da altura do $Q D \ell_{Q D}(\AA)$ para diferentes concentrações de In. Estas curvas representam os QDs cujas dimensões possuem dois níveis, sendo que a energia do primeiro estado excitado coincide com a altura da barreira. 
Tabela 4.3: Expressões que descrevem o raio da base, $a_{Q D}(\AA)$, em função da altura do $\mathrm{QD}, \ell_{Q D}(\AA)$, para diferentes concentrações de In. Estas curvas representam os QDs cujas dimensões resultam em QDs com apenas dois níveis de energia confinados, sendo que a energia do primeiro estado excitado coincide com a altura da barreira.

\begin{tabular}{|c|c|}
\hline$a_{Q D}=a_{Q D}\left(\ell_{Q D}\right)$ & $\operatorname{In}_{\mathrm{x}} \mathrm{Ga}_{1-\mathrm{x}} \mathrm{As}$ \\
\hline$a_{Q D}=\frac{8,48162 \times 10^{37}+2,91091 \times 10^{36} \times \ell_{Q D}}{-9,61419 \times 10^{35}+4,49721 \times 10^{34} \ell_{Q D}+7,71725 \times 10^{32} \times \ell_{Q D}^{2}}$ & $x=1$ \\
\hline$a_{Q D}=\frac{8,4983 \times 10^{37}+2,90872 \times 10^{36} \times \ell_{Q D}}{-9.60696 \times 10^{35}+4,48164 \times 10^{34} \times \ell_{Q D}+7,66967 \times 10^{32} \times \ell_{Q D}^{2}}$ & $x=0,95$ \\
\hline$a_{Q D}=\frac{4,22467 \times 10^{37}+1,43907 \times 10^{36} \ell_{Q D}}{-4,75299 \times 10^{35}+2,20667 \times 10^{34} \times \ell_{Q D}+3,75836 \times 10^{32} \ell_{Q D}^{2}}$ & $x=0,9$ \\
\hline$a_{Q D}=\frac{4,39619 \times 10^{37}+1,48709 \times 10^{36} \times \ell_{Q D}}{-4,91159 \times 10^{36}+2,26446 \times 10^{34} \times \ell_{Q D}+3,82998 \times 10^{32} \times \ell_{Q D}^{2}}$ & $x=0,85$ \\
\hline$a_{Q D}=\frac{3,12876 \times 10^{38}+1,04856 \times 10^{37} \times \ell_{Q D}}{-3,46319 \times 10^{36}+1,58189 \times 10^{35} \times \ell_{Q D}+2,65074 \times 10^{33} \times \ell_{Q D}^{2}}$ & $x=0,8$ \\
\hline$a_{Q D}=\frac{3,91608 \times 10^{37}+1,29698 \times 10^{36} \times \ell_{Q D}}{-4,2837 \times 10^{35}+1,93367 \times 10^{34} \times \ell_{Q D}+3,20211 \times 10^{32} \times \ell_{Q D}^{2}}$ & $x=0,75$ \\
\hline$a_{Q D}=\frac{5.40621 \times 10^{37}+1,76458 \times 10^{36} \ell_{Q D}}{-5,82808 \times 10^{35}+2,59272 \times 10^{34} \times \ell_{Q D}+4,2313 \times 10^{32} \times \ell_{Q D}^{2}}$ & $x=0,7$ \\
\hline$a_{Q D}=\frac{2,07453 \times 10^{36}+6,65282 \times 10^{34} \times \ell_{Q D}}{-2,1973 \times 10^{34}+9,60409 \times 10^{32} \times \ell_{Q D}+1,53997 \times 10^{3} 1 \ell_{Q D}^{2}}$ & $x=0,65$ \\
\hline$a_{Q D}=\frac{4.52082 \times 10^{36}+1,41953 \times 10^{35} \times \ell_{Q D}}{-4,68845 \times 10^{34}+2,0065 \times 10^{33} \times \ell_{Q D}+3,15019 \times 10^{31} \times \ell_{Q D}^{2}}$ & $x=0,6$ \\
\hline$a_{Q D}=\frac{2,62618 \times 10^{39}+7,80792 \times 10^{37} \times \ell_{Q D}}{-2,57881 \times 10^{37}+1,04499 \times 10^{36} \times \ell_{Q D}+1,55343 \times 10^{34} \times \ell_{Q D}^{2}}$ & $x=0,5$ \\
\hline$a_{Q D}=\frac{3,72005 \times 10^{38}+9,17366 \times 10^{36} \times \ell_{Q D}}{-3,02989 \times 10^{36}+1,01836 \times 10^{35} \times \ell_{Q D}+1,25564 \times 10^{33} \times \ell_{Q D}^{2}}$ & $x=0,3$ \\
\hline
\end{tabular}

Agora, conhecendo-se as dimensões dos QDs que possuem dois níveis, iremos procurar os QDs de $\operatorname{In}_{\mathrm{x}} \mathrm{Ga}_{1-\mathrm{x}}$ As que possuem energia de ionização dentro de uma das janelas de mínima absorção atmosférica. A energia de ionização é definida como a diferença de energia entre o primeiro estado excitado e o estado fundamental:

$$
E_{i o n}\left(a_{Q D}, \ell_{Q D}, x\right)=E_{1}\left(a_{Q D}, \ell_{Q D}, x\right)-E_{0}\left(a_{Q D}, \ell_{Q D}, x\right)
$$




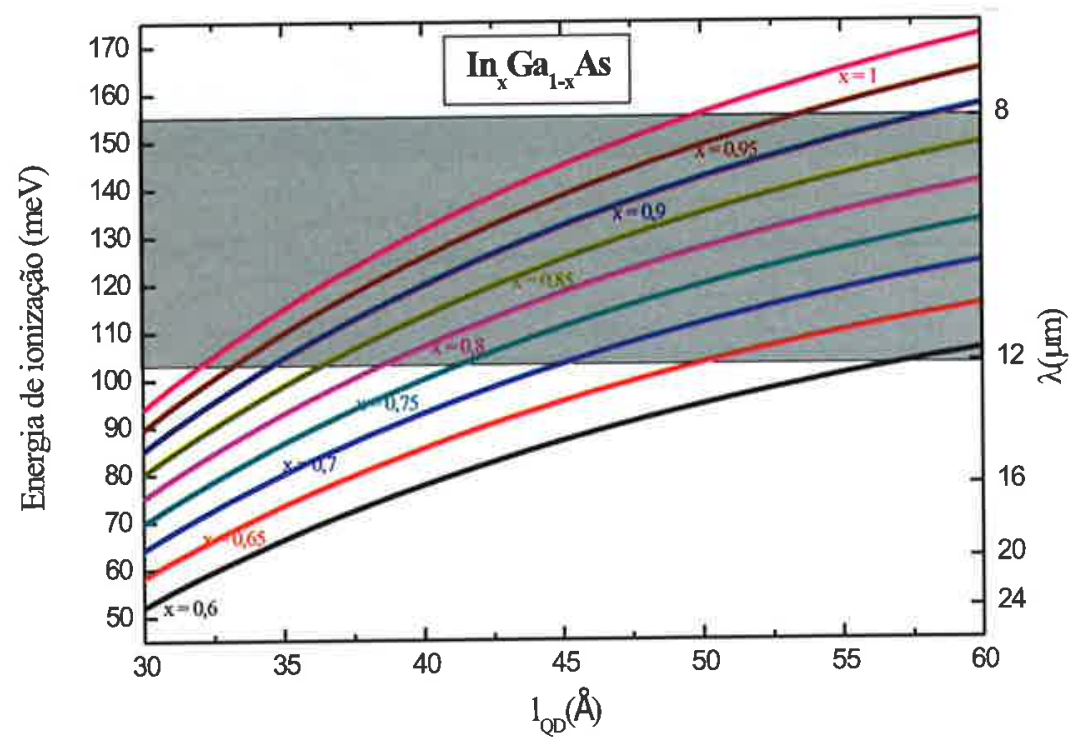

Figura 4.8: Energia de ionização (eixo do lado esquerdo) com seu correspondente comprimento de onda (eixo do lado direito) em função da altura do QD para diferentes concetrações de In. A faixa em cinza seleciona os QDs que possuem energia de ionização dentro da janela de mínima absorção atmosférica (8-12 $\mu \mathrm{m})$.

e estamos procurando soluções onde

$$
8 \leq E_{i o n}\left(a_{Q D}, \ell_{Q D}, x\right) \leq 12 \mu m
$$

Para encontramos a energia de ionização dos QDs de acordo com as condições já expostas, devemos substituir as expressões mostradas na Tabela 4.3 na Eq. 4.25 para cada uma das concentrações de In especificadas. Assim, para cada concentração de índio, obtemos uma expressão para a energia de ionização que só depende da altura do $\mathrm{QD}\left(E_{i o n}=E_{i o n}\left(a_{Q D}\left(\ell_{Q D}\right), \ell_{Q D}, x\right)\right)$.

$\mathrm{Na}$ Fig. 4.8, mostramos as curvas que descrevem o comportamento da energia de ionização em função da altura do QD para diferentes concentrações de In. Nesta figura, dentro da faixa cinza, mostramos quais são as alturas dos QDs que resultam em uma energia de ionização na faixa de mínima absorção atmosférica (8-12 $\mu \mathrm{m})$ para diferentes concentrações In.

Na Fig. 4.9, podemos observar que não existem QDs cuja energia de ionização esteja na outra faixa de mínima absorção atmosférica no intervalo de 3-5 $\mu \mathrm{m}$ pois, como é observado, as energias de ionização são no máximo $232 \mathrm{meV}$, ou seja, esta energia é menor que a necessária para a deteç̧ão nesta faixa de energia. 


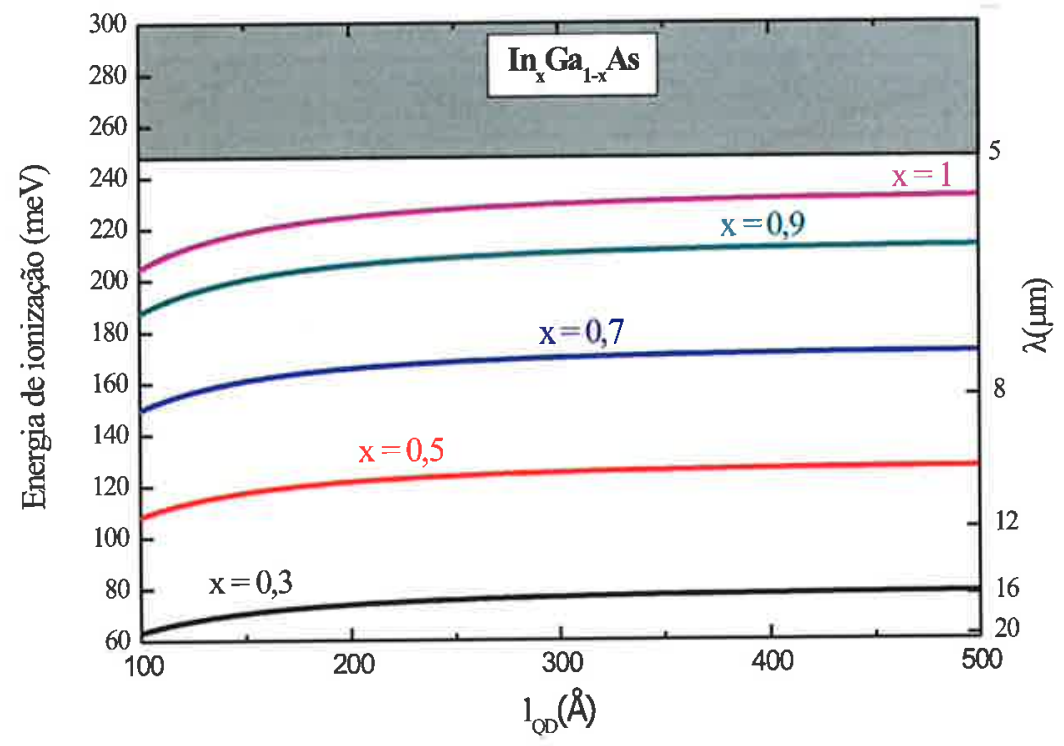

Figura 4.9: Energia de ionização (eixo do lado esquerdo) com seu respectivo comprimento de onda (eixo do lado direito) em função da altura do QD para diferentes concetrações de In. A faixa em cinza corresponde a janela de mínima absorção atmosférica 3-5 $\mu \mathrm{m}$.

Na Fig. 4.8, na qual foi observado QDs cuja energia de ionização está na faixa de mínima absorção atmosférica de 8-12 $\mu \mathrm{m}$, não foi apresentado de forma explícita a relação entre as alturas e os raios dos QDs. Como já foi discutido, a relação entre raios e alturas varia com a concentração de In. Então, para podermos comparar com as dimenções de QDs obtidas no MBE, mostraremos, separadamente, as curvas referentes às energias de ionização para diferentes concentrações de In. Assim, para cada concentração de In encontraremos as geometrias de QDs que podem ser obtidas no MBE e possuem energia de ionização dentro da faixa de mínima absorção atmosférica $(8-12 \mu \mathrm{m})$.

Começaremos com o InAs, pois como podemos observar na Fig. 4.8, estes QDs possuem energia de ionização dentro da faixa desejada. Na Fig. 4.10, mostramos a energia de ionização dos QDs de InAs em função da altura do QD (eixo horizontal inferior) com seu correspondente raio (eixo horizontal superior). A faixa amarela destaca as dimenções usuais dos QDs de InAs/GaAs que podem ser obtidas variandose as condições de crescimeto no sistema de MBE. Portanto, podemos visualizar que os QDs de InAs/GaAs com raios da base entre $150 \AA$ e $71,6 \AA$ e respectivas alturas no intervalo $30,9 \AA$ e $50 \AA$ possuem energia de ionização dentro da janela de mínima absorção atmosférica 8-12 $\mu \mathrm{m}$. 


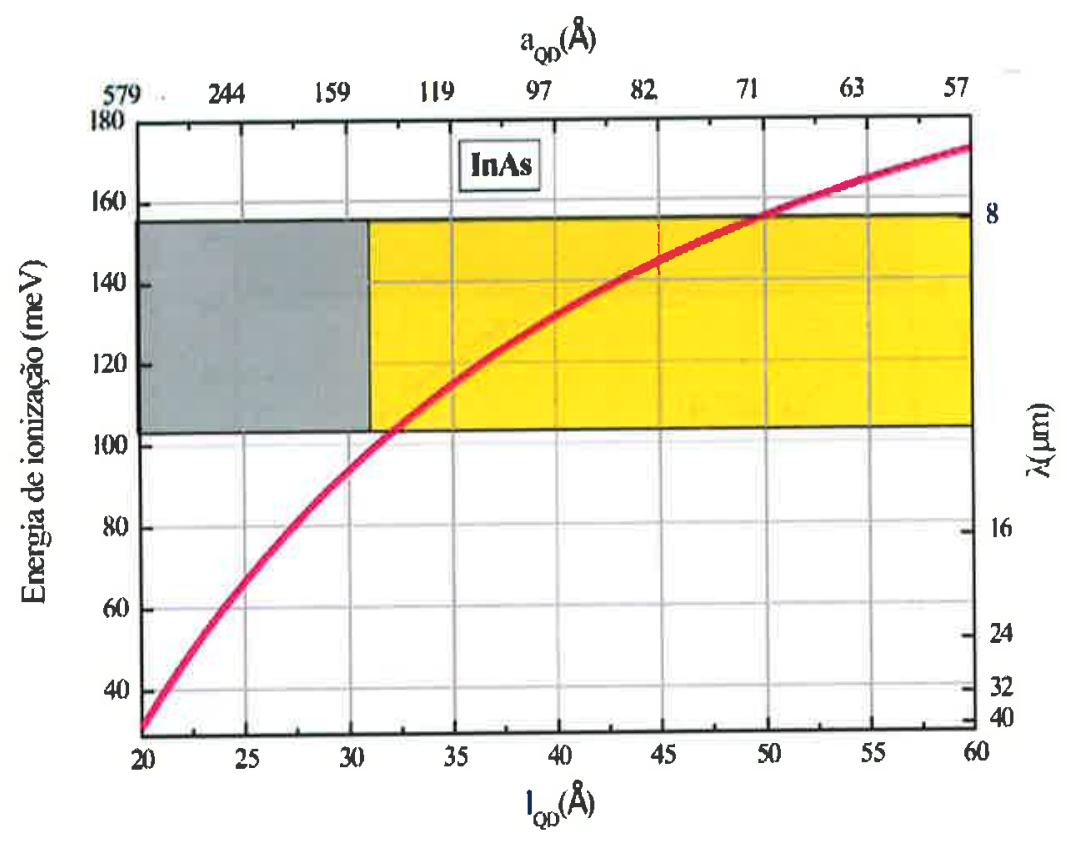

Figura 4.10: Energia de ionização (eixo esquerdo) com seu respectivo comprimento de onda (eixo direito) em função da altura do QD (eixo horizontal inferior) com o seu respectivo raio (eixo horizontal superior) para QDs de InAs. A faixa em cinza destaca a região de mínima absorção atmosférica $(8-12 \mu \mathrm{m})$ e a faixa em amarelo seleciona as dimensões dos QDs de InAs que são possíveis obter-se no sistema MBE.

Para as ligas de $\operatorname{In}_{x} \mathrm{Ga}_{1-x}$ As, vamos mostrar as curvas da energia de ionização em função da altura com seu correspondente raio da base, sem destacar as dimensões de QDs que podem ser produzidos no MBE. Não foi possível fazer esta seleção pois o grupo do LNMS não possui um estudo sistemático sobre a distribuição de tamanhos de QDs em função da concentração de In, que podem ser obtidos pelo MBE. Entretanto, sabemos que a distribuição de alturas e raios dos QDs formados pela liga de InGaAs se desloca em relação ao InAs, isto é, com a diminuição da concentração de In, ocorre um aumento das alturas dos QDs formados pelas ligas de InGaAs produzidas no MBE e uma diminuição dos raios da base dos QDs. Este fato é decorrência da diminuição da concentração de In, que ocasionana uma diminuição no parâmetro de rede e consequentemente a energia elástica acumulada na liga é menor e, portanto, o material depositado nos pontos quânticos não é sulficiente para alcançar o volume crítico $^{2}$ e relaxarem. Dessa forma, para a liga de InGaAs iremos destacar apenas a faixa de mínima absorção atmosférica.

\footnotetext{
${ }^{2} \mathrm{O}$ volume crítico se refere ao volume de material que pode ser incorporado aos pontos quânticos já existentes. No caso do volume da ilha ultrapassar esse volume crítico, esta relaxa e dá origem à estruturas maiores e incoerentes.
} 


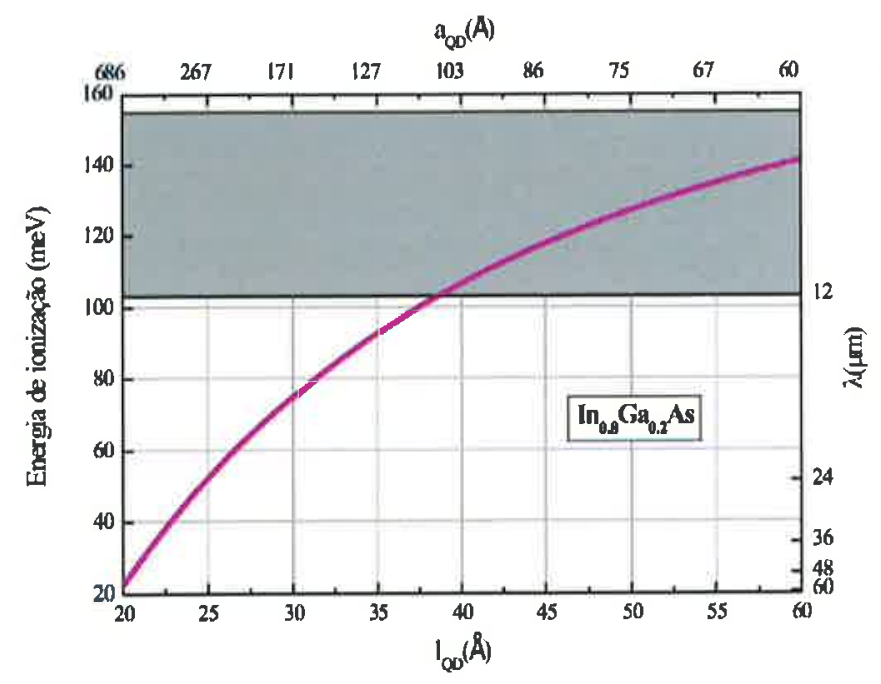

Figura 4.11: Energia de ionização (eixo esquerdo) com seu respectivo comprimento de onda (eixo direito) em função da altura do QD (eixo horizontal inferior) com o seu respectivo raio (eixo horizontal superior) dos QDs de $\mathrm{In}_{0.8} \mathrm{Ga}_{0.2}$ As. A faixa em cinza destaca a região de mínima absorção atmosférica $(8-12 \mu \mathrm{m})$.

As Figs. 4.11 e ?? mostram as energias de ionização dos QDs de $\operatorname{In}_{0.8} \mathrm{Ga}_{0.2}$ As e $\mathrm{In}_{0.6} \mathrm{Ga}_{0.4}$ em função das alturas dos QDs (eixo horizontal inferior) e dos seus respectivos raios (eixo horizontal superior). Na Fig. 4.11 podemos visualisar o aumento dos raios para a mesma faixa de alturas consideradas na Fig. 4.10. Observamos também que as alturas de $38 \AA$ a $60 \AA$ possuem energias de ionização dentro da janela de mínima absorção atmosférica 8-12 $\mu \mathrm{m}$.

Na Fig. ?? podemos visualizar um limite para o qual diminuindo a concentração de In, a curva não cruzará a faixa cinza. Nesta figura observamos também o aumento dos raios da base em relação à mesma faixa de alturas consideradas na Fig. 4.10. 


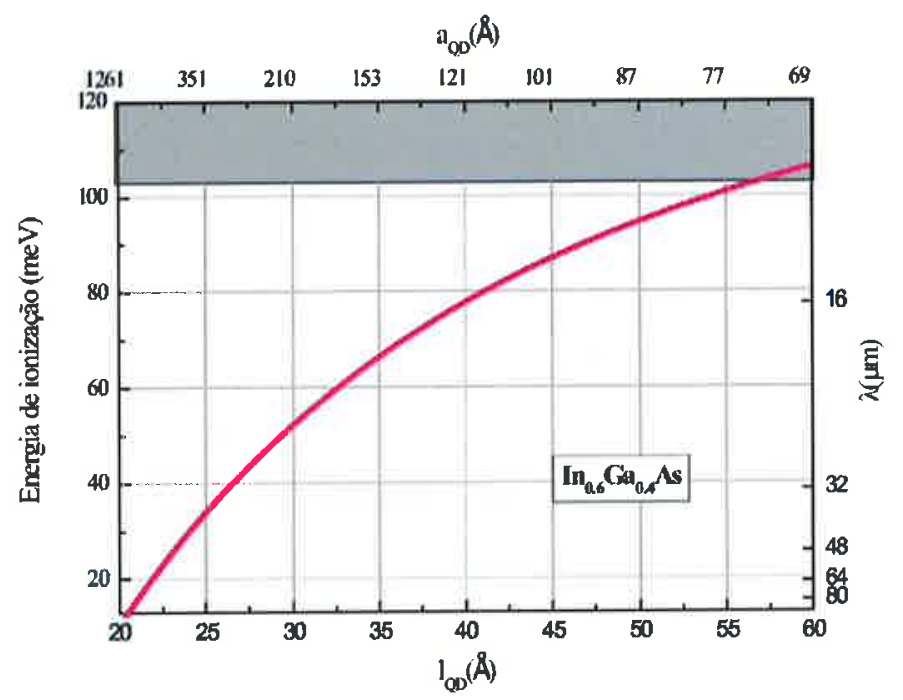

Figura 4.12: Energia de ionização (eixo esquerdo) com seu respectivo comprimento de onda (eixo direito) em função da altura do QD (eixo horizontal inferior) com o seu respectivo raio (eixo horizontal superior) dos QDs de $\mathrm{In}_{0.6} \mathrm{Ga}_{0.4}$ As. A faixa em cinza destaca a região de mínima absorção atmosférica $(8-12 \mu \mathrm{m})$. 


\section{Capítulo 5}

\section{Resultados da corrente no escuro e da detectividade dos fotodetetores}

Neste capítulo vamos apresentar os resultados da corrente de escuro e da detectividade para fotodetectores de pontos quânticos de InAs em função de parâmetros que definem a estrutura da região ativa da amostra, que definem a estrutura eletrônica dos pontos quânticos, e de fatores externos. A estrutura eletrônica é definida pela altura do QD $\left(\ell_{Q D}\right)$ e pelo raio de sua base $\left(a_{Q D}\right)$. A estrutura da região ativa da amostra é definida pelo número de camadas $K$ contendo os QDs, pela espessura $(L)$ da camada de material semicondutor entre camadas adjacentes de QDs, pela concentração $\left(\Sigma_{Q D}\right)$ de QDs e pela concentração de doadores $\left(\Sigma_{D}\right)$ em cada camada. Os fatores externos são a tensão de porta que é aplicada ao dispositivo e a temperatura de operação do fotodetector.

Os parâmetros utilizados para obter os resultados que serão apresentados a seguir estão descritos na Tabela 5.1. A escolha desses parâmetros foi feita usando o seguinte critério:

- Utilizamos para $\sigma, \epsilon_{r}$ e $K$ os mesmos valores que aqueles utilizados na ref. [24].

- $L, \Sigma_{Q D}, a_{Q D}$ e $\ell_{Q D}$ são os valores dos parâmetros que estão sendo utilizados para produzir os fotodetectores no LNMS do IFUSP. 
5. Resultados da corrente no escuro e da detectividade dos fotodetetores

Tabela 5.1: Parâmetros dos QDIPs de InAs.

\begin{tabular}{|c|c|c|}
\hline \hline$L=40-50 \mathrm{~nm}$ & $K=10$ & $\epsilon_{r}=12$ \\
\hline$\Sigma_{Q D}=2-4 \times 10^{10} \mathrm{~cm}^{-2}$ & $a_{Q D}=8-12,5 \mathrm{~nm}$ & $\ell_{Q D}=4-5 \mathrm{~nm}$ \\
\hline$\sigma=10^{-11} \mathrm{~cm}^{-2}$ & & \\
\hline \hline
\end{tabular}

\subsection{Corrente no escuro e detectividade em função dos fatores externos}

Queremos inicialmente fazer uma comparação entre dispositivos operando em diferentes temperaturas e tensões de porta. Para isto, iremos fixar as dimensões dos QDs que definem a estrutura eletrônica e os parâmetros que definem a região ativa do fotodetector. Os parâmetros sobre as dimensões dos QDs que serão utilizados estão apresentados na Tabela 5.2. A escolha dessas dimensões de QDs levou em consideração os seguintes critérios:

- QDs com estas dimensões possuem apenas dois níveis de confinamento;

- QDs com estas dimensões possuem energia de ionização na faixa de mínima absorção atmosférica;

- QDs com estas dimensões podem ser obtidos no crescimento por MBE.

Tabela 5.2: Características da estrutura eletrônica de um QD com altura $\ell_{Q D}=40 \AA$ e $a_{Q D}=97,1 \AA$.

\begin{tabular}{|c|c|}
\hline \hline Níveis confinados & 2 \\
\hline$N_{Q D}$ & 6 \\
\hline$E_{\text {ion }}$ & $131,3 \mathrm{mev}$ \\
\hline$\lambda$ & $9,4 \mu \mathrm{m}$ \\
\hline \hline
\end{tabular}

Com o modelo teórico descrito no Capítulo ?? vamos calcular inicialmente o número médio de elétrons nos QDs, $\langle N\rangle$, a corrente no escuro, $J_{\text {escuro, e a de- }}$ tectividade, $D^{*}$, em função da tensão de porta. Estas grandezas estão mostradas nas Figs. 5.1 e 5.2 para diferentes razões entre as concentrações de doadores, $\Sigma_{D}$, e de QDs, $\Sigma_{Q D}$. Nas Figs. 5.1 e 5.2, as curvas foram obtidas para razões no intervalo $0,2 \leq \Sigma_{D} / \Sigma_{Q D} \leq 0,8$. Estes valores foram escolhidos levando-se em consideração o 


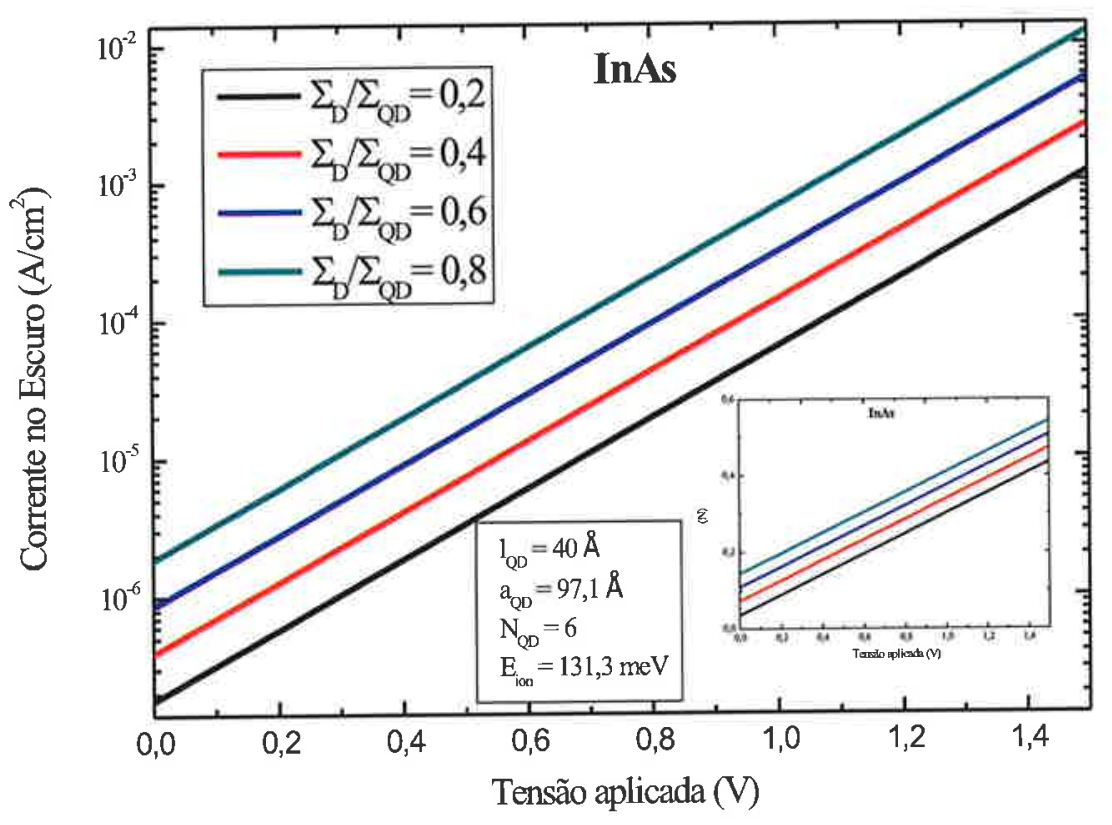

Figura 5.1: Corrente no escuro e número médio de elétrons nos QDs (inset) em função da tensão aplicada, na temperatura de operação de $\mathrm{T}=77 \mathrm{~K}$, para diferentes razões entre as concentrações de doadores $\left(\Sigma_{D}\right)$ e de QDs $\left(\Sigma_{Q D}\right)$. Os outros parâmetros estruturais utilizados para o cálculo foram: $K=10$ (número de camadas), $L=40 \mathrm{~nm}$ (espaçamento entre as camadas) e $\sigma=10 \times 10^{-11} \mathrm{~cm}^{-2}$ (seção de fotoescape).

fato que a concentração de doadores deverá ser uma certa porcentagem da concentração de QDs, pois o número médio de elétrons nos QDs $(\langle N\rangle)$ não pode ser maior que o número máximo de elétrons nos QDs $\left(N_{Q D}\right)$. [5]

A Figura 5.1 mostra a corrente no escuro e o número médio de elétrons em função da tensão de porta para diferentes razões entre as concentrações de doadores $\left(\Sigma_{D}\right)$ e de QDs $\left(\Sigma_{Q D}\right)$. Podemos observar que o número médio de elétrons não ultrapassa o número máximo de elétrons nos QDs para a faixa de tensões aplicadas, o que mostra a validade do modelo neste intervalo de tensões. Podemos observar também que a corrente no escuro aumenta com o aumento da razão $\left(\Sigma_{D} / \Sigma_{Q D}\right)$, pois com o aumento desta razão, aumenta também o número de elétrons na amostra e conseqüentemente aumenta o número de elétrons que são injetados termicamente na corrente. Também podemos observar nessa figura o aumento da corrente no escuro com o aumento da tensão de porta. Para entendermos este resultado evitando a complexa expressão que descreve a corrente no escuro em função da tensão aplicada (Eq. 3.34), vamos 


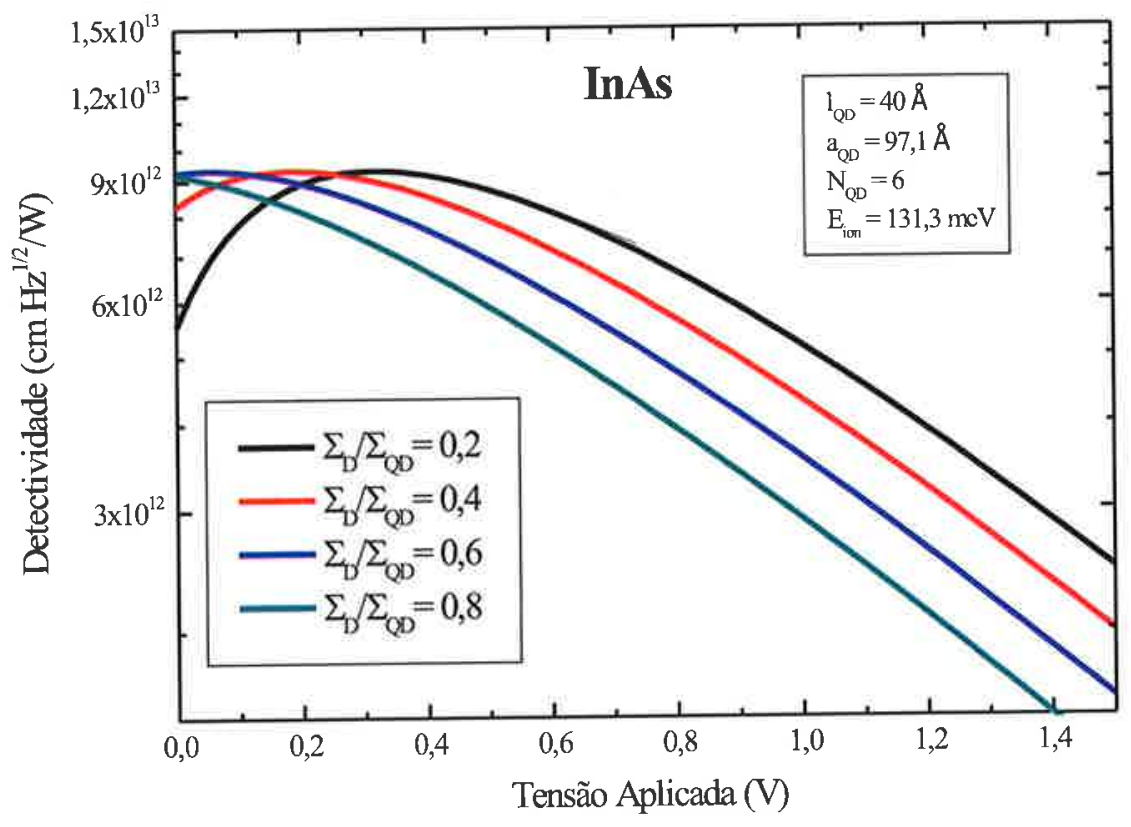

Figura 5.2: Detectividade em função da tensão aplicada, na temperatura de operação de $\mathrm{T}=77 \mathrm{~K}$, para diferentes razões entre as concentraçoes de doadores $\left(\Sigma_{D}\right)$ e de QDs $\left(\Sigma_{Q D}\right)$. Os outros parâmetros estruturais utilizados para o cálculo foram: $K=10$ (número de camadas), $L=40 \mathrm{~nm}$ (espaçamento entre as camadas) e $\sigma=10 \times$ $10^{-11} \mathrm{~cm}^{-2}$ (seção de fotoescape).

considerar que a corrente é descrita pela expressão:

$$
J=n e v
$$

onde $n$ é a densidade de portadores, e é a carga do elétron e $v$ é a velocidade dos elétrons. Como a velocidade dos elétrons é igual a $v=\mu E$, onde $\mu$ é a mobilidade dos elétrons e $E$ é o campo elétrico, a expressão anterior ainda pode ser reescrita como:

$$
J=n e \mu E
$$

Como o aumento da tensão aplicada causa um aumento do campo elétrico, concluímos pela expressão anterior que a corrente no escuro aumenta com o aumento do campo elétrico, ou seja, com o aumento da tensão aplicada. Na Figura 5.2 podemos observar picos de detectividade para as diferentes razões utilizadas. Dessa maneira teremos máximos de detectividade para diferentes tensões de porta dependendo da razão $\left(\Sigma_{D} / \Sigma_{Q D}\right)$ utilizada na elaboração da região ativa dos fotodetectores de in- 


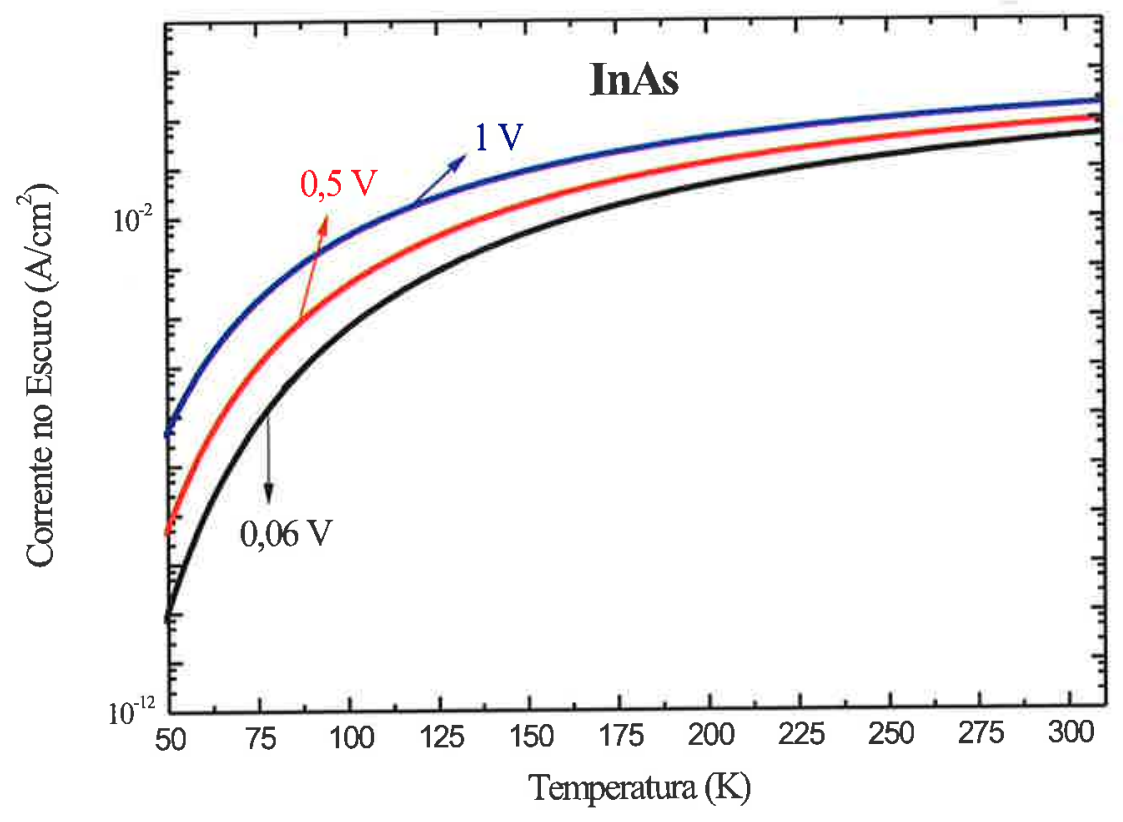

Figura 5.3: Corrente no escuro em função da temperatura para diferentes tensões de porta e para as dimensões de QDs apresentadas na Tabela 5.2. Os outros parâmetros estruturais utilizados para o cálculo foram: $K=10$ (número de camadas), $L=$ $40 \mathrm{~nm}$ (espaçamento entre as camadas), $\Sigma_{D}=0,6 \times \Sigma_{Q D}$ (concentração de doadores) e $\Sigma_{Q D}=2 \times 10^{10} \mathrm{~cm}^{-2}$ (concentração de QDs).

fravermelho.

Agora, vamos mostrar o comportamento da corrente no escuro e da detectividade em função da temperatura para diferentes tensões de porta. Na Figura 5.2 foi observado que a detectividade é máxima para uma tensão de porta de $0,06 \mathrm{~V}$ e uma razão $\Sigma_{D} / \Sigma_{Q D}=0,6$. Assim, foi calculada a corrente no escuro em função da temperatura para as tensões $0,06 \mathrm{~V}, 0,5 \mathrm{~V}$ e $1 \mathrm{~V}$, onde a tensão de $0,06 \mathrm{~V}$ representa um máximo na detectividade. Estes resultados, apresentados na Fig. 5.3, mostram um aumento significativo da corrente no escuro com o aumento da temperatura no intervalo de $50<\mathrm{T}<175 \mathrm{~K}$ (ocasionado pelo aumento da geração térmica dos portadores), mas uma tendência à saturação para $\mathrm{T}>175 \mathrm{~K}$. Esta tendência à saturação está relacionada com a densidade constante de QDs utilizada no cálculo destas curvas $\left(\Sigma_{Q D}=2 \times 10^{10} \mathrm{~cm}^{-2}\right)$. A utilização de valores maiores para $\Sigma_{Q D}$ resultaria curvas com formas semelhantes mas deslocadas para cima, isto é, com maiores valores de correntes no escuro.

A Figura 5.4 representa a detectividade em função da temperatura para diferentes tensões de porta. Nesta figura podemos observar a diminuição da detectividade com 
o aumento da temperatura, em virtude do aumento do ruído causado pela geração térmica dos portadores (elétrons).

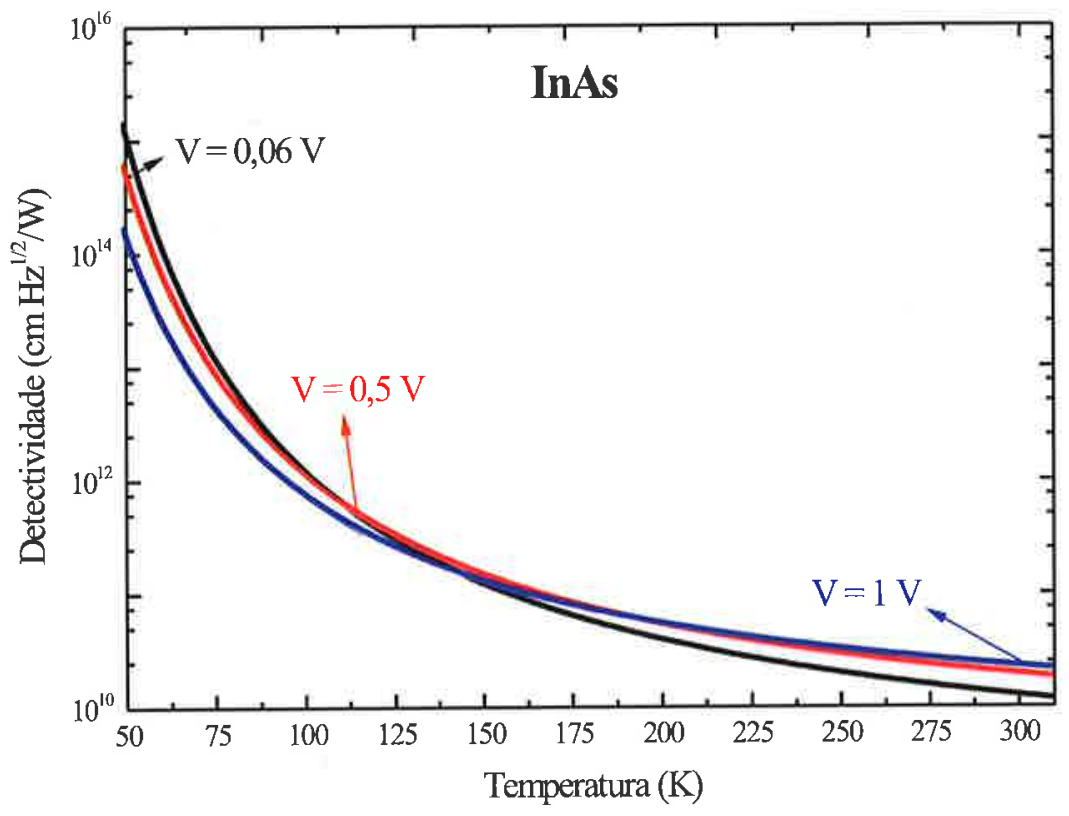

Figura 5.4: Detectividade em função da temperatura para diferentes tensões de porta, para as dimensões de QDs apresentadas na Tabela 5.2. Os parâmetros estruturais utilizados para estes cálculos foram $K=10$ (número de camadas), $L=40 \mathrm{~nm}$ (espaçamento entre as camadas), $\Sigma_{D}=0,6 \times \Sigma_{Q D}$ (concentração de doadores), $\Sigma_{Q D}=2 \times 10^{10} \mathrm{~cm}^{-2}$ (concentração de QDs) e $\sigma=10 \times 10^{-11} \mathrm{~cm}^{-2}$ (seção de fotoescape).

\subsection{Corrente no escuro e detectividade em função dos parâmetros estruturais}

Para mostrarmos os resultados da corrente no escuro e da detectividade em função dos parâmetros da região ativa da amostra, primeiramente vamos fixar os parâmetros que definem a estrutura eletrônica (mostrados na Tabela 5.2) e os fatores externos (temperatura e tensão aplicada). Na Fig. 5.5 mostramos a corrente no escuro em função do número de camadas $(K)$. Nesse cálculo foi mantido o volume da região ativa fixo, ou seja, o produto entre o espaçamento $(L)$ e o número de camadas $(K)$ foi mantido constante (isto é, $K \times L=$ constante) de forma que o campo elétrico tenha o mesmo valor constante na região ativa dos diferentes fotodetectores para uma dada tensão aplicada ao dispositivo. Na Fig. 5.5 observamos a diminuição da 


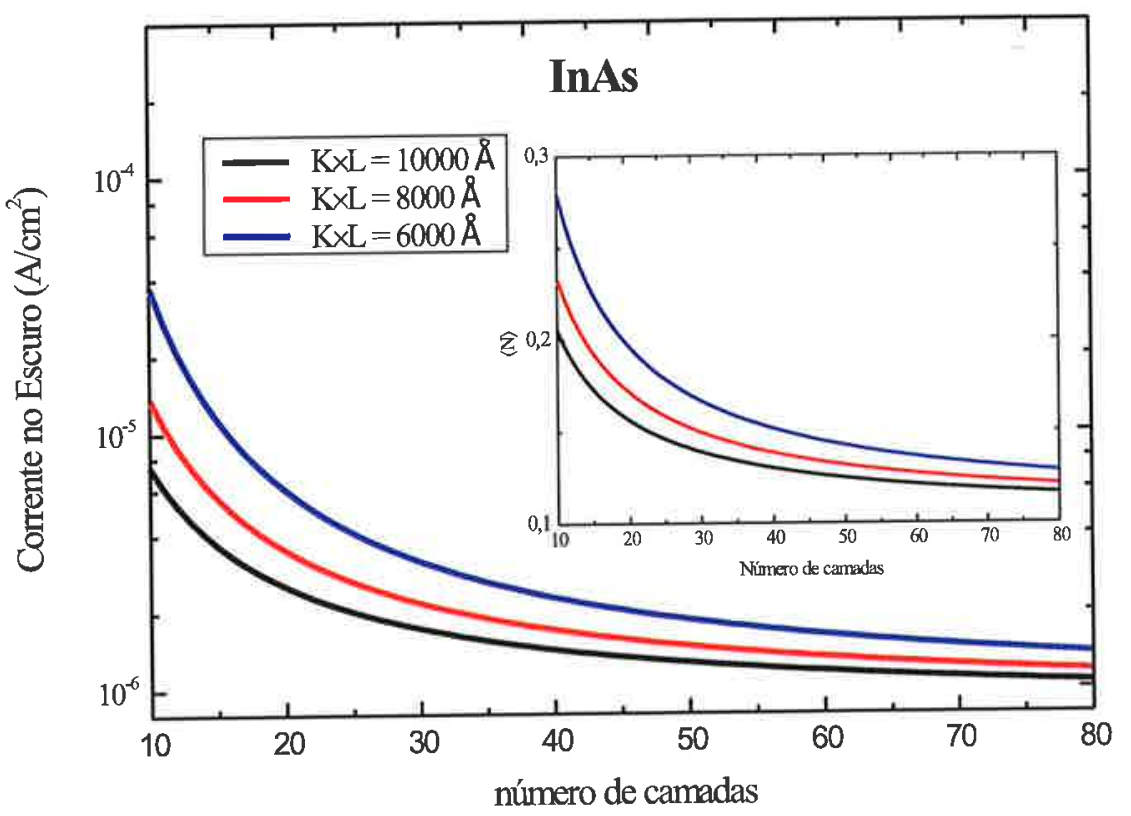

Figura 5.5: Corrente no escuro e número médio de elétrons (inset) em função do número de camadas $(K)$ para diferentes espessuras da região ativa. As dimensões dos QDs utilizadas nos cálculos estão apresentadas na Tabela 5.2. Os outros parâmetros estruturais utilizados no cálculo foram: $\Sigma_{D}=0,6 \times \Sigma_{Q D}$ (concentração de doadores) e $\Sigma_{Q D}=2 \times 10^{10} \mathrm{~cm}^{-2}$ (concentração de QDs). Os fatores externos utilizados foram $\mathrm{V}=1 \mathrm{~V}$ e $\mathrm{T}=77 \mathrm{~K}$.

corrente no escuro com o aumento do número de camadas. Essa diminuição devese à diminuição do número médio de elétrons nos QDs em virtude do aumento do número de camadas, o que acarreta uma diminuição da taxa de geração térmica de elétrons já que um número menor de elétrons encontram-se nos QDs.

A Fig. 5.6 mostra a detectividade em função do número de camadas. O cálculo da detectividade foi feita de forma similar ao cálculo da corrente no escuro mostrada na Fig. 5.5 onde o volume da região ativa foi mantido constante. Na Fig. 5.6 podemos observar o aumento da detectividade com o número de camadas e com o aumento da espessura da região ativa. O aumento da detectividade deve-se à diminuição do ruído, isto é, pela diminuição da corrente no escuro causada pelo aumento do número de camadas (veja a Fig. 5.5).

A Fig. 5.7 mostra a corrente no escuro em função da concentração de QDs para as tensões de porta em destaque. A faixa amarela nesta figura destaca as concentrações de QDs obtidas usualmente no crescimento por MBE (Tabela 5.1). Nesta figura é observado que o comportamento da corrente no escuro em função da concentração de QDs é inversamente proporcional ao comportamento do número médio de elétrons 


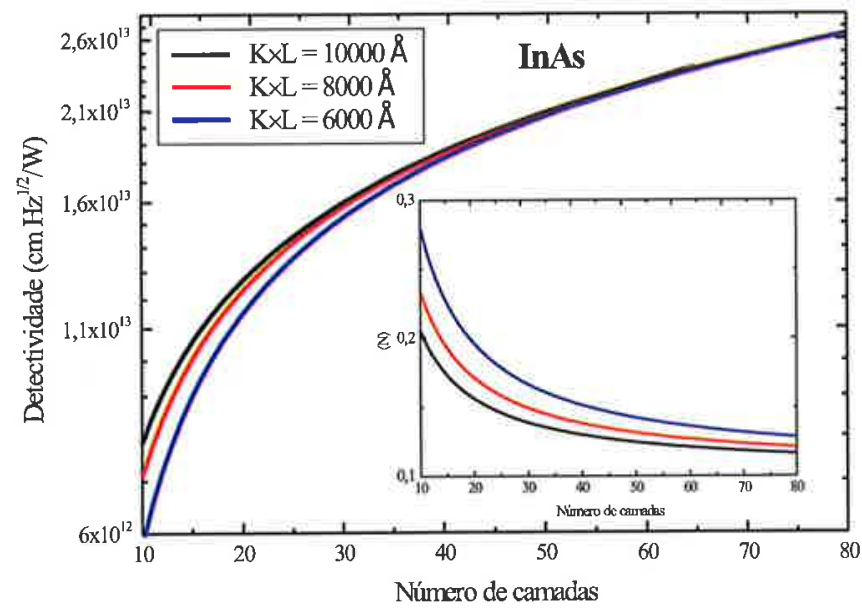

Figura 5.6: Detectividade e número médio de elétrons (inset) em função do número de camadas $(K)$ para diferentes espessuras da região ativa. As dimensões dos QDs utilizadas nos cálculos estão apresentadas na Tabela 5.2. Os outros parâmetros estruturais utilizados para estes cálculos foram: $\Sigma_{D}=0,6 \times \Sigma_{Q D}$ (concentração de doadores), $\Sigma_{Q D}=2 \times 10^{10} \mathrm{~cm}^{-2}$ (concentração de QDs) e $\sigma=10 \times 10^{-10} \mathrm{~cm}^{-2}$ (seção de captura). Os fatores externos utilizados no cáculo foram $\mathrm{V}=1 \mathrm{~V}$ e $\mathrm{T}=$ $77 \mathrm{~K}$.

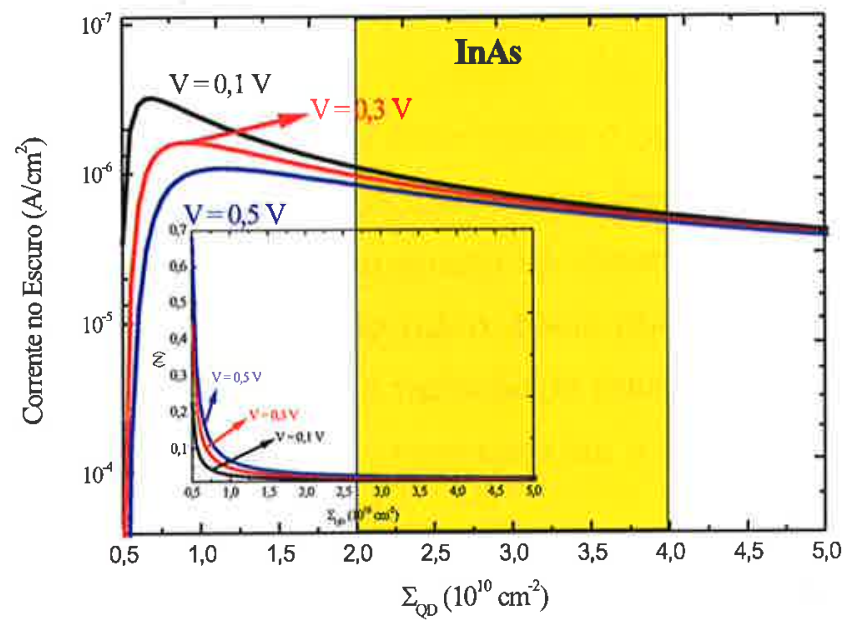

Figura 5.7: Corrente no escuro e número médio de elétrons (inset) em função da concentração de $\mathrm{QDs}\left(\Sigma_{Q D}\right)$ para diferentes tensões de porta. As dimensões dos QDs utilizadas nos cálculos estão apresentadas na Tabela 5.2. Os outros parâmetros utilizados para os cálculos foram $\Sigma_{D}=0,6 \times \Sigma_{Q D}$ (concentração de doadores) e T $=77 \mathrm{~K}$. A região amarela destaca as concentrações de QDs usualmente obtidas pelo crescimento por MBE.

de em função da concentração de QDs, como podemos observar no inset da figura.

A Figura 5.8 mostra a detectividade em função da concentração de QDs para 


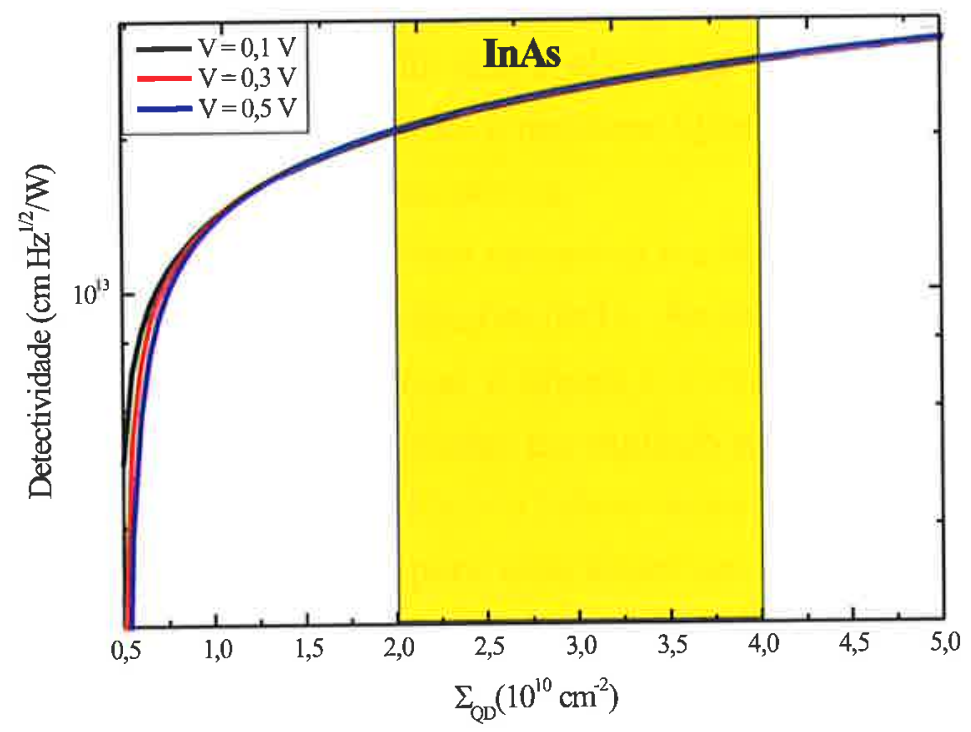

Figura 5.8: Detectividade em função da concetração de $\mathrm{QDs}\left(\Sigma_{Q D}\right)$ para diferentes tensões de porta. As dimensões dos QDs utilizadas estão apresentadas na Tabela 5.2. Os outros parâmetros utilizados para os cálculos foram $\Sigma_{D}=0,6 \times \Sigma_{Q D}$ (concentração de doadores), e $\sigma=10 \times 10^{-10} \mathrm{~cm}^{-2}$ (seção de captura) e $\mathrm{T}=$ 77 K. A faixa amarela destaca as concentrações de QDs usualmente obtidas pelo crescimento por MBE.

as tensões em destaque. Nesta figura observamos o aumento da detectividade em função do aumento da concentração de QDs e uma fraca dependência da detectividade com a variação da tensão. O aumento da detectividade com o aumento da concentração deve-se ao decréscimo do ruído, como podemos ver na Figura 5.7, e a fraca dependêncai do dispositivo com a variação da tensão deve-se ao fato do número médio de elétrons não variar significativamente com a variação da tensão.

\subsection{Corrente no escuro e detectividade em função da estrutura eletrônica}

Nessa seção mostraremos os resultados da corrente no escuro e da detectividade em função da estrutura eletrônica. Primeiramente iremos fixar os fatores externos e os parâmetros estruturais que definem a região ativa do dispositivo. Em seguida, mantendo as dimensões dos QDs fixas, vamos investigar a influência da composição da liga de $\operatorname{In}_{x} \mathrm{Ga}_{1-x} \mathrm{As}$ no comportamento da corrente no escuro e da detectividade. Vamos utilizar diferentes concentrações de índio, mas ainda mantendo a condição 
que os QDs devem possuir somente dois níveis de energia sendo que a energia do primeiro estado excitado deve coincidir com a altura da barreira de potencial. Ou seja, vamos variar a concentração de índio e procurar QDs cuja energia de ionização estão na faixa de mínima absorção atmosférica.

As Figs. 5.9(a)-(b) mostram a corrente no escuro e a detectividade em função da altura dos QDs para diferentes concentrações de In. As curvas representadas nestas figuras foram obtidas correlacionando-se a altura e o raio da base dos QDs com as respectivas energias de ionização obtidas no cápitulo anterior para as diferentes concetrações de In. Nas Figs. Figs. 5.9(a)-(b) observamos um mínimo (máximo) na corrente no escuro (na detectividade) para uma altura em torno de $47 \AA$ para o QD de InAs e um mínimo em torno de $46 \AA$ para o QD de $\operatorname{In}_{0,8} \mathrm{Ga}_{0,2}$ As. O resultado mais interessante destas figuras é que, para uma dada concentração de índio, existe uma geometria otimizada que possibilita obter um mínimo na corrente de escuro $\left(J_{d a r k, \min }\right)$ ou máximo na detectividade $\left(D_{\max }^{*}\right)$. Este é um resultado extremamente importante para o planejamento da estrutura dos fotodetectores. Por exemplo, para concentraçõs de índio no intervalo de $0,8 \leq x \leq 1$, deve-se tentar obter QDs que tenham a altura em torno de $47 \AA$. Com estas dimensões, será possível obter valores de corrente no escuro próximos do valor $J_{d a r k, \min }$ ou $D_{m a x}^{*}$.

Na Fig. 5.10 mostramos a corrente no escuro mímina em função da concentração de índio no intervalo $0,6 \leq x \leq 1$. Observamos que o melhor desempenho dos fotodetectores de infravermelho é sempre obtido para pontos quânticos com alturas na faixa de $40 \AA$, que podem ser obtidas com a técnica de crescimento por MBE. Observe que nesta figura, as dimensões dos QDs são tais que eles têm energia de ionização na janela de mínima absorção atmosférica de $8 \mu \mathrm{m}$ a $12 \mu \mathrm{m}$. 

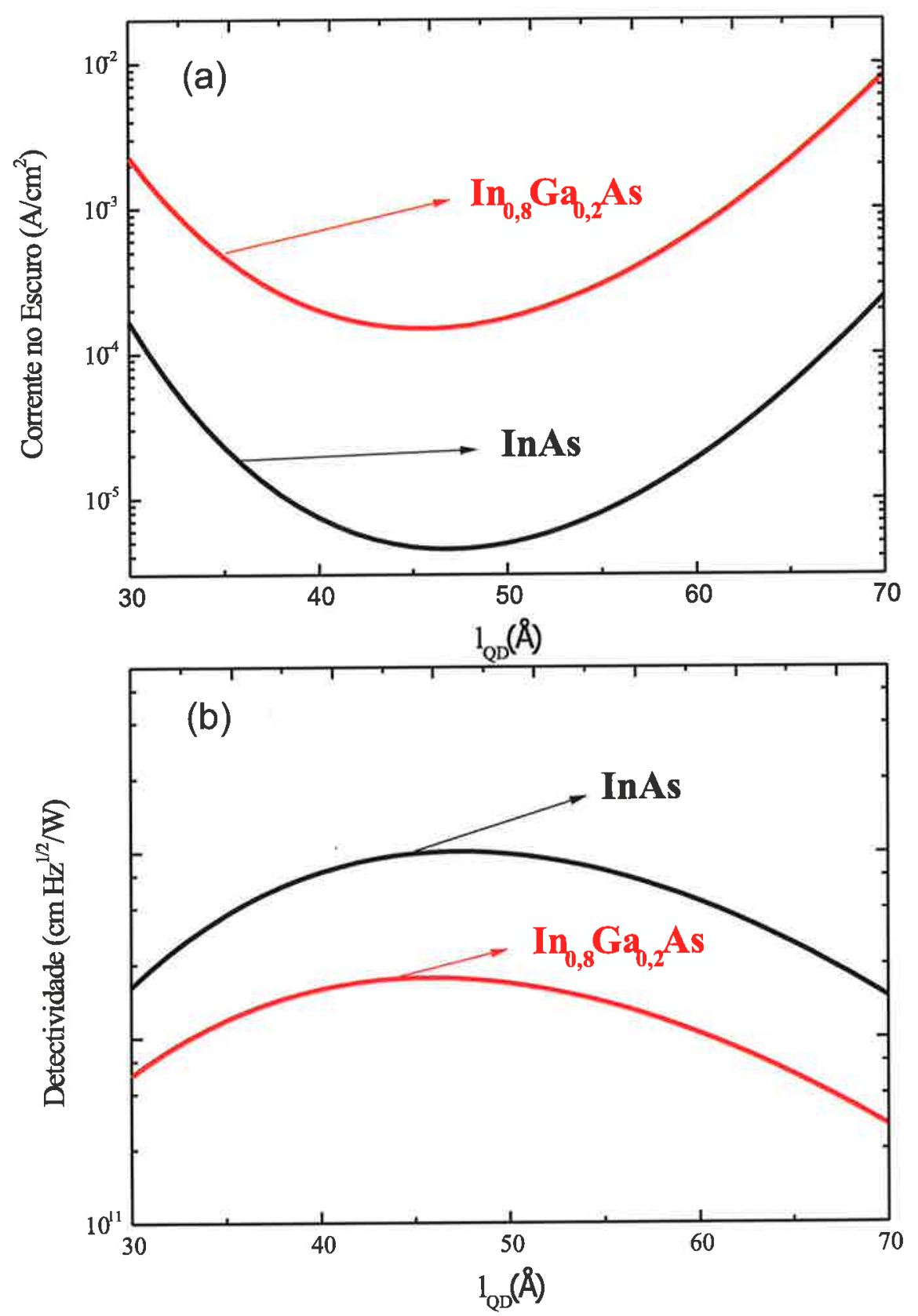

Figura 5.9: Corrente no escuro (a) e detectividade (b) em função da altura dos QDs para duas concetrações de In $(x=1$ e $x=0,8)$. Os outros parâmetros utilizados para os cálculos foram $\Sigma_{D}=0,6 \times \Sigma_{Q D}$ (concentração de doadores), $\Sigma_{Q D}=2 \times 10^{10} \mathrm{~cm}^{-2}$ (concentração de QDs), V $=1 \mathrm{~V}$ e T $=77 \mathrm{~K}$. 


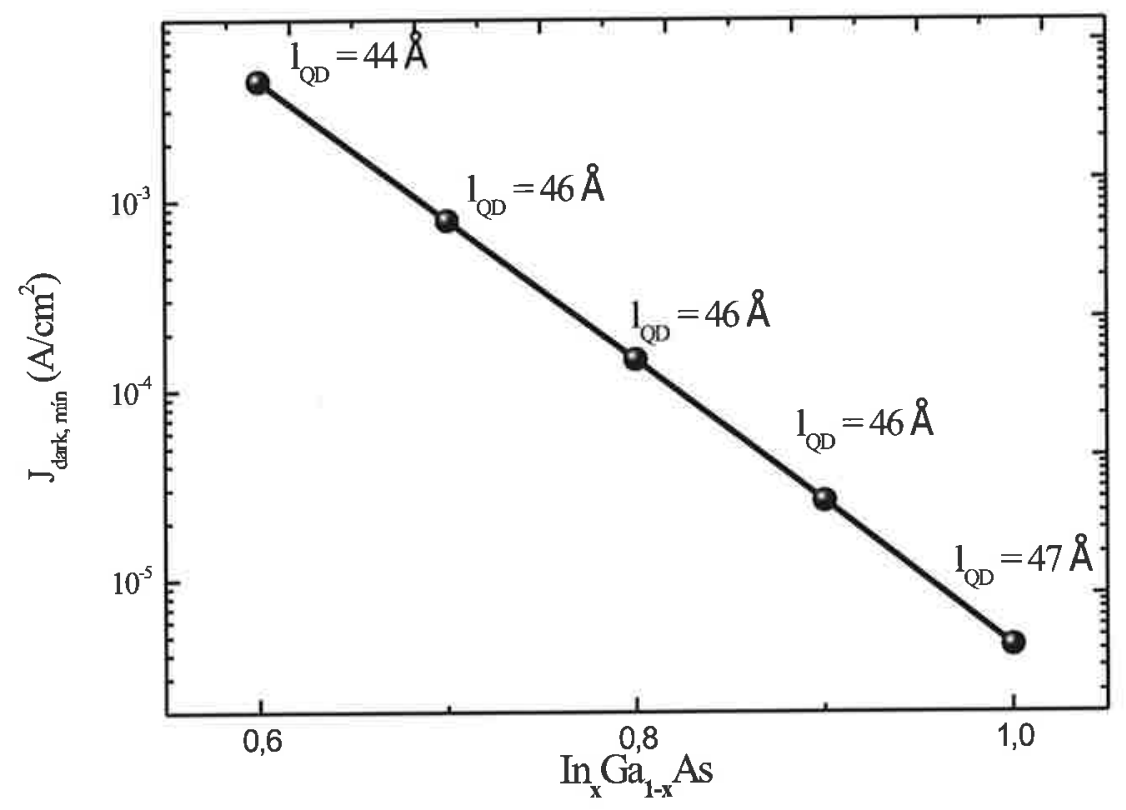

Figura 5.10: Corrente no escuro mínima em função da concentração de índio na liga de $\operatorname{In}_{x} \mathrm{Ga}_{1-x}$ As. 


\section{Capítulo 6}

\section{Conclusões}

Nesse trabalho, utilizamos um modelo analítico para avaliar o desempenho de fotodetectores de infravermelho contendo pontos quânticos formados pela liga ternária de $\operatorname{In}_{x} \mathrm{Ga}_{1-x} \mathrm{As}$, em função de parâmetros que definem a estrutura da região ativa da amostra, que definem a estrutura eletrônica dos pontos quânticos, e de fatores externos. A avaliação do desempenho do dispositivo foi feita através do cálculo da corrente no escuro e da detectividade do fotodetector.

O modelo analítico utilizado para o cálculo da corrente no escuro e da detectividade (descrito no Cap. 3) só pode ser aplicado para estruturas onde a energia do primeiro estado excitado dos QDs coincide com a altura da barreira de potencial. Desta forma, inicialmente, identificamos as dimensões dos QDs de $\operatorname{In}_{x} \mathrm{Ga}_{1-x} \mathrm{As}$, que de acordo com o modelo adotado para o cálculo da estrutura eletrônica dos QDs (Cap. 4), possuem apenas dois níveis confinados de energia e cujas energias de ionização encontram-se dentro das janelas de mínima absorção atmosférica. Com base nesta informação, selecionamos os valores das dimensões dos QDs que podem ser obtidas no crescimento por MBE (veja a Figura 4.10) e, portanto, que possuem energias de ionização dentro das janelas de mínima absorção atmosférica.

Nossos resultados sobre a corrente no escuro e a detectividade mostram (no Cap. 5) que:

- Fatores externos:- Verificamos que o aumento da tensão de porta diminui o desempenho do dispositivo. Entretanto, calibrando a razão $\Sigma_{D} / \Sigma_{Q D}$ podemos otimizar o o desempenho com o aumento da tensão. O aumento da temperatura diminui drasticamente o desempenho do dispositivo, pois este aumento faz com que a geração térmica aumente.

- Parâmetros estruturais:- Observamos que variando os parâmetros estrutu- 


\section{Conclusões}

rais que definem a região ativa do fotodetector, a razão $\Sigma_{D} / \Sigma_{Q D}$ não altera o desempenho máximo do dispositivo. $\mathrm{O}$ aumento do número de camadas no dispositivo aumenta o desempenho do mesmo, embora, tipicamente, os dispositivos sejam fabricados com apenas 10 camadas de QDs para evitar efeitos de degradação das camadas semicondutoras durante o crescimento por MBE, que diminuirão o desempenho do fotodetector. Observamos também que a diminuição do espaçamento entre as camadas aumenta o desempenho, assim como o aumento da espessura da região ativa do dispositivo aumenta a performance do mesmo.

- Estrutura eletrônica:- Realizamos várias cálculos sobre a estrutura eletrônica dos QDs e procuramos correlacionamos a altura do QD com o raio da sua base de forma que a energia do primeiro estado excitado coincidisse com a altura da barreira. Assim pudemos indentificar quais as dimensões dos QDs e as concentrações de In, que de acordo com o modelo adotado, resultam em QDs que possuem energia de ionização dentro de uma das janelas de mínima absorção atmosférica. Depois desta identificação das concentrações e das dimensões que possuem a energia na faixa procurada, observamos que o desempenho máximo para os dispositivos formados com os QDs de InAs são obtidos para os que possuem uma altura de $47 \AA$ e para os QDs de $\mathrm{In}_{0,2} \mathrm{Ga}_{0,8} \mathrm{As}$ vemos que a melhor performance é obtida para QDs com altura igual $46 \AA$. 


\section{Capítulo 7}

\section{Anexo 1 - Autoenergias do poço de potencial finito escrito em} termos das autoenergias do poço de potencial infinito

Neste apêndice apresentaremos o desenvolvimento detalhado do formalismo teórico que foi apresentado de forma resumida na seção 4.1, e que nos permite calcular as energias de confinamento de elétrons e buracos em pontos quânticos de $\operatorname{In}_{x} \mathrm{Ga}_{1-x} \mathrm{As}$. Como vimos na seção seção 4.1, se desprezarmos a interação Coulombiana entre o par elétron-buraco, a Hamiltoniana do sistema pode ser escrita da seguinte forma:

$$
H=\frac{p_{e}^{2}}{2 m_{e}^{*}}+\frac{p_{h}^{2}}{2 m_{h}^{*}}+V_{e}\left(\overrightarrow{r_{e}}\right)+V_{h}\left(\overrightarrow{r_{h}}\right)
$$

ou ainda, de forma mais compacta como:

$$
H=H_{e}+H_{h}
$$

onde

$$
H_{e}=\frac{p_{e}^{2}}{2 m_{e}^{*}}+V_{e}\left(\overrightarrow{r_{e}}\right)
$$

e

$$
H_{h}=\frac{p_{h}^{2}}{2 m_{h}^{*}}+V_{h}\left(\overrightarrow{r_{h}}\right)
$$

A equação que teremos de resolver para calcular as energias de confinamento dos 
7. Anexo 1 - Autoenergias do poço de potencial finito escrito em termos das autoenergias do poço de potencial infinito

elétrons e buracos é dada por:

$$
H \Psi\left(\overrightarrow{r_{e}}, \overrightarrow{r_{h}}\right)=E \Psi\left(\overrightarrow{r_{e}}, \overrightarrow{r_{h}}\right)
$$

Como a Hamiltoniana descrita pela Eq. 7.2 não contém termos cruzados envolvendo as coordenadas dos elétrons e dos buracos, podemos escrever $\Psi\left(\overrightarrow{r_{e}}, \overrightarrow{r_{h}}\right)=$ $\Psi_{e}\left(\overrightarrow{r_{e}}\right) \Psi_{h}\left(\overrightarrow{r_{h}}\right)$. Substituindo esta função de onda na Eq. 7.5 , e utilizando o método de separação de variáveis obtemos:

$$
\begin{gathered}
\left(H_{e}+H_{h}\right) \Psi\left(\overrightarrow{r_{e}}, \overrightarrow{r_{h}}\right)=E \Psi\left(\overrightarrow{r_{e}}, \overrightarrow{r_{h}}\right) \\
\left(H_{e}+H_{h}\right) \Psi_{e}\left(\overrightarrow{r_{e}}\right) \Psi_{h}\left(\overrightarrow{r_{h}}\right)=E \Psi_{e}\left(\overrightarrow{r_{e}}\right) \Psi_{h}\left(\overrightarrow{r_{h}}\right) \\
\Psi_{h}\left(\overrightarrow{r_{h}}\right) H_{e} \Psi_{e}\left(\overrightarrow{r_{e}}\right)+\Psi_{e}\left(\overrightarrow{r_{e}}\right) H_{h} \Psi_{h}\left(\overrightarrow{r_{h}}\right)=E \Psi_{e}\left(\overrightarrow{r_{e}}\right) \Psi_{h}\left(\overrightarrow{r_{h}}\right)
\end{gathered}
$$

Dividindo a última expressão por $\Psi\left(\overrightarrow{r_{e}}, \overrightarrow{r_{h}}\right)=\Psi_{e}\left(\overrightarrow{r_{e}}\right) \Psi_{h}\left(\overrightarrow{r_{h}}\right)$ obtemos:

$$
\frac{1}{\Psi_{e}\left(\overrightarrow{r_{e}}\right)} H_{e} \Psi_{e}\left(\overrightarrow{r_{e}}\right)+\frac{1}{\Psi_{h}\left(\overrightarrow{r_{h}}\right)} H_{h} \Psi_{h}\left(\overrightarrow{r_{h}}\right)=E
$$

onde $E=E_{e}+E_{h}$. Desta forma obtemos uma equação para elétrons

$$
H_{e} \Psi_{e}\left(\overrightarrow{r_{e}}\right)=E_{e} \Psi_{e}\left(\overrightarrow{r_{e}}\right)
$$

e uma outra para buracos

$$
H_{h} \Psi_{h}\left(\overrightarrow{r_{h}}\right)=E_{h} \Psi_{h}\left(\overrightarrow{r_{h}}\right)
$$

que pode ser escrita como:

$$
-\frac{\hbar^{2}}{2 m_{e / h}^{*}} \nabla^{2} \Psi_{e / h}+V_{e}\left(r_{e / h}\right)=E_{e / h} \Psi_{e / h} .
$$

Escrevendo o Laplaciano em coordenadas cilíndricas e assumindo que $\Psi(r, \theta, z)=$ $g_{r}(z) f(r, \theta)$ podemos escrever a Eq. 7.9 como:

$$
\left[-\frac{\hbar^{2}}{2 m^{*}}\left[r^{-2}\left(r \frac{\partial}{\partial r} r \frac{\partial}{\partial r}+\frac{\partial^{2}}{\partial \theta^{2}}\right)+\frac{\partial^{2}}{\partial z^{2}}\right]+V(r, z)\right] g_{r}(z) f(r, \theta)=E g_{r}(z) f(r, \theta)
$$

ou ainda 


$$
\begin{aligned}
& -\frac{\hbar^{2}}{2 m^{*}} g_{r}(z) r^{-2}\left(r \frac{\partial}{\partial r} r \frac{\partial}{\partial r} f(r, \theta)+g_{r}(z) \frac{\partial^{2}}{\partial \theta^{2}} f(r, \theta)\right)+ \\
& +f(r, \theta) \frac{\partial^{2}}{\partial z^{2}} g_{r}(z)+V(r, z) g_{r}(z) f(r, \theta)=E g_{r}(z) f(r, \theta)
\end{aligned}
$$

Dividindo a expressão anterior por $g_{r}(z) f(r, \theta)$ temos:

$$
-\frac{\hbar^{2}}{2 m^{*}} \frac{1}{f} r^{-2}\left(r \frac{\partial}{\partial r} r \frac{\partial}{\partial r} f(r, \theta)+\frac{1}{f} \frac{\partial^{2}}{\partial \theta^{2}} f(r, \theta)\right)+\frac{1}{g_{r}} \frac{\partial^{2}}{\partial z^{2}} g_{r}(z)+V(r, z)=E
$$

Escrevendo

$$
\frac{1}{g_{r}} \frac{\partial^{2}}{\partial z^{2}} g_{r}(z)+V(r, z)=E_{0}(r)
$$

a Eq. 7.12 pode ser escrita como:

$$
-\frac{\hbar^{2}}{2 m^{*}} \frac{1}{f} r^{-2}\left(r \frac{\partial}{\partial r} r \frac{\partial}{\partial r} f(r, \theta)+\frac{1}{f} \frac{\partial^{2}}{\partial \theta^{2}} f(r, \theta)\right)+E_{0}(r)=E .
$$

Portanto, podemos reescrever as equações acima como:

$$
\frac{\partial^{2}}{\partial z^{2}} g_{r}(z)+V(r, z) g_{r}(z)=E_{0}(r) g_{r}(z)
$$

e

$$
-\frac{\hbar^{2}}{2 m^{*}} r^{-2}\left(r \frac{\partial}{\partial r} r \frac{\partial}{\partial r} f(r, \theta)+\frac{\partial^{2}}{\partial \theta^{2}} f(r, \theta)\right)+E_{0}(r) f(r, \theta)=E f(r, \theta) .
$$

As equações 7.15 e 7.16 determinam a solução aproximada do sistema. Observe que $E_{0}(r)$ é a energia relacionada com o confinamento da partícula na direção $z$ e $r$ é um parâmetro e não uma variável. Como vemos na Fig. 4.1, podemos associar a cada ponto $r$ medido a partir da origem do sistema de cooordenadas (ponto " $O$ " da figura) um poço de potencial finito com largura igual à altura $t(r)$. Vamos considerar que o potencial $V(r, z)$ é igual a zero dentro do QD $\left(0<z<t(r)\right.$ e $\left.0<r<a_{Q D}\right)$ e igual a $V_{0}$ fora do QD. Em seguida, vamos resolver a Eq. 7.15 para um poço de potencial finito, e assim encontraremos a energia $E_{0}(r)$. Depois de determinarmos $E_{0}(r)$ para um potencial finito, vamos reescrever está energia em termos dos autovalores de 
energia de um poço de potencial infinito, pois estes possuem solução analítica.

\subsection{Autoenergias do poço finito}

Aqui, mostraremos como podemos escrever as autoenergias de um poço de potencial finito em termos de uma série de autoenergias do poço de potencial infinito. A vantagem de se adotar este procedimento é que conhecemos muito bem, para o poço de potencial infinito, tanto os seus autovalores de energia quanto as suas respectivas autofunções. Então, primeiramente, vamos escrever a equação de Schröedinger em uma dimensão:

$$
-\frac{\hbar^{2}}{2 m} \frac{d^{2} \Psi(z)}{d z^{2}}+V(z) \Psi(z)=E \Psi(z)
$$

onde

$$
V(z)= \begin{cases}V_{0} & \text { se }|z| \geq \frac{L}{2} \\ 0 & \text { se }|z|<\frac{L}{2}\end{cases}
$$

onde $V_{0}$ é uma constante positiva.

Resolvendo a equação 7.17 para $z<\frac{-L}{2}$, temos $-\frac{\hbar^{2}}{2 m} \frac{d^{2} \Psi(z)}{d z^{2}}=E \Psi(z) \Rightarrow \frac{d^{2} \Psi(z)}{d z^{2}}=$ $\frac{-2 m E}{\hbar^{2}} \Psi(z)$ onde $l^{\prime}=\frac{\sqrt{-2 m E}}{\hbar}$. Portanto, podemos reescrever a equação anterior como:

$$
\frac{d^{2} \Psi(z)}{d z^{2}}=l^{\prime 2} \Psi(z)
$$

que tem como solução geral a função $\Psi(z)=F \exp \left(-l^{\prime} z\right)+C \exp \left(l^{\prime} z\right)$. O coeficiente $F$ dessa função deve ser igual a zero, pois fisicamente só se adimite solução finita. Já dentro da barreira, $V(z)=V_{0}$ e a equação de Schrödinger (Eq. 7.17) é escrita como $-\frac{\hbar^{2}}{2 m} \frac{d^{2} \Psi(z)}{d z^{2}}+V_{0} \Psi(z)=E \Psi(z) \Rightarrow \frac{d^{2} \Psi(z)}{d z^{2}}=\frac{2 m\left(V_{0}-E\right)}{\hbar^{2}} \Psi(z)$ onde $l=\frac{\sqrt{2 m\left(V_{0}-E\right)}}{\hbar^{2}}$. Portanto, podemos reescrever está última equação como

$$
\frac{d^{2} \Psi(z)}{d z^{2}}=-l^{2} \Psi(z)
$$

que tem como solução geral a função $\Psi(z)=A \sin (l z)+B \cos (l z)$. O último passo é escrever a solução da equação 7.17 para $x>\frac{L}{2}$. Adotando o mesmo procedimento que anteriormente, podemos considerar a solução geral para essa região com sendo dada por $\Psi(z)=D \exp \left(-l^{\prime} z\right)$. Dessa forma, vemos que a solução da equação 7.17 em cada uma das três regiões definidas pelo potencial é dada por: 


$$
\Psi(z)= \begin{cases}C \exp \left(l^{\prime} z\right) & \text { se } z<\frac{-L}{2} \\ A \sin (l z)+B \cos (l z) & \text { se }|z| \leq \frac{L}{2} \\ D \exp \left(-l^{\prime} z\right) & \text { se } z>\frac{L}{2}\end{cases}
$$

Agora, sabendo que $\Psi(z)$ e $\frac{d \Psi(z)}{d z}$ são contínuas em todo o espaço, temos que impor as condições:

$$
\begin{gathered}
\Psi\left(-\frac{L}{2}\right)=\Psi\left(\frac{L}{2}\right) \\
\frac{d \Psi}{d z}\left(-\frac{L}{2}\right)=\frac{d \Psi}{d z}\left(\frac{L}{2}\right)
\end{gathered}
$$

Para a segunda condição, devemos obter $\frac{d \Psi(z)}{d z}$. Assim, derivando a função de onda da Eq. 7.21 obtemos:

$$
\frac{d \Psi(z)}{d z}= \begin{cases}C l^{\prime} \exp \left(l^{\prime} z\right) & \text { se } z<\frac{-L}{2} \\ A l \cos (l z)-B l \sin (l z) & \text { se }|z| \leq \frac{L}{2} \\ -D l^{\prime} \exp \left(-l^{\prime} z\right) & \text { se } z>\frac{L}{2}\end{cases}
$$

Reescrevendo as condições dada pelas equações 7.22 e 7.24 em termos de duas novas constantes $\varsigma=\frac{l L}{2}$ e $\eta=\frac{l^{\prime} L}{2}$ obtemos as quatro equações abaixo:

$$
\begin{gathered}
-A \sin (\varsigma)+B \cos (\varsigma)=C \exp (-\eta) \\
A l \cos (\varsigma)+B l \sin (\varsigma)=C l^{\prime} \exp (-\eta) \\
A \sin (\varsigma)+B \cos (\varsigma)=D \exp (-\eta) \\
A l \cos (\varsigma)-B l \sin (\varsigma)=-D l^{\prime} \exp (-\eta)
\end{gathered}
$$

Estas quatro equações podem ser manipuladas para obtermos a equação transcendental que fornece os autovalores de energia para uma partícula confinada em um poço de potencial finito. Assim, somando as equações 7.25 e 7.27 obtemos

$$
2 B \cos (\varsigma)=(C+D) \exp (-\eta)
$$


Ainda subtraindo a equação 7.28 de 7.26 temos:

$$
2 B l \sin (\varsigma)=l^{\prime}(C+D) \exp (-\eta)
$$

Dividindo a expressão 7.30 por 7.29 obtemos que $\tan (\varsigma)=\frac{l^{\prime}}{l}$, onde $\varsigma=\frac{l L}{2}$ e $\eta=\frac{l^{\prime} L}{2}$. Assim, podemos reescrever a expressão anterior como

$$
\varsigma \tan \varsigma=\eta
$$

Fazendo algumas manipulações, e definindo

$$
\begin{aligned}
& \alpha=\frac{\sqrt{2 m E}}{\hbar} \frac{L}{2}, \\
& P=\frac{\sqrt{2 m V_{0}}}{\hbar} \frac{L}{2},
\end{aligned}
$$

vemos que $\eta$ pode ser escrito como $\eta^{2}=\frac{2 m}{\hbar^{2}}\left(V_{0}-E\right) \frac{L^{2}}{4}=P^{2}-\alpha^{2}$, ou seja, $\eta=$ $\sqrt{P^{2}-\alpha^{2}}$. Portanto podemos reescrever a equação 7.31 como:

$$
\alpha \tan \alpha=\sqrt{P^{2}-\alpha^{2}} \Rightarrow \tan \alpha=\sqrt{\frac{P^{2}}{\alpha^{2}}-1}
$$

A solução da Eq. 7.34 fornece as autoenergias de uma partícula confinada em um poço de potencial finito com altura da barreira $V_{0}$, que podem ser determinadas numericamente ou através da intersecção das curvas tan $\alpha \operatorname{com} \sqrt{\frac{P^{2}}{\alpha^{2}}-1}$. Como estamos procurando uma expressão analítica para determinar as autoenergias do poço de potencial finito, a resolução gráfica ou a númerica da Eq. 7.34 não nos é conveniente. Desta forma, continuaremos a desenvolver o formalismo até conseguirmos expressar as autoenergias do poço de potencial finito em termos das autoenergias do poço de pontencial infinito. Este desenvolvimento será apresentado na seção seguinte.

\subsection{Solução para o poço finito escrita em termos da série do potencial infinito}

Nesta seção vamos determinar uma equação que nos permite calcular todas as autoenergias para uma partícula confinada em um poço de potencial finito em termos 
das autoenergias do poço infinito. Para isso usaremos primeiro as Eqs. 7.25 e 7.26 para expressarmos a constante $A$ em termos de $C$. Multiplicando a Eq. 7.25 pelo termo $\frac{-\sin \varsigma}{\cos \varsigma}$ obtemos a Eq. 7.35,

$$
+A \frac{\sin ^{2} \varsigma}{\cos \varsigma}-B \sin \varsigma=-C \frac{\sin \varsigma}{\cos \varsigma} \exp (-\eta)
$$

e em 7.26 denominando uma razão $\frac{l^{\prime}}{l}=\frac{\beta}{\alpha}$ temos a Eq. 7.36:

$$
A \cos \varsigma+B \sin \varsigma=\frac{\beta}{\alpha} C \exp (-\eta)
$$

Somando as duas equações acima obtemos a relação entre as constantes $A$ e $C$ :

$$
A=C\left(-\sin \varsigma+\frac{\beta}{\alpha} \cos \varsigma\right) \exp (-\eta)
$$

Agora, usaremos novamente as Eqs. 7.25 e 7.26 para expressarmos $B$ em termos de $C$. Para isso, temos que multiplicar a equação 7.26 por $\frac{\sin (\varsigma)}{\cos (\varsigma)}$ e, ainda, devemos substituir a razão $\frac{l^{\prime}}{l}=\frac{\beta}{\alpha}$ para obtermos a expressão seguinte:

$$
A \sin \varsigma+B \frac{\sin ^{2} \varsigma}{\cos \varsigma}=\frac{\alpha}{\beta} C \frac{\sin \varsigma}{\cos \varsigma} \exp (-\eta)
$$

Somando a equação anterior com a Eq. 7.25 obtemos:

$$
B=C\left[\frac{\beta}{\alpha} \sin \varsigma+\cos \varsigma\right] \exp (-\eta)
$$

Agora, substituindo as equações 7.37 e 7.39 na equação 7.27 temos:

$$
\begin{gathered}
C\left(\sin \varsigma+\frac{\beta}{\alpha} \cos \varsigma\right) \sin \varsigma+C\left(\frac{\beta}{\alpha} \sin \varsigma+\cos \varsigma\right) \cos \varsigma=D \Rightarrow \\
C\left[-\sin ^{2} \varsigma+\cos ^{2} \varsigma+\frac{\beta}{\alpha}(\cos \varsigma \sin \varsigma+\sin \varsigma \cos \varsigma)\right]=D .
\end{gathered}
$$

Assim, obtemos uma relação entre $C$ e $D$,

$$
D=C\left[\cos (2 \varsigma)+\frac{\beta}{\alpha} \sin (2 \varsigma)\right] .
$$


Por último, substituindo as equações 7.37 e 7.39 na equação 7.28 obtemos:

$$
\left.D=-C\left[\cos 2 \varsigma-\frac{\beta}{\alpha} \sin 2 \varsigma\right]\right] .
$$

Igualando as equações 7.42 e 7.43, obtemos uma equação para :

$$
\left(\frac{\beta}{\alpha}-\frac{\alpha}{\beta}\right) \sin 2 \varsigma+2 \cos 2 \varsigma=0
$$

que é uma condição de quantização. As razões na equação anterior podem ser reescritas em termos de $\alpha(7.32)$ e $P(7.33)$ como:

$$
\frac{\beta}{\alpha}=\frac{l^{\prime}}{l}=\frac{\eta}{\varsigma}:=\frac{\sqrt{P^{2}-\alpha^{2}}}{\alpha},
$$

e

$$
\frac{\alpha}{\beta}=\frac{\alpha}{\sqrt{P^{2}-\alpha^{2}}} .
$$

Substituindo as Eqs. 7.45 e 7.46 na Eq. 7.44 obtemos

$$
\left(\frac{P}{\alpha \sqrt{1-\left(\frac{\alpha}{P}\right)^{2}}}-\frac{2 \alpha}{P \sqrt{1-\left(\frac{\alpha}{P}\right)^{2}}}\right) \sin 2 \alpha+2 \cos 2 \alpha=0 .
$$

Se multiplicamos a Eq. 7.47 por $\frac{\alpha}{P} \sqrt{1-\left(\frac{\alpha}{P}\right)^{2}}$ teremos

$$
\left[1-2\left(\frac{\alpha}{P}\right)\right]^{2} \sin 2 \alpha+2 \frac{\alpha}{P} \sqrt{1-\left(\frac{\alpha}{P}\right)^{2}} \cos 2 \alpha=0 .
$$

Definimdo $\sin \phi=\frac{\alpha}{P}$ e $\cos \phi=\sqrt{1-\left(\frac{\alpha}{P}\right)^{2}}$, temos:

$$
\sin 2 \phi=2 \frac{\alpha}{P} \sqrt{1-\left(\frac{\alpha}{P}\right)^{2}}
$$

e

$$
\cos 2 \phi=1-2\left(\frac{\alpha}{P}\right)^{2}
$$

Substiuindo estas duas últimas expressões na Eq. 7.48 obtemos:

$$
\cos 2 \phi \sin 2 \alpha+\sin 2 \phi \cos 2 \alpha=0
$$

ou

$$
\sin [2(\phi+\alpha)]=0 .
$$


Esta última equação é a condição de quantização que estávamos procurando. Assim, vemos que a Eq. 7.52 só é igual a zero para $n \pi$, onde $n=0,1,2 \ldots$ Portanto $2(\alpha+\phi)=n \pi$ o que implica que

$$
\alpha+\arcsin \frac{\alpha}{P}=\frac{n \pi}{2} \text {. }
$$

Esta equação é a condição de quantização para $\alpha$. Para determinamos o espectro de energia, precisamos fazer uma inversão na Eq. 7.53, com o objetivo de determinar as energias na região do poço. Esta região de interesse é especificada pelo raio $r=\frac{\alpha}{P}$ $\in[0,1]$, onde $r=0$ descreve energias bem abaixo de $V_{0}$ e $r=1$ descreve energias próximas de $V_{0}$. Agora iremos expandir, em série de Taytor, a fase $\phi$ em torno de $r$. Fazendo esta expansão obtemos:

$$
\arcsin \frac{\alpha}{P}=\arcsin r+\frac{1}{\sqrt{1-r^{2}}}\left(\frac{\alpha}{P}-r\right)+\frac{r}{2\left(1-r^{2}\right)^{\frac{3}{2}}}\left(\frac{\alpha}{P}-r\right)^{2}+\ldots
$$

Substituindo a expansão acima na Eq. 7.53 obtemos

$$
\alpha+\arcsin r+\frac{1}{\sqrt{1-r^{2}}}\left(\frac{\alpha}{P}-r\right)+\frac{r}{2\left(1-r^{2}\right)^{\frac{3}{2}}}\left(\frac{\alpha}{P}-r\right)^{2}+\ldots=\frac{n \pi}{2} .
$$

A Eq. 7.55 relaciona o número quântico $n$ com as potências de $\left(\frac{\alpha}{P}-r\right)$, mas queremos inverter esta relação, ou seja, queremos escrever $\left(\frac{\alpha}{P}-r\right)$ em termos das potências de $n$. Para isso, precisamos inverter a Eq. 7.55 com o teorema da inversão de séries. Então, primeiramente, reescrevemos a Eq. 7.55 como:

$$
\frac{1}{\sqrt{1-r^{2}}}\left(\frac{\alpha}{P}-r\right)+\frac{r}{2\left(1-r^{2}\right)^{\frac{3}{2}}}\left(\frac{\alpha}{P}-r\right)^{2}+\ldots=\frac{n \pi}{2}-\alpha-\arcsin r
$$

Definindo

$$
\chi=\frac{n \pi}{2}-r P-\arcsin r
$$

reescrevemos 7.56 como:

$$
\frac{1}{\sqrt{1-r^{2}}}\left(\frac{\alpha}{P}-r\right)+\frac{r}{2\left(1-r^{2}\right)^{\frac{3}{2}}}\left(\frac{\alpha}{P}-r\right)^{2}+\ldots=\chi
$$

Utilizando o teorema da inversão (que será descrito na seção seguinte) de séries na expressão anterior obtemos:

$$
\left(\frac{\alpha}{P}-r\right)=\frac{P \sqrt{1-r^{2}}}{1+P \sqrt{1-r^{2}}} \chi-\frac{P r}{\left(1+P \sqrt{1-r^{2}}\right)^{3}} \chi^{2}+\ldots
$$


Isolando $\alpha$ na. Eq. 7.59 podemos escrever

$$
\alpha=P\left[r+\frac{P \sqrt{1-r^{2}}}{1+P \sqrt{1-r^{2}}} \chi-\frac{r P}{\left(1+P \sqrt{1-r^{2}}\right)^{3}} \chi^{2}+\ldots\right]
$$

Como $\alpha=\frac{\sqrt{2 m E}}{\hbar} \frac{L}{2}$, a equação anterior pode ser escrita como:

$$
\frac{\sqrt{2 m E}}{\hbar} \frac{L}{2}=P\left[r+\frac{P \sqrt{1-r^{2}}}{1+P \sqrt{1-r^{2}}} \chi-\frac{r P}{\left(1+P \sqrt{1-r^{2}}\right)^{3}} \chi^{2}+\ldots\right]
$$

Elevando ao quadrado toda a igualdade mostrada na expressão anterior teremos:

$$
\frac{2 m E}{\hbar^{2}} \frac{L^{2}}{4}=P^{2}\left[r+\frac{P \sqrt{1-r^{2}}}{1+P \sqrt{1-r^{2}}} \chi-\frac{r P}{\left(1+P \sqrt{1-r^{2}}\right)^{3}} \chi^{2}+\ldots\right]^{2}
$$

Isolando o valor de $E$ na última equação obtemos

$$
E=\frac{2 P^{2} \hbar^{2}}{m L^{2}}\left[r+\frac{P \sqrt{1-r^{2}}}{1+P \sqrt{1-r^{2}}} \chi-\frac{r P}{\left(1+P \sqrt{1-r^{2}}\right)^{3}} \chi^{2}+\ldots\right]^{2} .
$$

Finalmente, expandindo em série o termo quadrático da expressão anterior (termo entre colchetes), obtemos o espectro de energia de um poço de potencial finito em termos da série das energias de um poço de potencial infinito:

$$
\begin{aligned}
E & =2 P^{2} \frac{\hbar^{2}}{m L^{2}}\left[r^{2}+\frac{2 r \sqrt{1-r^{2}}}{1+P \sqrt{1-r^{2}}} \chi+\frac{\left(1-r^{2}\right)\left(1+P \sqrt{1-r^{2}}-r^{2}\right.}{\left(1+P \sqrt{1-r^{2}}\right)^{3}} \chi^{2}\right. \\
& \left.-\frac{r P\left(4-r^{2}\right)+4 r \sqrt{1-r^{2}}}{3\left(1+P \sqrt{1-r^{2}}\right)^{5}} \chi^{3} \cdots\right]
\end{aligned}
$$

Agora, fazendo $r=0$ (que descreve o espectro de energia bem abaixo de $V_{0}$ ) na Eq. 7.64, temos uma aproximação local para o espectro de energia dado por:

$$
\begin{aligned}
E & =2 P^{2} \frac{\hbar^{2}}{m L^{2}}\left[0^{2}+\frac{2 \times 0 \sqrt{1-0^{2}}}{1+P \sqrt{1-0^{2}}}\left(\frac{n \pi}{2}-0-0\right)\right. \\
& +\frac{\left(1-0^{2}\right)\left(1+P \sqrt{1-0^{2}}-0^{2}\right.}{\left(1+P \sqrt{1-0^{2}}\right)^{3}}\left(\frac{n \pi}{2}-0-0\right)^{2} \\
& \left.-\frac{0 \times P\left(4-0^{2}\right)+4 \times 0 \sqrt{1-0^{2}}}{3\left(1+P \sqrt{1-0^{2}}\right)^{5}}\left(\frac{n \pi}{2}-0 P-\arcsin 0\right)^{3} \ldots\right]
\end{aligned}
$$


7. Anexo 1 - Autoenergias do poço de potencial finito escrito em termos das autoenergias do poço de potencial infinito

que nos fornece as autoenergias do poço de potencial finito:

$$
E_{n}=\frac{2 P^{2}}{(P+1)^{2}} \frac{\hbar^{2}}{m L^{2}}\left[\left(\frac{n \pi}{2}\right)^{2}+\text { termos de ordem superior }\right]
$$

Lembrando que a energia do poço infinito é dada por $E_{n}^{\text {infinito }}=\frac{n^{2} \pi^{2} \hbar^{2}}{2 m L^{2}}$ podemos escrever:

$$
E_{n}^{\text {finito }}=\frac{P^{2}}{(P+1)^{2}} E_{n}^{\text {infinito }}+\text { termos de ordem superior }
$$

Vemos que se $P$ tende ao infinito na Eq. 7.67 , ou seja, no limite quando $V_{0}$ vai para infinito, obtemos o resultado esperado, que nesse caso é:

$$
\lim _{P \rightarrow \infty} E_{n}^{\text {finito }}=E_{n}^{\text {infinito }}
$$

que reproduz a mesma expressão para as energias de um poço de potencial infinito.

\subsection{Inversão de série}

Primeiramente vamos construir duas séries representadas pelas Eqs. 7.69 e 7.70 que satisfazem a relação $f(z(w))=w$, ou seja, $f$ é a função inversa de $z$ :

$$
\begin{gathered}
w=f(z)=a_{1} z+a_{2} z^{2}+O\left(z^{3}\right) \\
z(w)=b_{1} w+b_{2} w^{2}+O\left(w^{3}\right)
\end{gathered}
$$

O nosso objetivo é escrever os coeficientes $b_{n}$ em termos de $a_{n}$. Dessa forma, o primeiro passo é reescrever as Eqs. 7.69 e 7.70 como

$$
\begin{gathered}
a_{1} z=w-a_{2} z^{2}+O\left(z^{3}\right) \\
z=\frac{1}{a_{1}} w-\frac{a_{2}}{a_{1}} z^{2}-\frac{a_{3}}{a_{1}} z^{3}+O\left(z^{4}\right),
\end{gathered}
$$

obtendo assim a seguinte expansão em segunda ordem:

$$
z=\frac{1}{a_{1}} w-O\left(z^{2}\right)
$$

Para obtermos uma expansão de terceira ordem, substituiremos a Eq. $7.73 \mathrm{em}$ 
7. Anexo 1 - Autoenergias do poço de potencial finito escrito em termos das autoenergias do poço de potencial infinito

7.72:

$$
z=\frac{1}{a_{1}} w-\frac{a_{2}}{a_{1}}\left(\frac{1}{a_{1}} w-O\left(z^{2}\right)\right)^{2}-\frac{a_{3}}{a_{1}}\left(\frac{1}{a_{1}} w-O\left(z^{2}\right)\right)^{3}+O\left(w^{3}\right)
$$

ou

$$
\begin{aligned}
z & =\frac{1}{a_{1}} w-\frac{a_{2}}{a_{1}}\left(\frac{1}{a_{1}^{2}} w^{2}+2 w O\left(z^{2}\right)+O\left(w^{4}\right)\right) \\
& -\frac{a_{3}}{a_{1}}\left(\frac{1}{a_{1}^{3}} w+\frac{3 w^{2}}{a_{1}^{2}} O\left(w^{3}\right)\right)+O\left(w^{3}\right)
\end{aligned}
$$

que ainda pode ser escrita como

$$
z=\frac{1}{a_{1}} w-\frac{a_{2}}{a_{1}^{3}} w^{2}+O\left(w^{3}\right)
$$

onde ignoramos os termos de ordem superior.

Para obtermos os termos de uma expansão de quarta ordem, aplicaremos os mesmos passos aplicados anteriomente, ou seja, substituiremos a Eq. 7.76 na 7.72 obtendo dessa forma a Eq. 7.77:

$$
z=\frac{1}{a_{1}} w-\frac{a_{2}}{a_{1}^{3}} w^{2}+\frac{2 a_{2}^{2}-a_{3} a_{1}}{a_{1}^{5}} w^{3}+O\left(w^{4}\right)
$$

Como exemplo podemos fazer a inversão da Eq. 7.58

$$
\chi=\frac{1}{\sqrt{1-r^{2}}}\left(\frac{\alpha}{P}-r\right)+\frac{r}{2\left(1-r^{2}\right)^{\frac{3}{2}}}\left(\frac{\alpha}{P}-r\right)^{2}+\ldots
$$

Antes de fazer a inversão, vamos reescrever a equação acima somando um termo igual a zero no segundo membro da igualdade,

$$
P\left(\frac{\alpha}{P}-r\right)=\alpha-r P=\alpha-\alpha=0
$$

ou seja, se somamos $P\left(\frac{\alpha}{P}-r\right)$ ao segundo membro da equação anterior obtemos

$$
\chi=\left(\frac{1+P \sqrt{1-r^{2}}}{\sqrt{1-r^{2}}}\right)\left(\frac{\alpha}{P}-r\right)+\frac{r}{2\left(1-r^{2}\right)^{\frac{3}{2}}}\left(\frac{\alpha}{P}-r\right)^{2}+\ldots
$$

Agora podemos inverter a Eq. 7.80, ou seja, podemos escrever $\left(\frac{\alpha}{P}-r\right)$ em termos 
7. Anexo 1 - Autoenergias do poço de potencial finito escrito em termos das autoenergias do poço de potencial infinito

de potências de $\chi$ como

$$
\left(\frac{\alpha}{P}-r\right)=b_{1} \chi+b_{2} \chi^{2}+b_{3} \chi^{3}+O\left(\chi^{4}\right)
$$

e obtendo da Eq. 7.77 os coeficientes:

$$
\begin{gathered}
b_{1}=\frac{1}{a_{1}}=\frac{\sqrt{1-r^{2}}}{1+P \sqrt{1-r^{2}}} \\
b_{2}=-\frac{a_{2}}{a_{1}^{3}}=\frac{r}{2\left(1+P \sqrt{1-r^{2}}\right)^{3}}
\end{gathered}
$$

Substituindo os coeficientes $b_{1}$ e $b_{2}$, a série invertida fica com a mesma forma obtida na Eq. 7.59:

$$
\left(\frac{\alpha}{P}-r\right)=\frac{\sqrt{1-r^{2}}}{1+P \sqrt{1-r^{2}}} \chi+\frac{r}{2\left(1+P \sqrt{1-r^{2}}\right)^{3}} \chi^{2}+O\left(\chi^{3}\right)
$$




\section{Referências Bibliográficas}

[1] Superlattice and negative differential conductivity in semiconductors, L. Esaki e R. Tsu, IBM Jl. Res. Dev. 14, 61 (1970).

[2] Growth of a GaAs-GaAlAs superlattice, L. L. Chang, L. Esaki, W. E. Howard e R. Ludeke, J. Vac. Sci. Technol. 10, 11 (1973).

[3] New transport phenomenon in a semiconductor superlattice, L. Esaki e L. L. Chang, Phys. Rev. Lett. 33, 495 (1974).

[4] The technology and physics of molecular beam epitaxy, editado por E. H. C. Parker, Plenum Press, New York, 1985.

[5] Current status review and future prospects of CBE, MOMBE and GSMBE, W. T. Tsang, J. Crystal Growth 107, 960 (1991).

[6] J. B. Mullin, S. J. C. Irvine, R. H. Moss, P. N. Robson e D. R. Wight em Metalorganic vapour phase epitaxy, North-Holland, Amsterdã, 1994.

[7] S. M. Sze em Physics of semiconductor devices, John Wiley \& Sons, Singapura, 1981.

[8] Jasprit Singh em Semiconductor optoelectronics: physics and technology, editado por George T. Hoffman, McGraw-Hill, Singapura, 1995.

[9] Applications of multiple quantum wells, selective doping and superlattices, editado por Raymond Dingle, Semiconductors and Semimetals, v. 24 (1987).

[10] E. F. Schubert em Delta doping of semiconductors: electronic, optical and structural properties of materials and devices, Semiconductors and Semimetals, editado por Arthur C. Gossard, Academic, New York (1994), v. 40, p.1.

[11] Gerald Bastard em Wave mechanics applied to semiconductor heterostructures, Les Éditions de Physique, Paris, 1988. 
[12] Superbright green InGaN single-quantum-well-structure light-emitting-diodes, S. Nakamura, M. Senoh, N. Iwasa, S. Nagahama, T. Yamada e T. Mukai, Japan. J. Appl. Phys. 34, L1332 (1995).

[13] Blue and green semiconductor lasers: a status report, Arto Nurmikko e Robert L. Gunshor, Semicond. Sci. Technol. 12, 1337 (1997).

[14] Nitride-based semiconductors for blue and green light-emitting devices, F. A. Ponce e D. P. Bour, Nature 386, 351 (1997).

[15] Prediction of soil macronutrients content using near-infrared spectroscopy, Y. He, M. Huang, A. Garcia, A. Hernadez e H. Song, Computers and Electronics in Agriculture. 58, 144 (2007).

[16] Transmission type fast detector for nutrient in fruit, Y. Liu, X. Chen e A. Ouyang, Food Science and Technology. 41, 1720 (2001).

[17] Using reflectance sensors in agronomy and weed science, W. L. Felton, C. L. Alston, B. M. Haigh, P. G. Nash e G. A. Wicks e G. E. Hanson, Weed Technology 16, $520(2002)$.

[18] Sensor systems for measuring soil compaction: Review and analysis, A. Hemmat e V. I. Adamchuck, Computers and Eletronics in Agriculture 63, 89 (2008).

[19] Medical infrared imaging - diferentiating facts from fiction, and the impact of high precision quantum well infrared photodetector camera systems, and other factors, in its reemergence, M. A. Fauci, R. Breiter, W. Cabanski, W. Fick, R. Koch, J. Ziegler e S. D. Gunapala, Infrared Phys. Technol. 42, 337 (2001).

[20] Infrared sensors for ballistic missile defense, M. Z. Tidrow e W. R. Dyer, Infrared Phys. Technol. 42, 333 (2001).

[21] Third-generation infrared photodetector arrays, A. Rogalski, J. Antoszewski e L. Faraone, J. Appl. Phys. 105, 091101 (2009).

[22] The emergence of $\mathrm{Hg}_{\mathrm{x}} \mathrm{Cd}_{1-\mathrm{x}} \mathrm{Te}$ as a modern infrared-sensitive material, P.W. Kruse, Semiconductors and Semimetals 18, 1 (1981).

[23] Quantum-well infrared photodetectors, B. F. Levine, J. Appl. Physics 74, 1 (1993) 
[24] Assessment of quantum dot infrared photodetectors for temperature operation, P. Maryniuk, S. Krishna e A. Rogalski, J. Appl. Phys. 104, 034314 (2008).

[25] Stresses and strains in epilayers stripes and quantum structures of III-V compound semiconductors, S. C. Jain, M. Willander e H. Maes, Semicond. Sci. Technol. 11, 641 (1996).

[26] Room-temperature lasing operation of a quantum-dot vertical-cavity surfaceemitting laser, Hideaki Saito, Kenichi Nishi, Ichiro Ogura, Shigeo Sugou e Yoshimasa Sugimoto, Appl. Phys. Lett. 69, 3140 (1996).

[27] Red-emitting semiconductor quantum-dot lasers, S. Fafard, J. McCaffrey, Y. Fenk e S. Charbonneau, Science 274, 1350 (1996).

[28] Critical layer thickness for self-assembled InAs islands on GaAs, D. Leonard, K. Pond e P. M. Petroff, Phys. Rev. B 50, 11687 (1994).

[29] Artificial atoms, M. A. Kastner, Phys. Today 46, 24 (1993).

[30] D. Leonard, M. Krishnamurthy, C. M. Reaves, S. P. Denbaars e P. M. Petroff, Appl. Phys. Lett. 63, 3202 (1993).

[31] J. M. Moison, F. Houzay, F. Barthe, L. Leprince, E. André e O. Vatel, Appl. Phys. Lett. 64(2), 196 (1994).

[32] Y. Sugiyama e M. Sugawara em Molecular beam epitaxial growth of selfassembled InAs/GaAs quantum dots, Semiconductors and Semimetals, Academic, New York (1999), v. 60, p. 117.

[33] M. J. da Silva, Crescimento e caracterização de pontos quânticos de InAs autoformados, Dissertação de mestrado, IFUSP, São Paulo (1999).

[34] Mass transfer in Stranski-Krastanov growth of InAs on GaAs, T. R. Ramachandran, R. Heitz, P. Chen e A. Madhukar, Appl. Phys. Lett. 70, 640 (1997).

[35] A new method for studying semiconducting surfaces in air by scanning tunneling microscopy, A. S. Ferlauto e A. A. Quivy, Modern Physics Letters B 10(24), 1189 (1996).

[36] Growth of self-organized InGaAs islands by molecular beam epitaxy, A. A. Quivy, M. A. Cotta e J. R. Leite, Brazilian Journal of Physics 27A, 154 (1997). 


\section{Bibliografia}

[37] Device model for quantum dot infrared photodetectors and their dark-current characteristics, V. Ryzhii, I. Khmyrova, V. Pipa, V. Mitin e M. Willander, Semicond. Sci. Technol. 16(5), 331 (2001).

[38] Theory of an intersubband infrared phototransistor whith a nonuniform quantum well, V. Ryzhii, I. Khmyrova, M. Ershov e T. Lizuka, Semicond. Sci. Technol. 10(7), 997 (1995).

[39] Charge-carrier statistics at InAs/GaAs quantum dots, O. Engström e P. T. Landsberg, Phys. Rev. B 72(7), 075360 (2005).

[40] Introdução à Fúsica Estatística de Sílvio R. A. Salinas, editado por EDUSP (2008).

[41] On the detectivity of quantun-dot infrared photodetectors, V. Ryzhii, I. Khmyrova, V. Mitin, M. Stroscio e M. Willander, Applied Physics Letters 78(22), 3523 (2001).

[42] An introduction to self-assembled quantum dots, B. J. Riel, Am. J. Phys. 76 (8), 750 (2008).

[43] Calculation of the energy levels in InAs/GaAs quantum dots, J. -Y. Marzin e G. Bastard, Solid State Commun. 92(5), 437 (1994).

[44] Efficient method for calculating electronic states in self-assembled quantum dots, M. Roy e P. A. Malsym, Phys. Rev. B 68, 235308 (2003).

[45] General series solution for finite square-well energy levels for use in wave-packet studies, D. L. Aronstein e C. R. Stroud Jr., Am. J. Phys. 68(10), 943 (2000).

[46] S. L. Chuang em Physics of Optoelectronic Devices (Wiley, New York, 1995) p. 186.

[47] S. L. Chuang em Physics of Optoelectronic Devices (Wiley, New York, 1995) p. 148.

[48] Self-consistent calculation of the electronic structure and electron-electron interaction in self-assembled InAs-GaAs quantum dot structures, L. R. C. Fonseca, J. L. Jimenez, J. P. Leburton, R. M. Martin, Phys. Rev. B 57(7), 4017 (1998). 
[49] Intersubband optical absorption in quantum dots-in-a-well heterostructure, $\mathrm{X}$. Han, J. Li, J. Wu, G. Cong, X. Liu, Q. Zhu e Z. Wang, J. Appl. Phys. 98, 053703 (2008)

[50] S. L. Chuang em Physics of Optoelectronic Devices (Wiley, New York, 1995) p. 150 .

[51] Band lineups and deformation potentials in the model-solid theory, C. G. Van de Walle, Phys. Rev. B39(3), 1871 (1989).

[52] Optical and crystallographic properties and impurity incorporation of $\mathrm{Ga}_{\mathrm{x}} \operatorname{In}_{1-\mathrm{x}} \mathrm{As}(0.44<x<0.49)$ grown by liquid phase epitaxy, vapor phase epitaxy, and metal organic chemical vapor deposition, K. -H. Goetz, D. Bimberg, H. Jurgensen, J. Selders, A. V. Solomonov, G. F. Glinskii e M. Razeghi, J. Appl. Phys. 54, 4543 (1983).

[53] Preparation and properties of bulk $\mathrm{Ga}_{\mathrm{x}} \mathrm{In}_{1-\mathrm{x}}$ As crystals, Y. T. Leu, F. A. Thiel, H. Scheiber, B. I. Miller e J. Bachmann, J. Electron Mater. 8(5), 663 (1979).

[54] Material parameters of $\operatorname{In}_{1-x} \mathrm{Ga}_{\mathrm{x}} \mathrm{As}_{\mathrm{y}} \mathrm{P}_{1-\mathrm{y}}$ and related binaries, S. Adachi, J. Appl. Phys. 53, 8775(1982). 